\title{
BEMOD. A DSGE MODEL FOR THE SPANISH \\ ECONOMY AND THE REST \\ OF THE EURO AREA
}

Javier Andrés, Pablo Burriel

and Anger Estrada.

Documentos de Trabajo

N. 0631

\section{BATCOTE ESPANA}

\section{6}

\author{
Eurosistena
}


BEMOD: A DSGE MODEL FOR THE SPANISH ECONOMY AND THE REST

OF THE EURO AREA 
BEMOD: A DSGE MODEL FOR THE SPANISH ECONOMY AND THE REST OF THE EURO AREA $\left(^{*}\right)$

\author{
Javier Andrés \\ BANCO DE ESPAÑA AND UNIVERSIDAD DE VALENCIA
}

Pablo Burriel

BANCO DE ESPAÑA

Ángel Estrada

OFICINA ECONÓMICA DE PRESIDENCIA DEL GOBIERNO 
The Working Paper Series seeks to disseminate original research in economics and finance. All papers have been anonymously refereed. By publishing these papers, the Banco de España aims to contribute to economic analysis and, in particular, to knowledge of the Spanish economy and its international environment.

The opinions and analyses in the Working Paper Series are the responsibility of the authors and, therefore, do not necessarily coincide with those of the Banco de España or the Eurosystem.

The Banco de España disseminates its main reports and most of its publications via the INTERNET at the following website: http://www.bde.es.

Reproduction for educational and non-commercial purposes is permitted provided that the source is acknowledged.

\section{@ BANCO DE ESPAÑA, Madrid, 2006}

ISSN: 0213-2710 (print)

ISSN: 1579-8666 (on line)

Depósito legal: M.50792-2006

Imprenta del Banco de España 


\section{Abstract}

In this paper we present the theoretical foundations and the simulation results obtained with a new dynamic general equilibrium model developed at the Banco de España for the Spanish economy and the rest of Euro area. The model is designed to help in simulating the effect of alternative shocks on the main aggregate variables.

The main contributions of this work from a theoretical perspective are the modelling of a monetary union composed of two regions, the inclusion of housing as a durable good with its own sector of production and the degree and detail of the disaggregation considered for each country in the model, which replicates the Quarterly National Accounts. On the empirical side, the main contribution is the detailed calibration of the most important ratios of the Spanish and rest of the Euro area economies.

Keywords: SDGE model, open economy, simulation, shocks, macroeconomic policies.

JEL Codes: E32, E50, F41 


\section{Introduction}

In this paper we present the theoretical foundations and the simulation results obtained with a new dynamic general equilibrium model developed at the Banco de España for the Spanish economy and the rest of Euro area. The model is designed to help in simulating the effect of alternative shocks on the main aggregate variables. In particular, a version of this model is expected to be used in the near future to run simulations and alternative scenario analysis for the Spanish economy within the forecast process. Therefore, one of the requirements of the model is to replicate the developments of most of the variables included in the Spanish Quarterly National accounts, which is why the model structure is more elaborated than what is standard in the literature.

In recent years, there has been a surge of interest in developing optimizationbased models that are better designed to fit the data. Christiano, Eichenbaum and Evans (2005) show that a dynamic stochastic general equilibrium model (DSGE), which includes sticky nominal wages and prices, plus several adjustment costs, is successful in accounting for the estimated effects of a monetary policy shock. Smets and Wouters (2003) prove that the forecasting ability of this type of models is comparable to that of an unconstrained Bayesian VAR. These works have shown the possibilities of DSGE models to contribute to policy analysis. As a consequence, a number of central banks and other international institutions, like the IMF, are in the process of building microfounded DSGE models to be used as inputs into the policy debate. Some recent examples of this current trend are the US FED (model named SIGMA, Erceg, Guerrieri and Gust (2005)), the Bank of Canada (model called TOTEM, Binette, Murchison, Perrier and Rennison (2004)), the Bank of Finland who has one model for the Finnish economy (AINO, Kilponen and Ripatti (2006)) and another for the Euro area (EDGE, Kortelainen (2002)), the Bank of England (model called BEQM, Harrison et al (2005)), the ECB who is developing a new Area Wide model (Coenen, McAdam and Straub (2006)) and the Bank of Sweden (Adolfson et al (2005)).

The model presented in this paper shares many characteristics with the models developed in other institutions, but it also includes some innovations. In particular, the main theoretical contributions of this work are in terms of the country structure, since we model a monetary union composed of two regions, while the literature has concentrated its attention on modelling either a small open economy or two countries with independent monetary policy, generally the Euro area and the US. This country structure will allow for an analysis of how differences 
in economic structures across regions of a monetary union affect the common monetary policy, but also of how differences in fiscal and other country specific policies interact with the common monetary policy. However, these issues will be studied in depth in further work. Other theoretical contributions are the inclusion of housing as a durable good with its own sector of production and the degree and detail of the disaggregation considered for each country in the model, which allows us to replicate most variables included in the Quarterly National Accounts.

The main empirical contribution of this work is the detailed calibration of the most important ratios of the Spanish and rest of the Euro area economies, based on input-output tables and balance of payments data for the five largest Euro area economies (Germany, France, Italy, Spain and Netherlands) ${ }^{1}$. The simulation exercises will be done under two sets of calibrations: one, symmetric across both areas and based on the calibration for Spain, to highlight the main mechanisms of the model, and another, asymmetric in order to highlight how differences in the economic structure affect those mechanisms at play.

Finally, it is important to indicate that the work presented here is part of a larger project taking place at the Banco de España to develop and estimate a DSGE model of the Spanish economy. This project builds upon the modelling effort developed at the Banco, a good description of which can be found in Banco de España (2006). In an initial stage, detailed in this paper, the aim is to develop a general model to serve as framework for the overall project. Therefore, given its size and complexity, the model will be initially calibrated. However, later on, smaller versions of this model will be estimated using Bayesian techniques to pin down those parameters for which there is greater uncertainty. Given this empirical strategy, those parameters that cannot be easily obtained using available information, like the parameters of the monetary or fiscal policy rules, the degree of nominal inertia in prices and wages or the persistence and variance of the shocks, etc., in this paper will be either set at the values normally found in this literature or alternatively, at values which simplify the analysis.

\subsection{Overview of the model:}

The main characteristics of the model are the following:

Countries. The model considers a world made of three countries: Spain $(H)$, the rest of the Euro area $(F)$ and the rest of the world $(W)$. The domestic

\footnotetext{
${ }^{1}$ The rest of the Euro area is constructed for the calibration of the model as an aggregate of Germany, France, Italy and Netherlands
} 
country $(H)$ and the rest of the Euro area $(F)$ are modeled as a monetary union, meaning that they operate in a fixed exchange rate regime, and their common currency floats against the dollar, which is the representative currency of the rest of the world. These two countries share the same monetary authority that sets the nominal interest rate; the relevance of each country in the determination of the interest rate by the monetary authority can be changed. Preferences and the production structure in countries $H$ and $F$ are fully specified, whereas the economic structure of the rest of the world is less so: consumption, investment and their corresponding prices are exogenously given.

Households. Consumption, labour supply, saving and capital accumulation decisions are taken by a representative rational household that faces no restrictions in the financial market.

Producers. Production takes place in a continuum of intermediate goodsproducing firms indexed by $j \in[0,1]$. The intermediate goods-producing firms can generate three kinds of goods: traded goods $(T)$, non-traded goods $(N T)$ and housing $(D)$. The $F$ country has the same productive structure. As usual in this literature, the model features enough symmetry to allow the analysis to also focus on the behaviour of a representative goods-producing firm. These economies may differ because of variations in preferences and price setting structures. Production requires three inputs, capital $(K)$, labour $(N)$ and oil $(O)$. Capital utilization $(C U)$ is variable and increases the user cost of capital so that firms choose it also optimally. Each sector has a different technology and may suffer sector specific or economy-wide shocks to total factor productivity. We also assume that factors of production can move across sectors at no cost but do not move across boundaries. Only goods and assets are traded.

Variables and aggregators. Aggregate real variables (consumption, investment, etc.) are obtained as a CES aggregation of its components. This is the result of the maximization problem face by the competitive firms that operate at different levels of the distribution process.

Public sector. The public sector levies taxes (both lump-sum and distortionary) and issues bonds to finance public expenditure. This expenditure is non-productive, does not generate utility for households and is produced by the non-traded goods sector.

Asset structure. There are three assets in the economy. $B$ and $F B$ are respectively $H$ and $F$ one period maturity government bonds that, for simplicity, we shall assume can only be held by residents in each country. Financial trade takes place through dollar denominated one-period maturity international bonds that 
may be held by residents in the $H$ (denoted by $A$ ) and the $F(F A)$ economies or by the rest of the world $(W A)$. Households have to bear a cost of adjusting their portfolios.

Foreign Trade. All three economies interact with each other through trade in consumption and investment goods. The rest of the world, $W$, is the only oil producing country in the world.

Nominal and real frictions. There is nominal inertia in both wages and prices. Intermediate producers set prices on a staggered basis. Price inertia differs across prices of traded and non-traded goods, as well as across prices of consumption and investment goods. Price indices are the optimal combination that stem from the zero profit condition of the competitive final producing firms. Capital adjustment is costly and firms operate in a market in which they enjoy some monopoly power, thus they charge a markup on the marginal cost.

Shocks. The model allows for shocks to preferences, prices of the rest of the world, in particular oil price, foreign demand, sector specific and economy-wide total factor productivity, fiscal spending and to the monetary policy rule.

The rest of the paper is organized as follows. In section 2 the optimization problem of the representative household is solved. In the following section the structure of production and price determination is shown. Section 4 indicates how to obtain the aggregate variables of the model, while in section 5 the calibration of the model is explained. Finally, section 6 describes the results of the simulation exercises and section 7 concludes.

\section{The representative household}

The representative household is the final consumer of the goods and services produced, with the following (separable) preferences over consumption $\left(c_{t}\right)$, the housing stock $\left(D_{t}\right)$ and leisure $\left(1-n_{t}\right)$

$$
U_{t}(i)=E_{t} \sum_{t=0}^{\infty} \beta^{t} \varepsilon_{t}^{a}\left[\frac{1}{1-\sigma}\left(\frac{c_{t}(i)}{\left(c_{t-1}(i)\right)^{\gamma}}\right)^{(1-\sigma)}+\frac{\left(D_{t}(i)\right)^{\left(1-\sigma_{D}\right)}}{1-\sigma_{D}}-\frac{\left(n_{t}(i)\right)^{(1+\varphi)}}{1+\varphi}\right]
$$

where $\beta$ represents the rate of time preference, $\varepsilon_{t}^{a}$ a is preference shock, $\sigma^{-1}$ is the intertemporal elasticity of substitution of consumption, $\sigma_{D}^{-1}$ is the intertemporal elasticity of substitution of the housing services and $\varphi^{-1}$ is the elasticity of labour holding the marginal utility of consumption constant. There are habits in the 
consumption of goods and services indexed by $\gamma(\in(0,1))$, while there is no role assigned for money in the model. Furthermore, households are assumed to be rational and have access to perfect capital markets.

Households are the owners of capital, both productive and housing, the former is supplied to producing firms at the rental cost $r_{t}$. Wealth may be held in capital, domestic bonds $(B)$ or international assets $(A)$ denominated in dollars. In this last case, the exchange rate $(s)$ determines the value of the assets in domestic currency. We assume that there are portfolio adjustment costs that depend on the ratio of foreign assets holdings with respect to nominal value added (i.e. $a_{t-1}=\frac{A_{t-1}}{v a_{t-1} P v_{t-1}}$ ), such that if $a_{t-1}>0$, the return on asset holdings is reduced, whereas the cost of servicing the debt increases if country $H$ is a borrower $\left(a_{t-1}<0\right)$. Moreover, this cost function is such that $\Psi(0)=1{ }^{2}$ These adjustment costs in the amount of international assets held by residents of country $\mathrm{H}\left(A_{t}\right)$ and of country $\mathrm{F}\left(F A_{t}\right)$ imply that these variables $\left(A_{t}, F A_{t}\right)$ should go to 0 and guarantees that the model is stationary in presence of transitory shocks (Benigno, 2001). ${ }^{3}$

Housing is included in this model as a consumer durable (see Erceg and Levin (2002) for a detailed discussion of this issue). Households do not obtain any income from renting part of their stock of housing but instead they derive utility from owning it, that is, the model assumes there is a bias towards home ownership. Equation (2.1) also contains a preference shock $\left(\varepsilon_{t}^{a}\right)$, which is a shock to the discount rate that affects the intertemporal elasticity of substitution of households.

Households earn their income in exchange for labour services $(W$, in nominal terms), from the returns on holdings of wealth and the profits of domestic firms they own $\left(\int_{0}^{1} \omega(j) d j\right)$. Capital income stems from holdings of domestic and foreign bonds as well as from capital, with nominal returns $R, W R$ and $r$ respectively. Households also receive a compensation for the intensity of use of the capital they rent $h \sum c u_{t}^{\mathcal{F}}(i)(\{\mathcal{F}=T, N, D\}){ }^{4}$ All these sources of income are subject to

${ }^{2}$ An example of this function would be:

$$
\Psi\left(a_{t-1}\right)=e^{-\Psi a_{t-1}}
$$

To rationalise the existence of transaction costs we assume that there is a financial intermediary that receives those payments as revenues in exchange for the services of financial intermediation. This financial firm is owned by residents of the foreign country so that total revenues for the foreign consumer budget constraint are augmented accordingly.

${ }^{3}$ Schmitt-Grohé and Uribe (2003) explore alternative ways to remove non-stationarity in open economy models with incomplete markets, stemming from the accumulation of foreign assets, and find that all produce similar conditional and unconditional correlations.

${ }^{4}$ The intensity of capital utilization $\left(c u_{t}\right)$ is decided by the firms that rent it. 
distortionary taxes ( $\tau_{c}$ on consumption, $\tau_{k}$ on capital income and $\tau_{w}$ on wages). Households spend their resources on consumption goods and services, investment goods $\left(I^{P}\right)$, housing investment $\left(I^{D}\right)$, investment on domestic bonds and international assets and pay lump-sum taxes $(T) .{ }^{5}$ Therefore, households face the following budget constraint where $\mathcal{F}=T, N, D$ :

$$
\begin{gathered}
{\left[\frac{B_{t}(i)}{R_{t} \Psi\left(a_{t-1}\right)}+\frac{s_{t}^{-1} A_{t}(i)}{W R_{t} \Psi\left(a_{t-1}\right)}+P I_{t}^{P} I_{t}^{P}(i)+P_{t}^{D} I_{t}^{D}(i)+\left(1+\tau_{c}\right) P C_{t} c_{t}(i)+P C_{t} T_{t}\right] \leq} \\
{\left[\begin{array}{c}
B_{t-1}(i)+\frac{A_{t-1}(i)}{s_{t}}+\left(\left(1-\tau_{k}\right) r_{t} k_{t-1}(i)+h \sum_{\mathcal{F}} c u_{t}^{\mathcal{F}}(i)\right) P C_{t} \\
+\left(1-\tau_{w}\right) W_{t} n_{t}(i)+\int_{0}^{1} \omega_{t}(j) d j
\end{array}\right]}
\end{gathered}
$$

The second constraint captures the motion law of the productive capital stock, where $\delta$ represents the depreciation rate and we allow for adjustment costs $(\Phi())$ to obtain a non trivial investment equation,

$$
k_{t}(i)=\Phi\left(\frac{I_{t}^{P}(i)}{k_{t-1}(i)}\right) k_{t-1}(i)+(1-\delta) k_{t-1}(i)
$$

The final constraint is similar to the previous one but for the housing stock, where $\delta_{D}$ is its depreciation rate and $\Phi^{D}($.$) represents the adjustment costs function,$

$$
D_{t}(i)=\Phi^{D}\left(\frac{I_{t}^{D}(i)}{D_{t-1}(i)}\right) D_{t-1}(i)+\left(1-\delta_{D}\right) D_{t-1}(i)
$$

\footnotetext{
${ }^{5} P C, P I^{P}, P^{D}$ are the corresponding prices of consumption goods, investment goods and housing.
} 
Household behaviour can be derived from the following Lagrangian:

$$
\begin{aligned}
& L_{t}(i)=E_{0} \sum_{t=0}^{\infty} \beta^{t}\left\{\varepsilon_{t}^{a}\left[\frac{1}{1-\sigma}\left(\frac{c_{t}(i)}{\left(c_{t-1}(i)\right)^{\gamma}}\right)^{(1-\sigma)}+\frac{\left(D_{t}(i)\right)^{\left(1-\sigma_{D}\right)}}{1-\sigma_{D}}-\frac{\left(n_{t}(i)\right)^{(1+\varphi)}}{1+\varphi}\right]\right. \\
& \left.-\lambda_{t}\left\{\begin{array}{c}
{\left[\begin{array}{c}
\frac{B_{t}(i)}{R_{t} \Psi\left(a_{t-1}\right)}+\frac{s_{t}^{-1} A_{t}(i)}{W R_{t} \Psi\left(a_{t-1}\right)}+P I_{t}^{P} I_{t}^{P}(i)+ \\
P_{t}^{D} I_{t}^{D}(i)+\left(1+\tau_{c}\right) P C_{t} c_{t}(i)+P C_{t} T_{t}
\end{array}\right] \leq} \\
+\left[\left(1-\tau_{k}\right) r_{t} k_{t-1}(i)+h \sum c u_{t}^{\mathcal{F}}(i)\right] P C_{t}
\end{array}\right]\right\} \\
& -\lambda_{t}^{k}\left[k_{t}(i)-\Phi\left(\frac{I_{t}^{P}(i)}{k_{t-1}(i)}\right) k_{t-1}(i)-(1-\delta) k_{t-1}(i)\right] \\
& \left.-\lambda_{t}^{D}\left[D_{t}(i)-\Phi^{D}\left(\frac{I_{t}^{D}(i)}{D_{t-1}(i)}\right) D_{t-1}(i)-\left(1-\delta_{D}\right) D_{t-1}(i)\right]\right\}
\end{aligned}
$$

The derivative with respect to domestic bonds relates the wealth shadow price $(\lambda)$ with the domestic real interest rate:

$$
\lambda_{t}(i)=\beta E_{t} \frac{R_{t} \lambda_{t+1}(i)}{\pi_{t+1}^{I P C}} \Psi\left(a_{t-1}\right)
$$

where $\pi^{I P C}$ represents the rate of inflation of the total consumption deflator. The second condition provides us with a link between the rate of change of $\lambda$ and the expected depreciation of the exchange rate.

$$
\lambda_{t}(i)=\beta \Psi\left(a_{t-1}\right) E_{t} \frac{W R_{t} \lambda_{t+1}(i)}{\pi_{t+1}^{I P C}}\left(\frac{s_{t+1}^{-1}}{s_{t}^{-1}}\right)
$$

Bringing together these two conditions we obtain the uncovered interest rate parity condition,

$$
E_{t}\left(\frac{s_{t} W R_{t}}{s_{t+1} R_{t}}\right)=1
$$

The marginal utility of consumption is enlarged by the presence of habits

$$
\lambda_{t}(i)=\left[\begin{array}{c}
\varepsilon_{t}^{a}\left[\frac{c_{t}(i)}{\left(c_{t-1}(i)\right)^{\gamma}}\right]^{-\sigma} \frac{1}{\left(c_{t-1}(i)\right)^{\gamma}} \\
-\beta \gamma E_{t} \varepsilon_{t+1}^{a}\left[\frac{c_{t+1}(i)}{\left(c_{t}(i)\right)^{\gamma}}\right]^{-\sigma} c_{t+1}(i) \frac{\left(c_{t}(i)\right)^{\gamma-1}}{\left(c_{t}(i)\right)^{2 \gamma}}
\end{array}\right]
$$


The optimal choice of productive investment yields the $q$ type conditions and dynamics,

$$
q_{t}(i)=\frac{1}{\Phi^{\prime}\left(\frac{I_{t}^{P}(i)}{k_{t-1}(i)}\right)}
$$

where

$$
\begin{gathered}
q_{t}(i)=\frac{\lambda_{t}^{k}(i)\left(1+\tau_{c}\right) P C_{t}}{\lambda_{t}(i) P I_{t}^{P}} \\
q_{t}(i)=\beta E_{t}\left\{\frac{\pi_{t+1}^{I P} \lambda_{t+1}(i)}{\pi_{t+1}^{I P C} \lambda_{t}(i)}\left[\begin{array}{c}
\frac{P C_{t+1}}{P I_{t+1}^{P}}\left(1-\tau_{k}\right) r_{t+1}+ \\
q_{t+1}(i)\left(\Phi_{t+1}(i)-\Phi_{t+1}^{\prime} \frac{I_{t+1}^{P}(i)}{k(i)}+(1-\delta)\right)
\end{array}\right]\right\}
\end{gathered}
$$

Similarly, for housing investment,

$$
\begin{gathered}
q_{t}^{D}(i)=\frac{1}{\Phi^{D^{\prime}}\left(\frac{I_{t}^{D}(i)}{D_{t-1}(i)}\right)} \\
q_{t}^{D}(i)=\frac{\lambda_{t}^{D}(i)\left(1+\tau_{c}\right) P C_{t}}{\lambda_{t}(i) P_{t}^{D}} \\
q_{t}^{D}(i)=\beta E_{t}\left\{\frac{\pi_{t+1}^{D} \lambda_{t+1}(i)}{\pi_{t+1}^{I P C} \lambda_{t}(i)}\left[\begin{array}{c}
\frac{\varepsilon_{t+1}^{a}}{\lambda_{t+1}(i)} \frac{P C_{t+1}}{P_{t+1}^{D}}\left(1+\tau_{k}\right) D_{t+1}^{-\sigma_{D}}(i)+ \\
q_{t+1}^{D}(i)\left(\Phi_{t+1}^{D}(i)-\Phi_{t+1}^{D^{\prime}} \frac{I_{t+1}^{D}(i)}{D_{t}(i)}+\left(1-\delta_{D}\right)\right)
\end{array}\right]\right\}
\end{gathered}
$$

where $\pi^{I P}, \pi^{D}$ represent productive investment and housing inflation.

\subsection{Labour supply and wage setting}

The partial derivative with respect to labour yields the standard marginal condition relating the real wage and the marginal rate of substitution between labour and income $(M R S)$ :

$$
\frac{\left(1-\tau_{w}\right) W_{t}}{\left(1+\tau_{c}\right) P C_{t}}=\frac{\varepsilon_{t}^{a}\left(n_{t}(i)\right)^{\varphi}}{\lambda_{t}(i)}
$$

Each household supplies a differentiated type of labour and thus enjoys some degree of monopoly power. A labour aggregator combines the labour services from all households and sells a bundle of such services in the same proportion as firms would choose according to a CES production technology:

$$
n_{t}=\left[\int_{0}^{1} n_{t}(i)^{\frac{\varepsilon_{W}-1}{\varepsilon_{W}}} d i\right]^{\frac{\varepsilon_{W}}{\varepsilon_{W}-1}}
$$


The aggregator minimizes the cost of producing a given amount of aggregate labour taking $W_{t}(i)$ as given. The household $i$ 's labour demand is thus given by:

$$
n_{t}(i)=\left(\frac{W_{t}(i)}{W_{t}}\right)^{-\varepsilon_{W}} n_{t}
$$

where $n_{t}$ is aggregate per capita hours. From the zero profit condition of the labour aggregator we obtain the aggregate wage index:

$$
W_{t} \equiv\left(\int_{0}^{1} W_{t}(i)^{1-\varepsilon_{W}} d i\right)^{\frac{1}{1-\varepsilon_{W}}}
$$

Furthermore, households act as price-setters in the labour market. Following Erceg, Henderson and Levin (2000), each period only a fraction 1- $\theta_{w}$ of workers reset their nominal wage. Let $\widetilde{W}_{t}$ (for simplicity we drop the index $i$ ) denote the newly set wage at time $t$, in nominal terms. Until the next re-optimization, that wage is adjusted automatically each period according to the indexation rule: $W_{t}=$ $W_{t-1} d_{t}^{\xi^{W}}$, where $d_{t}$ is assumed to be a function of aggregate variables observed at time $t$-1. $\xi^{W}$ measures the degree of indexation $\left(\xi^{W}=0\right.$ no indexation, $\xi^{W}=1$ full indexation). By forward iteration we obtain:

$$
W_{t, t+k}(i)=\widetilde{W}_{t}(i) \prod_{i=1}^{k} d_{t+i}^{\xi^{W}}
$$

It is also assumed that labour is firm specific, so that the ex-post wage will differ across households and hence the ex-ante and ex-post MRS needs not to be equal: $M R S_{t, t+k} \neq M R S_{t+k}$.

Therefore, the wage setting problem solved by the household consists in choosing the wage $\widetilde{W}_{t}(i)$ that maximizes the expected discounted stream of utility from equation (2.1), subject to the sequence of period budget constraints (equation $(2.2)$ ), and the labour demand schedule obtained above:

$$
n_{t, t+k}(i)=\left(\frac{\widetilde{W}_{t}(i) \prod_{i=1}^{k} d_{t+i}^{\xi^{W}}}{W_{t+k}}\right)^{-\varepsilon_{w}} n_{t+k}
$$

The first order condition of this problem is (to simplify the exposition we assume 
$\left.\tau_{w}=\tau_{c}=0\right)$

$$
\begin{aligned}
E_{t} \sum_{k=0}^{\infty}\left(\beta \theta_{w}\right)^{k}\left[\begin{array}{c}
U_{n_{t, t+k}}(i) \frac{\partial n_{t, t+k}(i)}{\partial \widehat{W}_{t}(i)}+ \\
U_{c_{t, t+k}}(i)\left(\frac{\partial W_{t, t+k}(i)}{\partial \widehat{W}_{t}(i)} \frac{n_{t, t+k}(i)}{P C_{t+k}}+\frac{W_{t, t+k}(i)}{P C_{t+k}} \frac{\partial n_{t, t+k}(i)}{\partial \widehat{W}_{t}(i)}\right)
\end{array}\right] \\
=E_{t} \sum_{k=0}^{\infty}\left(\beta \theta_{w}\right)^{k}\left[\begin{array}{c}
U_{c_{t, t+k}}(i) \frac{U_{n_{t, t+k}(i)}(i)}{U_{c_{t, t+k}}(i)} \frac{n_{t, t+k}(i)}{\widetilde{W}_{t}(i)}\left(-\varepsilon_{w}\right) \\
+U_{c_{t, t+k}}(i) \frac{n_{t, t+k}(i)}{\widetilde{W}_{t}(i)} \frac{W_{t, t+k}(i)}{P C_{t+k}}\left(1-\varepsilon_{w}\right)
\end{array}\right]=0
\end{aligned}
$$

where we have used the FOC of the household $\left(\lambda_{t+k}(i)=U_{c_{t+k}}(i)\right)$. Rearranging terms it implies that $\widetilde{W}_{t}(i)$ must satisfy:

$$
E_{t} \sum_{k=0}^{\infty}\left(\beta \theta_{w}\right)^{k} n_{t, t+k}(i) U_{c_{t, t+k}}(i)\left(\frac{\widetilde{W}_{t}(i) \prod_{i=1}^{k} d_{t+i}^{\xi^{W}}}{P C_{t+k}}-\frac{\varepsilon_{w}}{\varepsilon_{w}-1} M R S_{t, t+k}(i)\right)=0
$$

Aggregating across symmetric individuals and solving for the optimal wage $\widetilde{W}_{t}$

$$
\widetilde{W}_{t}=\frac{\varepsilon_{w}}{\varepsilon_{w}-1} \frac{E_{t} \sum_{k=0}^{\infty}\left(\beta \theta_{w}\right)^{k} n_{t, t+k} U_{c, t+k} M R S_{t, t+k}}{E_{t} \sum_{k=0}^{\infty}\left(\beta \theta_{w}\right)^{k} n_{t, t+k} U_{c, t+k} \frac{\prod_{i=1}^{k} d_{t+i}^{\xi W}}{P C_{t+k}}}
$$

where $M R S_{t, t+k}=-\frac{U_{n_{t, t+k}}\left(c_{t+k}, n_{t, t+k}\right)}{U_{c_{t, t+k}}\left(c_{t+k}, n_{t, t+k}\right)}$. Notice that the assumption of complete domestic financial markets guarantees a common level of consumption across households, independently of their current wage.

The average marginal rate of substitution is equal to

$$
M R S_{t+k}(i)=\frac{\varepsilon_{t}^{a}\left(n_{t+k}(i)\right)^{\varphi}}{\lambda_{t+k}(i)}
$$

Given that complete markets implies that $\lambda_{t, t+k}=\lambda_{t+k}$ and using the firm's optimal labour demand (equation (2.15)) we can relate the individual marginal rate of substitution to the average in the following way,

$$
M R S_{t, t+k}=M R S_{t+k}\left(\frac{n_{t, t+k}}{n_{t+k}}\right)^{\varphi}=M R S_{t+k}\left[\left(\frac{\widetilde{W_{t}}}{W_{t}}\right) \prod_{i=1}^{k} d_{t+i}^{\xi^{W}}\right]^{-\varphi \varepsilon_{w}}
$$

finally, the law of motion of aggregate wages is:

$$
W_{t}=\left[\left(1-\theta_{w}\right)\left(\widetilde{W}_{t}(i)\right)^{1-\varepsilon_{w}}+\theta_{w}\left(W_{t-1} d_{t}^{\xi^{W}}\right)^{1-\varepsilon_{w}}\right]^{\frac{1}{1-\varepsilon_{w}}}
$$

The log-linearization of wages is explained in Appendix C. 
Figure 3.1: Structure of production in each country

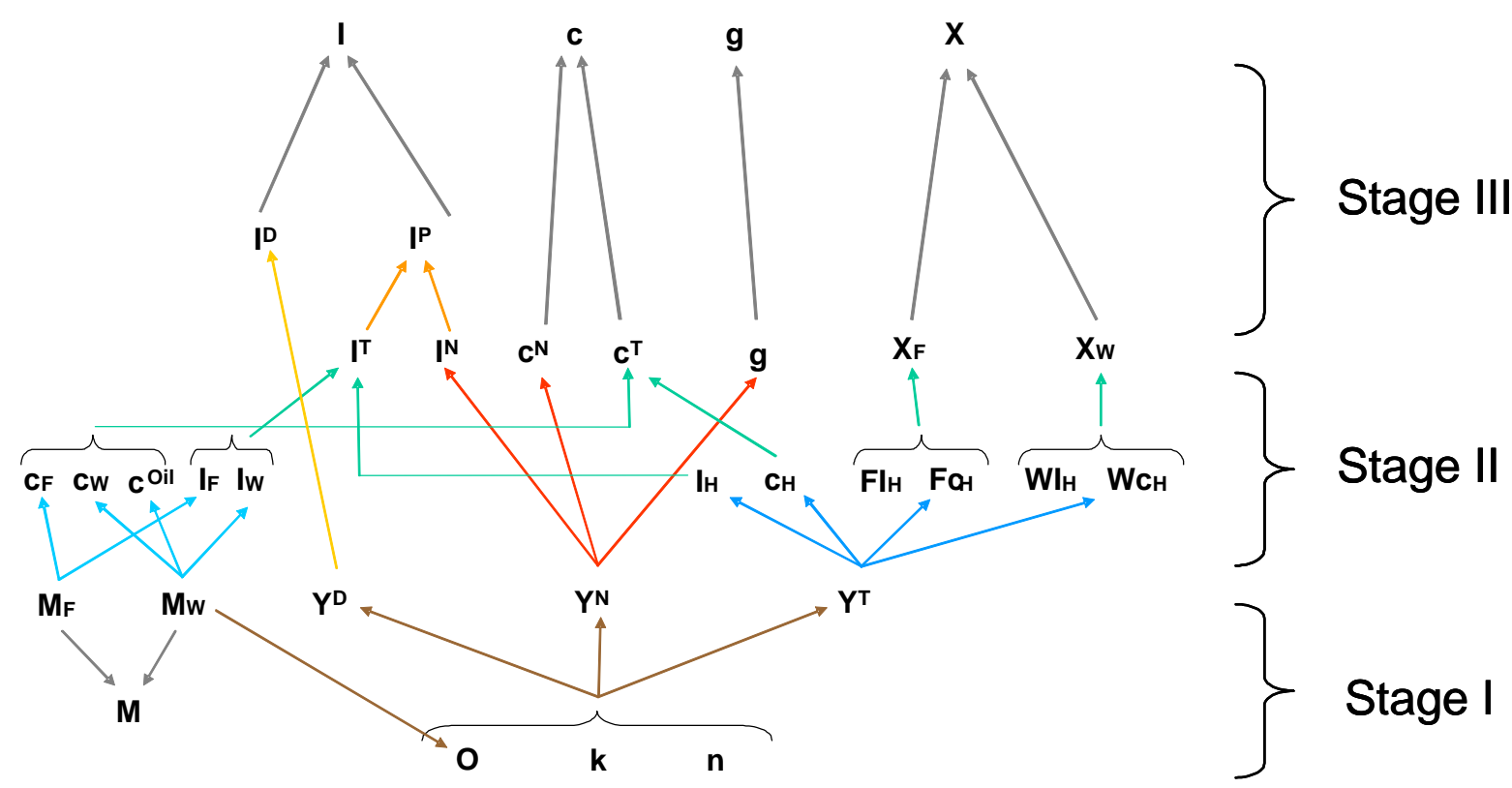

\section{Production}

The several stages at which production and exchange take place in this economy are portrayed in Figure 3.1. In a first stage (lower part of the figure), there is a continuum of firms producing different varieties of goods using a combination of inputs (labour, capital and imported raw materials). Then, in a second stage (middle part of the figure), the intermediate aggregators combine those varieties (traded, non-traded and housing goods) in order to generate bundles that are sold to the final goods aggregators of consumption and investment goods (consumption or investment traded and non-traded goods, public consumption goods, exports to rest of Euro area or rest of the world). Finally, in a third stage (top part of the figure), the final good aggregators combine these bundles of goods into the different baskets of goods demanded by households. 


\subsection{Final goods producing firms (final goods aggregators)}

Starting from the top of the production process (stage III of figure 3.1), final consumption goods are produced by competitive firms with a technology represented by the following CES aggregator,

$$
c_{t}=\left[\left(\omega_{C}^{N}\right)^{\frac{1}{\rho^{c}}}\left(c_{t}^{N}\right)^{\frac{\rho^{c}-1}{\rho^{c}}}+\left(\omega_{C}^{T}\right)^{\frac{1}{\rho^{c}}}\left(c_{t}^{T}\right)^{\frac{\rho^{c}-1}{\rho^{c}}}\right]^{\frac{\rho^{c}}{\rho^{c}-1}}
$$

where $\rho^{c}$ captures the elasticity of substitution between traded $\left(c_{t}^{T}\right)$ and nontraded goods $\left(c_{t}^{N}\right)$. The associated price index is obtained dividing the nominal expenditure through by the real quantity as follows,

$$
P C_{t}=\frac{P C_{t}^{N} c_{t}^{N}+P C_{t}^{T} c_{t}^{T}}{c_{t}}
$$

where $P C^{N}$ represents the consumption price of the non-traded good and $P C^{T}$ the corresponding price for the traded goods.

The distribution of total consumption between non-traded and traded goods is obtained by solving a standard maximization problem. That is, the aggregator chooses the composition of the basket by maximizing its revenues

$$
\begin{gathered}
\operatorname{Max}\left\{P C_{t} c_{t}-P C_{t}^{N} c_{t}^{N}-P C_{t}^{T} c_{t}^{T}\right\} \\
\text { st } \\
c_{t}=\left[\left(\omega_{C}^{N}\right)^{\frac{1}{\rho^{c}}}\left(c_{t}^{N}\right)^{\frac{\rho^{c}-1}{\rho^{c}}}+\left(\omega_{C}^{T}\right)^{\frac{1}{\rho^{c}}}\left(c_{t}^{T}\right)^{\frac{\rho^{c}-1}{\rho^{c}}}\right]^{\frac{\rho^{c}}{\rho^{c}-1}}
\end{gathered}
$$

implying that the demand of non-traded (traded) consumption goods will be a function of total consumption and the ratio between the price of non-traded (traded) goods and the price of total consumption:

$$
\begin{aligned}
c_{t}^{N} & =c_{t} \omega_{C}^{N}\left(\frac{P C_{t}^{N}}{P C_{t}}\right)^{-\rho^{c}} \\
c_{t}^{T} & =c_{t} \omega_{C}^{T}\left(\frac{P C_{t}^{T}}{P C_{t}}\right)^{-\rho^{c}}
\end{aligned}
$$

Thus, the relative demand of non-traded versus traded goods only depends on its relative prices

$$
\frac{c_{t}^{N}}{c_{t}^{T}}=\frac{\omega_{C}^{N}}{\omega_{C}^{T}}\left(\frac{P C_{t}^{N}}{P C_{t}^{T}}\right)^{-\rho^{c}}
$$


Similarly, traded consumption $c_{t}^{T}$ is a composite good of consumption goods produced at home, $c_{H, t}$, imported from the Euro area, $c_{F, t}$, imported from the rest of the world, $c_{W, t}$ and oil, $c_{t}^{O i l}$, that can be represented as an aggregator:

$$
c_{t}^{T}=\left[\begin{array}{c}
\left(\omega_{H C}\right)^{\frac{1}{\rho^{c T}}}\left(c_{H, t}\right)^{\frac{\rho^{c T}-1}{\rho^{c T}}}+\left(\omega_{F C}\right)^{\frac{1}{\rho^{c T}}}\left(c_{F, t}\right)^{\frac{\rho^{c T}-1}{\rho^{c T}}}+ \\
+\left(\omega_{C}^{O i l}\right)^{\frac{1}{\rho^{c T}}}\left(c_{t}^{O i l}\right)^{\frac{\rho^{c T}-1}{\rho^{c T}}}+\left(\omega_{W C}\right)^{\frac{1}{\rho^{c T}}}\left(c_{W, t}\right)^{\frac{\rho^{c T}}{\rho^{c T}}}
\end{array}\right]^{\frac{\rho^{c T}}{\rho^{c T}-1}}
$$

where, as in the previous case, $\rho^{c T}$ is the elasticity of substitution among different types of traded goods. ${ }^{6}$

In the case of the traded consumption goods the problem to be solved by the aggregator is the following:

$$
\begin{aligned}
& M a x\left\{P C_{t}^{T} c_{t}^{T}-\left(P_{t}^{C} c_{H, t}+F P_{t}^{C} c_{F, t}+s_{t}^{-1} P_{t}^{O i l} c_{t}^{O i l}+s_{t}^{-1} W P_{t}^{C} c_{W, t}\right)\right\} \\
& \text { st } \\
c_{t}^{T}= & {\left[\begin{array}{c}
\left(\omega_{H C}\right)^{\frac{1}{\rho^{c T}}}\left(c_{H, t}\right)^{\frac{\rho^{c T}-1}{\rho^{c T}}}+\left(\omega_{F C}\right)^{\frac{1}{\rho^{c T}}}\left(c_{F, t}\right)^{\frac{\rho^{c T}-1}{\rho^{c T}}}+ \\
+\left(\omega_{C}^{O i l}\right)^{\frac{1}{\rho^{c T}}}\left(c_{t}^{O i l}\right)^{\frac{\rho^{c T}}{\rho^{c T}}}+\left(\omega_{W C}\right)^{\frac{1}{\rho^{c T}}}\left(c_{W, t}\right)^{\frac{\rho^{c T}}{\rho^{c T}}}
\end{array}\right]^{\frac{\rho^{c T}}{\rho^{c T}-1}} }
\end{aligned}
$$

where $P^{C}$ is the price of the home produced traded consumption goods, $F P^{C}$ is that of those imported from the Euro area, $W P^{C}$ is the price of consumption goods imported from the rest of the world and $P^{O i l}$ is the international price of oil. Notice that the last two prices are defined in dollars. The first order conditions expressed as relative demands are

$$
\begin{gathered}
\frac{c_{F, t}}{c_{H, t}}=\frac{\omega_{F C}}{\omega_{H C}}\left(\frac{F P_{t}^{C}}{P_{t}^{C}}\right)^{-\rho^{c T}} \\
\frac{c_{t}^{O i l}}{c_{H, t}}=\frac{\omega_{C}^{O i l}}{\omega_{H C}}\left(\frac{s_{t}^{-1} P_{t}^{O i l}}{P_{t}^{C}}\right)^{-\rho^{c T}} \\
\frac{c_{W, t}}{c_{H, t}}=\frac{\omega_{W C}}{\omega_{H C}}\left(\frac{s_{t}^{-1} W P_{t}^{C}}{P_{t}^{C}}\right)^{-\rho^{c T}}
\end{gathered}
$$

\footnotetext{
${ }^{6}$ We have not considered the existence of adjustment costs in substituting home produced by foreign produced goods in the $c_{t}^{T}$ basket. If these costs were present we would obtain dynamic import equations in which the relative demand of foreign versus domestic countries would depend on past relative demands as well as the expected value of future relative prices. Thus generating smoother behaviour of the relative demand functions.
} 
Substituting out the expressions for the demands of individuals components of consumption into the definition of the aggregate deflator of consumption (equation (3.2)) we may express this price as a standard price index as follows:

$$
P C_{t}=\left[\omega_{C}^{N}\left(P C_{t}^{N}\right)^{1-\rho^{c}}+\omega_{C}^{T}\left(P C_{t}^{T}\right)^{1-\rho^{c}}\right]^{\frac{1}{1-\rho^{c}}}
$$

Similarly, we obtain the following expression for the price index of consumption of traded goods:

$$
P C_{t}^{T}=\left[\begin{array}{c}
\omega_{H C}\left(P_{t}^{C}\right)^{1-\rho^{c T}}+\omega_{F C}\left(F P_{t}^{C}\right)^{1-\rho^{c T}}+\omega_{C}^{O i l}\left(s_{t}^{-1} P_{t}^{O i l}\right)^{1-\rho^{c T}} \\
+\omega_{W C}\left(s_{t}^{-1} W P_{t}^{C}\right)^{1-\rho^{c T}}
\end{array}\right]^{\frac{1}{1-\rho^{c T}}}
$$

The sequence of aggregators in the case of investment is obtained in a symmetric manner to that of consumption with one exception: total investment $\left(I_{t}\right)$ is the aggregate of productive investment $\left(I_{t}^{P}\right)$ and housing $\left(I_{t}^{D}\right)$.

\subsection{Intermediate aggregators}

Intermediate aggregators are firms that combine the different varieties of goods produced by varieties-producing firms and aggregate them in a composite good (stage II of figure 3.1). These aggregators maximize the income from the basket, taking the varieties as inputs. We assume that this sector is competitive.

Thus, $c_{H, t}(j)$ varieties are aggregated in a basket $c_{H, t}$, selling goods at $P_{t}^{C}$. These varieties are imperfect substitutes with elasticity of substitution $\theta^{c}$ :

$$
\operatorname{Max}_{c_{H, t}(j)}\left\{P_{t}^{C} c_{H, t}-\int_{0}^{1} P_{t}^{C}(j) c_{H, t}(j) d j\right\}
$$

where:

$$
c_{H, t}=\int_{0}^{1}\left(c_{H, t}^{T}(j)^{\frac{\theta^{c}-1}{\theta^{c}}} d j\right)^{\frac{\theta^{c}}{\theta^{c}-1}}
$$

This leads to:

$$
c_{H, t}(j)=c_{H, t}\left(\frac{P_{t}^{C}(j)}{P_{t}^{C}}\right)^{-\theta^{c}}
$$

and, imposing the zero profits condition on the aggregator, it gives:

$$
P_{t}^{C}=\int_{0}^{1}\left(P_{t}^{C}(j)^{1-\theta^{c}} d j\right)^{\frac{1}{1-\theta^{c}}}
$$

The composite goods $F c_{H, t}, W c_{H, t}, I_{H, t}, F I_{H, t}, W I_{H, t}, c_{t}^{N}, I_{t}^{N}, I_{t}^{D}$ and aggregate prices $P_{t}^{I}, P C_{t}^{N}, P I_{t}^{N}, P_{t}^{D}$ are obtained in a similar manner. 


\subsection{Intermediate-goods producing firms}

Finally, at the bottom of the production process, we have a continuum of intermediate goods producing firms, which can be classified into three sectors that differ from each other in the technology used: traded, non-traded and housing. Each firm belonging to a sector produces a variety of that kind of good (stage I of figure 3.1). In the following subsections, we specify the equilibrium conditions for each firm, the prices of each variety and the demand for production factors in the traded goods sectors. The problem for firms in the non-traded goods and housing sectors are solved in a similar manner.

\subsubsection{Production and prices}

There is a homogeneous technology of production for both consumption and investment goods. Each intermediate firm in the traded goods sector produces a variety, $y_{t}^{T}(j)$, that can be sold at home or abroad as consumption or investment good:

$$
y_{t}^{T}(j)=y_{t}^{T C}(j)+y_{t}^{T I}(j)
$$

where,

$$
\begin{gathered}
y_{t}^{T C}(j)=c_{H, t}(j)+F c_{H, t}(j)+W c_{H, t}(j) \\
y_{t}^{T I}(j)=I_{H, t}(j)+F I_{H, t}(j)+W I_{H, t}(j)
\end{gathered}
$$

where $F c_{H, t}, W c_{H, t}\left(F I_{H, t}, W I_{H, t}\right)$ represent the foreign demand from the Euro area and the rest of the world, respectively, of domestically produced consumption (investment) goods. Thus $\left(F c_{H, t}+W c_{H, t}+F I_{H, t}+W I_{H, t}\right)$ represents total exports of the domestic country. The $F$ country demand of consumption and investment goods produced in the domestic economy is obtained from the intratemporal cost minimization problem of the household described in the previous section (and the corresponding one for the $F$ country). Since the economy of the rest of the world $(W)$ is not explicitly developed in our model we shall assume the demand functions for consumption and investment goods exports $\left(W c_{H, t}, W I_{H, t}\right)$ follow exogenous processes.

We assume that there is no price discrimination across countries, thus there is not pricing to market and prices in foreign markets are equal to those in domestic markets, but defined in foreign currency terms (i.e. multiplied by the exchange rate $\left.s_{t}\right) .{ }^{7}$ However, there is price discrimination across consumption and investment goods. That is, since firms face two segmented markets (for consumption

\footnotetext{
${ }^{7}$ Allowing for cross-country price discrimination would introduce an additional channel to
} 
and investment goods) they set two different prices: $P_{t}^{C}(j), P_{t}^{I}(j)$. However, $P_{t}^{C}(j)$ applies to $c_{H, t}(j), F c_{H, t}(j)$ and $W c_{H, t}(j)$, while $P_{t}^{I}(j)$ is the price of $I_{H, t}(j)$, $F I_{H, t}(j)$ and $W I_{H, t}(j)$.

\subsubsection{Sticky Prices}

If prices were fully flexible, firms would set them to maximize profits taking as given the demand for each variety. Thus prices would be equal to the corresponding mark-up over marginal costs $\left(m c_{t}^{T}\right)$ in nominal terms:

$$
\begin{aligned}
& P_{t}^{C}(j)=\left(\frac{\theta^{c}}{\theta^{c}-1}\right) P_{t}^{T}(j) m c_{t}^{T}(j) \\
& P_{t}^{I}(j)=\left(\frac{\theta^{I}}{\theta^{I}-1}\right) P_{t}^{T}(j) m c_{t}^{T}(j)
\end{aligned}
$$

where $P_{t}^{T}$ is defined below, see (4.9).

However, the empirical evidence suggest there is nominal inertia in prices, that is, prices tend to be sticky (see Álvarez et al. (2006) and Galí, Gertler and López-Salido (2001) for evidence on the Euro Area and Bils and Klenow (2004) for the US). Following Calvo (1983), we assume that firms set nominal prices on a staggered basis. Each firm resets its price with probability 1- $\theta$ each period, independently of the time elapsed since the last adjustment. Thus, each period a measure 1- $\theta$ of producers reset their prices, while $\theta^{k}$ will be the probability that the price set at time $t$ will still hold at time $t+k$ (thus, flexible prices require $\theta=0$ ). The fraction $\theta$ of firms which cannot reset their prices optimally adjusts prices according to a simple indexation rule to catch up with lagged inflation: ${ }^{8}$

$$
P_{t+i}^{C}(j)=P_{t+i-1}^{C}(j)\left(\frac{P_{t+i-1}^{C}}{P_{t+i-2}^{C}}\right)^{\xi^{P}}=P_{t+i-1}^{C}(j)\left(\pi_{t+i-1}^{C}\right)^{\xi^{P}}
$$

where $\xi^{P}$ is a parameter that indicates the degree of non-optimizers' price adjustment whose extreme values reflect no indexation $\left(\xi^{P}=0\right)$ or full indexation

explain different responses across countries to area-wide shocks. The possible relevance of this issue for the different regions of the Euro area will be explored in further research.

${ }^{8} \mathrm{~A}$ simpler but less realistic alternative, often used in the literature (see e.g. Galí and Gertler (1999)), is to have these firms adjusting to steady-state inflation $(\bar{\pi})$, sometimes assumed to be zero. In this case non-adjusting firms simply set $P_{t}^{C}(j)=P_{t-1}^{C}(j) \bar{\pi}$ and $P_{t}^{I}(j)=P_{t-1}^{I}(j) \bar{\pi}$. 
$\left(\xi^{P}=1\right)$. Likewise,

$$
P_{t+i}^{I}(j)=P_{t+i-1}^{I}(j)\left(\frac{P_{t+i-1}^{I}}{P_{t+i-2}^{I}}\right)^{\xi^{P}}=P_{t+i-1}^{I}(j)\left(\pi_{t+i-1}^{I}\right)^{\xi^{P}}
$$

where we are assuming that the structure of indexation is the same for consumption and investment goods prices.

Let us call $\widetilde{P}_{t}^{C}(j)$ and $\widetilde{P}_{t}^{I}(j)$ the newly set prices for varieties of consumption and investment goods respectively, at $t$. These prices are chosen to maximize the expected present discounted value of future dividends:

$$
\max _{\widetilde{P}_{t}^{C}(j), \widetilde{P}_{t}^{I}(j)} E_{t} \sum_{k=0}^{\infty}(\beta \theta)^{k} \zeta_{t+k}\left\{\begin{array}{c}
y_{t+k}^{T C}(j) \widetilde{P}_{t}^{C}(j) \prod_{i=1}^{k}\left(\pi_{t+i-1}^{C}\right)^{\xi^{P}} \\
+y_{t+k}^{T I}(j) \widetilde{P}_{t}^{I}(j) \prod_{i=1}^{k}\left(\pi_{t+i-1}^{I}\right)^{\xi^{P}} \\
-P_{t+k}^{T} m c_{t, t+k}^{T}(j) y_{t+k}^{T}(j)
\end{array}\right\}
$$

subject to:

$$
\begin{gathered}
y_{t+k}^{T}(j)=y_{t+k}^{T C}(j)+y_{t+k}^{T I}(j) \\
y_{t+k}^{T C}(j)=y_{t+k}^{T C}\left(\frac{\widetilde{P}_{t}^{C}(j) \prod_{i=1}^{k}\left(\pi_{t+i-1}^{C}\right)^{\xi^{P}}}{P_{t+k}^{C}}\right)^{-\theta^{c}} \\
y_{t+k}^{T I}(j)=y_{t+k}^{T I}\left(\frac{\widetilde{P}_{t}^{I}(j) \prod_{i=1}^{k}\left(\pi_{t+i-1}^{I}\right)^{\xi^{P}}}{P_{t+k}^{I}}\right)^{-\theta^{I}}
\end{gathered}
$$

where $y_{t+k}^{T C}(j)=c_{H, t+k}(j)+F c_{H, t+k}(j)+W c_{H, t+k}(j)$ and $y_{t+k}^{T I}(j)=I_{H, t+k}(j)+$ $F I_{H, t+k}(j)+W I_{H, t+k}(j)$. The first order conditions of this maximization problem are,

$$
\begin{aligned}
& E_{t} \sum_{k=0}^{\infty}(\beta \theta)^{k} \zeta_{t+k} y_{t+k}^{T C}(j)\left\{\prod_{i=1}^{k}\left(\pi_{t+i-1}^{C}\right)^{\xi^{P}}\left(1-\theta^{c}\right)+\frac{\theta^{c} P_{t+k}^{T} m c_{t, t+k}^{T}(j)}{\widetilde{P}_{t}^{C}(j)}\right\}=0 \\
& E_{t} \sum_{k=0}^{\infty}(\beta \theta)^{k} \zeta_{t+k} y_{t+k}^{T I}(j)\left\{\prod_{i=1}^{k}\left(\pi_{t+i-1}^{I}\right)^{\xi^{P}}\left(1-\theta^{I}\right)+\frac{\theta^{I} P_{t+k}^{T} m c_{t, t+k}^{T}(j)}{\widetilde{P}_{t}^{I}(j)}\right\}=0
\end{aligned}
$$

where $\zeta_{t+k}=\left(\frac{U_{c, t+k}}{U_{c, t}}\right)$. 
Solving and given that in equilibrium all firms are symmetric, the newly set price at each $t$ will be given by:

$$
\begin{aligned}
& \widetilde{P}_{t}^{C}=\left(\frac{\theta^{c}}{\theta^{c}-1}\right) \frac{E_{t} \sum_{k=0}^{\infty}(\beta \theta)^{k} \zeta_{t+k} P_{t+k}^{T} m c_{t, t+k}^{T} y_{t+k}^{T C}}{E_{t} \sum_{k=0}^{\infty}(\beta \theta)^{k} \zeta_{t+k} \prod_{i=1}^{k}\left(\pi_{t+i-1}^{C}\right)^{\xi^{P}} y_{t+k}^{T C}} \\
& \widetilde{P}_{t}^{I}=\left(\frac{\theta^{I}}{\theta^{I}-1}\right) \frac{E_{t} \sum_{k=0}^{\infty}(\beta \theta)^{k} \zeta_{t+k} P_{t+k}^{T} m c_{t, t+k}^{T} y_{t+k}^{T I}}{E_{t} \sum_{k=0}^{\infty}(\beta \theta)^{k} \zeta_{t+k} \prod_{i=1}^{k}\left(\pi_{t+i-1}^{I}\right)^{\xi^{P}} y_{t+k}^{T I}}
\end{aligned}
$$

These equations can be interpreted as dynamic markup equations, so firms set prices using the expected future evolution of demand and marginal costs. ${ }^{9}$ Finally, since the different varieties of goods aggregate to a composite good through an Armington aggregator, the corresponding aggregate prices will be given by:

$$
\begin{aligned}
& P_{t}^{C}=\left[\theta\left(P_{t-1}^{C}\left(\pi_{t-1}^{C}\right)^{\xi^{P}}\right)^{1-\theta^{c}}+(1-\theta) \widetilde{P}_{t}^{C\left(1-\theta^{c}\right)}\right]^{\frac{1}{1-\theta^{c}}} \\
& P_{t}^{I}=\left[\theta\left(P_{t-1}^{I}\left(\pi_{t-1}^{I}\right)^{\xi^{P}}\right)^{1-\theta^{I}}+(1-\theta) \widetilde{P}_{t}^{I\left(1-\theta^{I}\right)}\right]^{\frac{1}{1-\theta^{I}}}
\end{aligned}
$$

The log-linearization of prices is explained in Appendix C.

\subsubsection{Cost Minimization}

Once the demand and the prices of the different varieties of goods in each sector are set, the firms determine their factor demands by minimizing costs taking as given the prices of the inputs. This problem is subject to the production function constraint that depends on three factors: labour $(n)$, capital $(k)$ and oil $(O)$. In addition, we allow for changes in the utilization of installed capital (cu). The structure of the production function is equal for the first two sectors: CobbDouglas in value added and a CES in gross production (that is, including oil). In the case of the housing sector oil is not considered (see Appendix A). Moreover, the sectoral production functions differ in the underlying parameters.

Firms are allowed to change their capital capacity utilization, like in Chari, Kehoe \& McGrattan (2000), but this implies an additional cost for them that

\footnotetext{
${ }^{9}$ These expressions are in terms of the firm's specific marginal cost. For a procedure to express this variable in terms of an observable measure of aggregate marginal cost see Galí, Gertler and López-Salido (2001), Woodford (2003) and Sbordone (19999.
} 
is reflected in the function $h\left(c u_{t}^{T}\right) .{ }^{10}$ The $j_{t h}$ firm chooses factor demands and capital capacity utilization in perfectly competitive factor markets. Hence, it chooses $n_{t}^{T}(j), k_{t}^{T}(j), O_{t}^{T}(j)$ and $c u_{t}^{T}(j)$ to minimize total costs:

$$
\min _{\left\{n_{t}^{T}(j), k_{t}^{T}(j), O_{t}^{T}(j), c u_{t}^{T}(j)\right\}}\left\{\frac{W_{t}}{P_{t}^{T}(j)} n_{t}^{T}(j)+\frac{P C_{t} r_{t}}{P_{t}^{T}(j)} k_{t}^{T}(j)+\frac{s_{t}^{-1} P_{t}^{o i l}}{P_{t}^{T}(j)} O_{t}^{T}(j)+h\left(c u_{t}^{T}(j)\right)\right\}
$$

subject to

$y_{t}^{T}(j)=\left\{\varkappa_{T}^{\frac{\psi^{T}}{\psi^{T}-1}}\left(O_{t}^{T}(j)\right)^{\frac{\psi^{T}-1}{\psi^{T}}}+\left(1-\varkappa_{T}\right)^{\frac{\psi^{T}}{\psi^{T}-1}}\left[\left(c u_{t}^{T}(j) k_{t}^{T}(j)\right)^{\alpha_{T}}\left(z_{t} z_{t}^{T} n_{t}^{T}(j)\right)^{1-\alpha_{T}}\right]^{\frac{\psi^{T}-1}{\psi^{T}}}\right\}^{\frac{\psi^{T}}{\psi^{T}-1}}$

where $h^{\prime}>0$ and $z_{t}, z_{t}^{T}$ are total factor economy-wide and sector specific productivity shocks, respectively.

Factor demands and optimal capital capacity utilization are given by the first order conditions of this problem:

$$
\begin{gathered}
m c_{t}^{T}(j) \frac{\partial y_{t}^{T}(j)}{\partial n_{t}^{T}(j)}=\frac{W_{t}}{P_{t}^{T}(j)} \\
m c_{t}^{T}(j) \frac{\partial y_{t}^{T}(j)}{\partial k_{t}^{T}(j)}=\frac{P C_{t} r_{t}}{P_{t}^{T}(j)} \\
m c_{t}^{T}(j) \frac{\partial y_{t}^{T}(j)}{\partial O_{t}^{T}(j)}=\frac{P_{t}^{o i l}}{P_{t}^{T}(j)} \\
m c_{t}^{T}(j) \frac{\partial y_{t}^{T}(j)}{\partial c u_{t}^{T}(j)}=\frac{\partial h\left(c u_{t}^{T}\right)}{\partial c u_{t}^{T}(j)}
\end{gathered}
$$

where $m c_{t}^{T}(j)$ is the Lagrange multiplier that can be interpreted as the real marginal cost of producing an additional unit of output. Notice that, given cost minimization, the firm will take $m c_{t}^{T}(j)$ as given when choosing its output price. It is done similarly for the other sectors.

\footnotetext{
${ }^{10}$ In other models this cost is introduced as a higher depreciation of capital (see King, Plosser and Rebelo (1988) or Neiss and Pappa (2005)), but in a multisector model like ours, where capital accumulation is undertaken by households and capital utilization is decided by firms it seems more sensible to apply this cost directly to firms.
} 


\section{Aggregate variables}

\subsection{From production to value added.}

The link between (nominal) value added and production can be described by the following equations for the traded and non-traded sectors ${ }^{11}$

$$
\begin{gathered}
P v_{t}^{T} v a_{t}^{T}=P_{t}^{T} y_{t}^{T}-s_{t}^{-1} P_{t}^{O i l} O_{t}^{T} \\
P v_{t}^{N} v a_{t}^{N}=P_{t}^{N} y_{t}^{N}-s_{t}^{-1} P_{t}^{O i l} O_{t}^{N}
\end{gathered}
$$

where the $P v$ 's are the sectoral value added deflators. In real terms

$$
\begin{gathered}
v a_{t}^{T}=y_{t}^{T}-O_{t}^{T} \\
v a_{t}^{N}=y_{t}^{N}-O_{t}^{N}
\end{gathered}
$$

Then, real GDP $\left(v a_{t}\right)$ is obtained by aggregating across sectors

$$
v a_{t}=v a_{t}^{T}+v a_{t}^{N}+y_{t}^{D}
$$

and the GDP deflator is equal to

$$
P v_{t}=\frac{P v_{t}^{T} v a_{t}^{T}+P v_{t}^{N} v a_{t}^{N}+P_{t}^{D} y_{t}^{D}}{v a_{t}}
$$

\subsection{Aggregate constraints.}

In a symmetric equilibrium, total capital and labour of the economy are given by

$$
\begin{gathered}
k_{t-1}=k_{t}^{T}+k_{t}^{N}+k_{t}^{D} \\
n_{t}=n_{t}^{T}+n_{t}^{N}+n_{t}^{D}
\end{gathered}
$$

while the aggregate prices and resource constraints are, ${ }^{12}$

$$
\begin{gathered}
P^{T} y_{t}^{T}=P_{t}^{C} y_{t}^{T C}+P_{t}^{I} y_{t}^{T I}=P_{t}^{C}\left(c_{H, t}+F c_{H, t}+W c_{H, t}\right)+P_{t}^{I}\left(I_{H, t}+F I_{H, t}+W I_{H, t}\right) \\
y_{t}^{T}=y_{t}^{T C}+y_{t}^{T I}=c_{H, t}+F c_{H, t}+W c_{H, t}+I_{H, t}+F I_{H, t}+W I_{H, t}
\end{gathered}
$$

\footnotetext{
${ }^{11}$ Appendix B shows the consistency of these definitions and equilibrimum conditions both in nominal and in real terms.

${ }^{12}$ Notice that the price of public consumption goods is the same as the aggregate price of non-traded goods.
} 


$$
\begin{gathered}
P_{t}^{N}\left(y_{t}^{N}-g_{t}\right)=P C_{t}^{N} c_{t}^{N}+P I_{t}^{N} I_{t}^{N} \\
y_{t}^{N}==y_{t}^{N C}+y_{t}^{N I}=c_{t}^{N}+I_{t}^{N}+g_{t} \\
y_{t}^{D}=I_{t}^{D} \\
P_{t}=\frac{P_{t}^{N} y_{t}^{N}+P_{t}^{T} y_{t}^{T}+P_{t}^{D} y_{t}^{D}}{y_{t}} \\
y_{t}=y_{t}^{N}+y_{t}^{T}+y_{t}^{D}
\end{gathered}
$$

The balance of payments, including the risk premium, evolves as follows

$$
s_{t} W R_{t} \Psi\left(a_{t-1}\right) a_{t-1} \frac{v a_{t-1}}{\pi_{t}^{V A} v a_{t}}+\frac{P_{t}^{X} X_{t}-P_{t}^{M} M_{t}}{P v_{t} v a_{t}}=s_{t} a_{t}
$$

where, $a_{t}=\frac{A_{t}}{P v_{t} v a_{t}}$ and $\gamma_{y}=\frac{v a_{t+1}}{v a_{t}}$. Also the import and export deflators are defined as

$$
\begin{aligned}
P_{t}^{M} M_{t} & =\left[\begin{array}{c}
F P_{t}^{C} c_{F, t}+F P_{t}^{I} I_{F, t}+s_{t}^{-1} W P_{t}^{C} c_{W, t} \\
+s_{t}^{-1} W P_{t}^{I} I_{W, t}+s_{t}^{-1} P_{t}^{O i l}\left(c_{t}^{O i l}+O_{t}^{T}+O_{t}^{N}\right)
\end{array}\right] \\
P_{t}^{X} & =\frac{P_{t}^{C} F c_{H, t}+P_{t}^{I} F I_{H, t}+P_{t}^{C} W c_{H, t}+P_{t}^{I} W I_{H, t}}{X_{t}}
\end{aligned}
$$

\subsection{Policy rules.}

To close the model we need to specify how common monetary policy and each countries' fiscal polices are conducted. Monetary policy is represented by a standard Taylor rule:

$$
R_{t}=(R R) R_{t-1}^{\rho_{R}} T R_{t}^{\left(1-\rho_{R}\right)} \varepsilon_{t}^{R}
$$

where

$$
T R_{t}=\left(\left(\frac{\pi_{t}^{V A}}{\pi^{V A}}\right)^{\varpi}\left(\frac{F \pi_{t}^{V A}}{F \pi^{V A}}\right)^{(1-\varpi)}\right)^{\rho_{\pi}}\left(\left(\frac{v a_{t}}{v a}\right)^{\varpi}\left(\frac{F v a_{t}}{F v a}\right)^{(1-\varpi)}\right)^{\rho_{V A}}
$$

where $R R$ is the steady-state real interest rate, and $T R_{t}$ is the target rate. (4.19) and (4.20) represent that the monetary authority sets the nominal rate $\left(R_{t}\right)$ to prevent inflation deviating from its steady-state level and to counteract movements in the output gap. $\rho_{R}$ captures the degree of interest rate smoothing and $\rho_{\pi}$ and $\rho_{y}$ the elasticity of response to deviations of inflation and output from target. The weights attached to domestic and foreign variables in the rule $(\varpi)$ depend on 
the relative size of both countries. $\varepsilon_{t}^{R}$ represents the unanticipated component of monetary policy.

The government budget constraint is:

$$
\frac{B_{t}}{R_{t}}=B_{t-1}+P_{t}^{N} g_{t}+P C_{t} T_{t}-\tau_{k} P C_{t} r_{t} k_{t}-\tau_{w} W_{t} n_{t}-\tau_{c} P C_{t} c_{t}
$$

Provided that $\rho_{\pi}$ is above a certain threshold value, fiscal policy must be designed to prevent the level of debt to explode. Cyclical changes in tax rates are not very realistic and may, under some circumstances, lead to multiple (sunspot) equilibria (Schmitt-Grohé and Uribe, 1997). Therefore, all $\tau^{w}, \tau^{k}$ and $\tau^{c}$ are assumed constant and we shall assume that lump-sum taxes $\left(T_{t}\right)$ respond sufficiently to deviations of the level of debt as a proportion of GDP $\left(b_{t}\right)$ from target $\bar{b},{ }^{13}$

$$
T_{t}=T_{0}-T_{1}\left(b_{t-1}-\bar{b}\right)
$$

where:

$$
b_{t}=\frac{B_{t}}{P v_{t} v a_{t}}
$$

\section{Calibration}

The large size of this model is reflected in the number of parameters involved. The log-linear version of the model includes 254 parameters that need to be calibrated to run simulations (see Appendix D for the complete set of equations of the model and Appendix E for the log-linear version of the model). Since the theoretical structure of the model is similar for Spain and the rest of the Euro area, almost half of these parameters capture the same concepts for the two areas, so that the number of (non-repeated) parameters of the model is 133.

The calibration strategy chosen in this paper is to set different values for Spain and the rest of the Euro area only for those parameters that can be obtained from the input-output tables or balance of payments data, or from the (partial) solution of the steady state. The rest of parameters take similar values for Spain and the rest of the Euro area and are either calibrated using consensus values from the literature, like the discount rate of households, or set to values which do not prevent the identification of the mechanisms at play, like for example, setting all

\footnotetext{
${ }^{13}$ This class of feedback rules represent the quantitative deficit and/or debt targets such as the Stability and Growth Pact.
} 
the autoregressive parameters and variances of shocks to a similar value or setting to zero the weight of value added in the interest rate rule. In further research, we plan to estimate smaller versions of this model, which will allow us to recalibrate most of these parameters with different values across both areas. Under this calibration, the Euro area is constructed as an aggregate of Germany, France, Italy and the Netherlands. Given this empirical strategy, the parameters in the model can be classified into three groups depending on their nature:

Consensus and data moments. The first group is portrayed in Table 1 in Appendix F and includes the structural parameters (44) of the non-stochastic part of the model. Included in this group are the discount rate of the households, the elasticities of substitution across goods and varieties, the elasticity of output with respect to the different productive factors, the coefficients of the monetary rule, and so on. Most of these parameters were calibrated using consensus values taken from the literature or chosen to reproduce some data moments, others were simply guessed, while the rest were derived from the resolution of the steady state of the model. ${ }^{14}$ The resolution of the steady-state was confined exclusively to those equations necessary to obtain the $\omega^{\prime} s$ in all Armington aggregators in the model. This makes the model consistent with most relevant ratios in the economies involved and makes it possible to give a value to parameters that are difficult to pin down from estimated relative demand equations. In particular, it is worth mentioning that we have chosen a Taylor rule with no inertia and a coefficient on the output gap equal to zero.

Shocks. The second group, (Table 2) includes the coefficients of the autoregressive parameters and variances of the different shocks and exogenous variables considered in the model (12). These parameters are very important in the simulation exercises, since they determine the persistence of shocks. In future work we will try to estimate these parameters, in the meantime, they have been fixed at a similar sensible value, in line with other models in the literature.

Steady-state ratios. Finally, the third group of parameters corresponds to steady-state ratios (77) and is depicted in Table 3 . These are the only parameters that have been calibrated differently across both regions of the model using

\footnotetext{
${ }^{14}$ The exceptions are the elasticities of value added with respect to capital in the three sectors, that were calculated as one minus the ratio of labor income to value added costs from the inputoutput tables, and the tax rates of capital, consumption and wages, that were taken from the ratio of capital income, value added and social contributions tax receipts over the corresponding tax bases (nominal value of capital, consumption and labor income). All the required information comes from the input-output tables, as it will be explained in detail below.
} 
information from input-output tables (the Euro area has been constructed as an aggregate of Germany, France, Italy and Netherlands). However, since these tables are not completely consistent with the theoretical structure of the model, it has been necessary to transform them. In particular, we have made the following modifications:

First, only three branches of activity are considered in the model, which are identified in the input-output tables as traded sector (agriculture plus industry), non-traded sector (services plus construction industry, excluding housing) and housing. These three branches are obtained by simple aggregation of their components, except for the housing sector. The construction of houses is part of the construction industry, which is included in the services sector. In order to obtain a separate housing sector, we extract from the construction industry the part corresponding to housing according to the share of investment in housing in total investment in construction, provided by the tables of breakdown of gross fixed capital formation.

Second, the only intermediate input considered in the model is imported oil. This means that the other intermediate inputs, both domestically produced and imported, should be consolidated with some other aggregate of the economy. On the one hand, domestically produced intermediate inputs were simply eliminated from both, the production side and the demand side of the input-output tables. On the other hand, imported intermediate inputs were classified as final imported consumption or final investment goods according to the relevance in production of each type of goods in the corresponding importing branch. That is, if branch i imports 100 units of intermediate inputs and $70 \%$ of the production of that branch is consumption goods and 30\% investment goods, we consider $70 \%$ of those imports as imported final consumption goods and $30 \%$ as imported final investment goods.

Third, the elimination of all intermediate inputs from the input-output tables, except for oil, means that the basic accounting identity at the branch level does no longer hold. In particular, the accounting identity that should hold for branch $j$ is the following

$$
v a_{j}+i i_{j}^{i}=d f_{j}+i i_{i}^{j}-m_{j}
$$

That is, branch $j$ 's value added $\left(v a_{j}\right)$ plus its demand of intermediate inputs produced by other branches $\left(i i_{j}^{i}\right)$ (gross production) equals the demand of the final goods produced by this branch $\left(d f_{j}\right)$ plus the demand by other branches of the intermediate inputs produced by this branch $\left(i i_{i}^{j}\right)$, minus imports. Since branch $j$ 's demand of intermediate inputs produced by other branches () is different from 
the demand by other branches of the intermediate inputs produced by branch $j$ $\left(i i_{j}^{i} \neq i i_{i}^{j}\right)$, the elimination of intermediate inputs breaks this identity. In order to reconcile the identity we propose to redistribute the demand of final goods produced by branch $j\left(d f_{j}\right)$ between the different branches of activity which contributed to their production with intermediate inputs. This is done by assuming that the final demand of every good or service is a weighted average of the value added of all the different branches which produce intermediate inputs for this branch, where the weights are given by the share of intermediate consumption in gross production of each branch. Using an example, if there were only two branches of activity, one producing only intermediate inputs -tins for tuna fishand the other producing one final consumption good -tinned tuna-fish- using the intermediate input from the other branch -the tins-; then, the calculated inputoutput tables would only include the final consumption of the second good -tinned tuna fish-, since we would have eliminated the intermediate inputs produced by branch one and demanded by branch two -the tins. Using the transformation we propose, the final consumption good of branch two -tinned tuna fish- would be divided into final consumption of the first good -tins for tuna fish- and final consumption of the second good -tuna fish-, according to the formula mentioned above. This way the fulfilment of the accounting identities at a sectoral level are guaranteed.

Finally, the input-ouput tables provide the trade flows of Spain and the countries forming the rest of Euro area (Germany, France, Italy and the Netherlands) with the rest of the European Union and the rest of the world separately, but this geographic separation of trade does not coincide with the one in the model. In the case of Spain, we need trade flows with the rest of the Euro area and the rest of the world separately, while for the rest of the Euro area, we need trade flows with Spain and the rest of the world. This can be achieved by correcting the trade flows from the input-output tables using balance of payments data on the geographical structure of trade of Spain and the countries forming the rest of Euro area.

As was stated earlier, the only difference in the calibration between the two countries is in the steady-state parameters that have been obtained from the input-output tables. In particular, Spain shows a higher weight of tradeable in consumption than the Euro area, and a lower degree of openness to trade in consumption goods (this is probably the result of the late incorporation of Spain into the European Union). Obviously, imports of Spain from the Euro area are much higher than imports of the Euro area from Spain. Other important differences are 
that the building sector is larger in Spain than in the Euro area, that the weight of tradable investment is lower and the relevance of imported oil in the Spanish economy is somewhat higher. With respect to the public sector, its size is higher in the Euro area economy. Finally, it is important to highlight that the technology seems to be more labor intensive in Spain.

In the next section we will carry out simulation exercises under two sets of calibrations. First, we use a symmetric calibration across the two countries $H$ and $F$, based in the calibration for Spain, to understand the mechanisms at play in the model. Then, we use the (asymmetric) calibration explained here to study how these mechanisms are affected by differences across countries in parameters. However, one should keep in mind the fact that the only changes in the value of the coefficients across the two regions are in the steady-state parameters, in order to capture the differences in the underlying structure of the economy, but not in the behavioural parameters.

\section{Simulations}

We have undertaken six fairly standard simulation exercises to validate the model: a rise in Euro area interest rates, a rise in government spending both in the Euro area and in Spain only, a productivity shock common to all sectors of production of both countries (and in Spain only), a productivity shock specific to one sector and one country, an oil price shock and a shock to consumer preferences. All the shocks are implemented as a rise of a 1 per cent standard deviation of the variable shocked. As mentioned above, our strategy to proceed will be to run first simulations using a calibration symmetric across countries to study the mechanisms at play after each shock. Then, we re-run the simulations using a calibration with different parameters for Spain and the rest of the Euro area to see the impact of the different economic structures. In all the simulations the monetary rule is such that the monetary authorities only react to deviations of the CPI inflation rate.

\subsection{Symmetric calibration}

\subsubsection{Monetary shock}

This shock is implemented as a 1 per cent standard deviation increase in the nominal short-term interest rate. The persistence of the shock is increased because the shock is autocorrelated with coefficient 0.7. The overall impact of the shock is fairly standard (see figure 6.1). The rise in interest rates has a direct impact 
Figure 6.1: Monetary shock
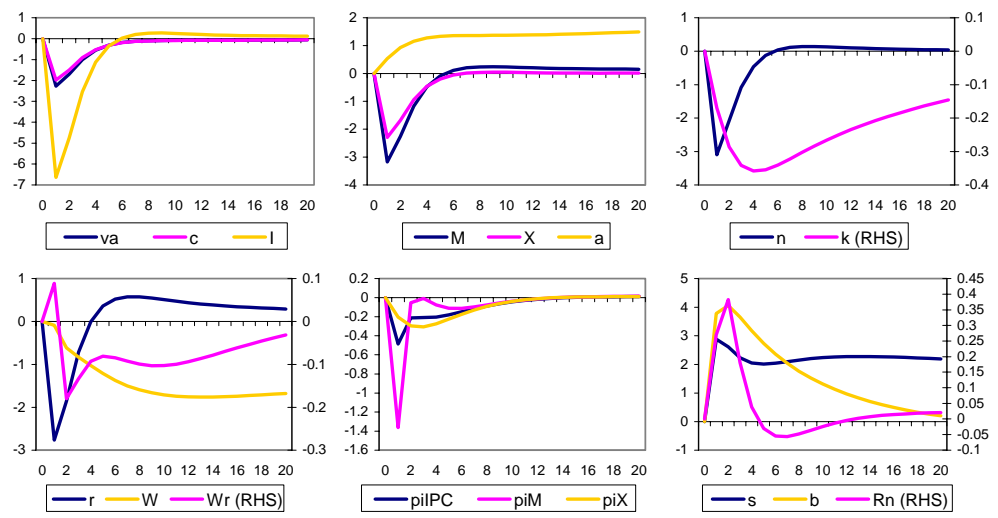

on domestic demand. The higher rates increase the user cost of investment, both productive and housing, which fall. At the same time, household's consumption falls, since the higher interest rate makes savings more attractive and households substitute consumption today for consumption tomorrow. This effect is reinforced by the fall in household's utility caused by the reduction in the housing stock. The fall in domestic demand reduces GDP, but in a smaller magnitude since net exports increase. In addition, the fall in activity reduces the demand for capital and labour as well as the nominal rental cost of capital and the nominal wage. However, since wages fall by less than prices, real wages (and productivity) increase. The reduction in the costs of production of firms is passed on to production and final prices, so that the GDP deflator and CPI fall. Import prices fall by more than domestic and export prices because of the assumption of complete pass-through of the appreciation of the exchange rate. Finally, the rise in interest rates increases the debt to GDP ratio.

\subsubsection{Fiscal shock}

This shock is implemented as a 1 per cent standard deviation temporary increase in government consumption for the whole Euro area, that is for Spain and the rest of Euro area simultaneously, with a high persistence $\left(\rho_{g}^{u}=0.7\right)$. The rise in government spending induces an immediate expansion of output, but the multiplier is smaller than one due to the fall in households' consumption (see figure 6.2). This pattern of response is quite standard for DSGE in which rational agents are engaged on a process of intertemporal substitution (Andrés and Doménech, 2006). 
Figure 6.2: Fiscal shock
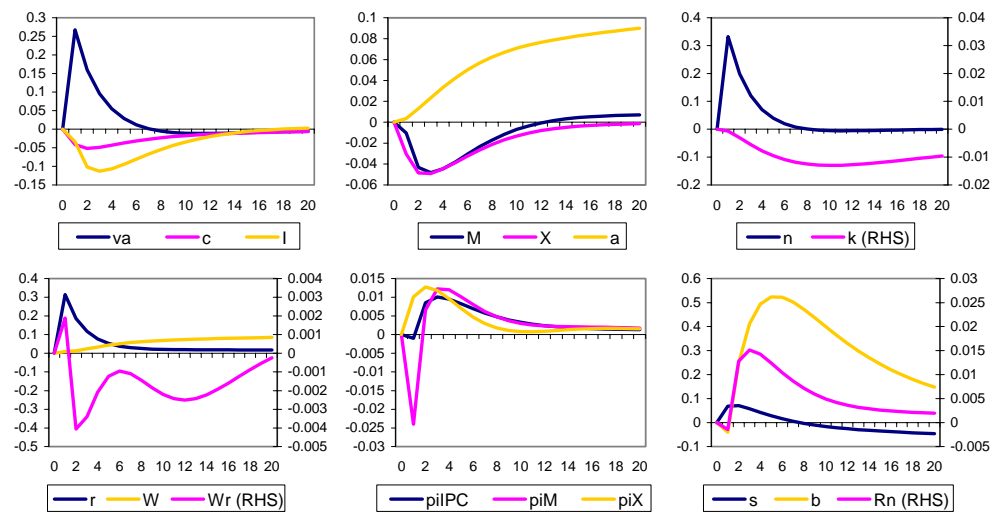

In this model all agents are Ricardian, so they reduce their consumption immediately since they expect that the rise in government spending will be financed through an increase in taxes today or in the future, to repay debt. Additionally, the subsequent rise in interest rates, due to the reaction of the monetary policy rule, reduces consumption further and crowds out both, productive and housing investment. The negative wealth effect on consumers rises labour supply, which combined with the fall in real wages increases employment. The rise in output pushes prices and wages up, although with a lag of one period, but making real wages fall for a few periods and then increase. This generates an increase of interest rates (although after an initial fall), matched by a rise in exchange rates.

When a similar shock is only applied to one of the two countries composing the area, e.g. Spain, qualitatively similar results are obtained. However, there are two main differences. First, interest rates are raised by less after this shock since inflation increases only in the country where government consumption has increased, i.e. Spain. This means that the crowding out effect on consumption and investment in Spain is smaller in this case and the impact on output larger. Second, the Spanish trade balance worsens on impact and for a few quarters. The reason for this is that the higher interest rates decrease activity and domestic inflation in the rest of the Euro area, reducing the demand for Spanish exports, but also reducing Spanish import prices from the rest of the Euro area, while increasing Spanish export prices to the rest of the Euro area. 
Figure 6.3: Productivity shock
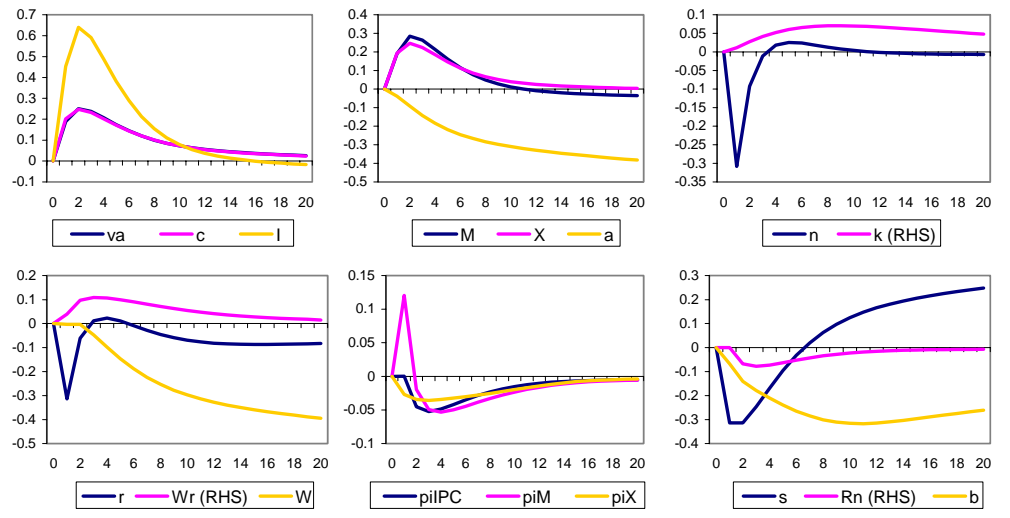

\subsubsection{Productivity shock}

Figure 6.3 shows the effects of a 1 per cent standard deviation temporary rise in productivity of all sectors of production (tradeable, non-tradeable and housing) in both regions of the Euro area, with a high persistence $\left(\rho_{z}^{u}=0.7\right)$. The response after the shock is fairly standard, with an overall increase in activity and a reduction of prices. Employment falls on impact, as is normally the case in models with nominal rigidities (Galí, 1999), but it recovers over time. The exchange rate depreciates on impact and then recovers until eventually it appreciates slightly. The cost of the domestic factors of production falls, since real wages increase by a smaller amount than productivity and the cost of capital falls. Finally, since prices fall, the monetary rule reduces interest rates. In terms of the sectoral impact of the shock, the exchange rate depreciation makes import prices increase on impact, specially energy prices, which affect more the tradable sector, since it is more energy dependent. This makes the marginal costs of the tradable sector drop by less than the other sectors and the same happens to its prices.

When the productivity shock affects only the Spanish economy, the results for Spain are qualitatively similar. The main difference is that the increase in productivity makes Spanish products more competitive than foreign ones, improving our trade balance on impact. However, this effect is partially compensated by the fact that interest rates fall by less in this case because prices increase in the other region of the Euro area, and the impact on activity is smaller. 
Figure 6.4: Oil price shock
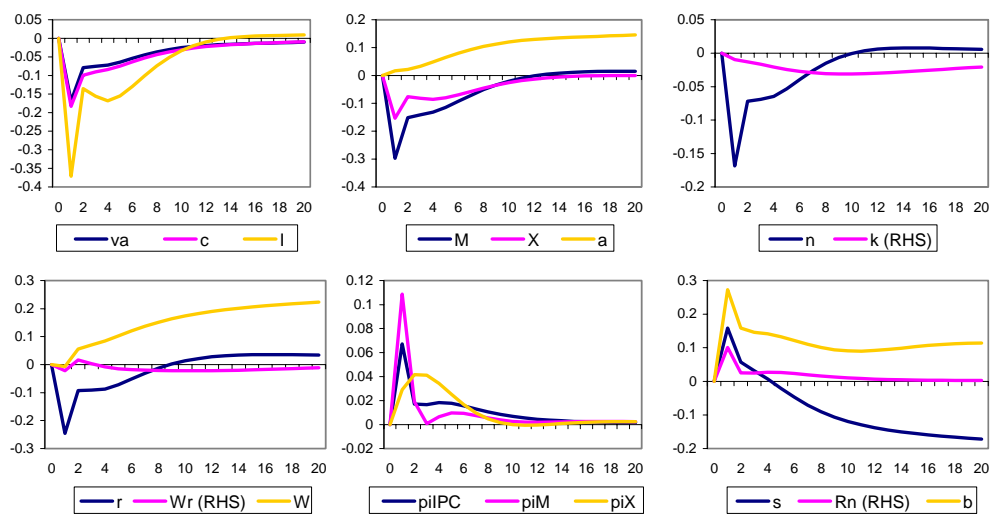

\subsubsection{Oil price shock}

This shock is implemented as a 1 per cent standard deviation temporary rise in the price of oil, with a persistence of 0.7 (see figure 6.4). The impact of the shock is quite standard, with a general decrease in activity and a rise in all prices, which is reinforced by a rise in nominal rates, but slightly compensated by the appreciation of the exchange rate. In line with the slowdown in activity, employment and capital fall. The rise in prices is translated into wages, but not completely, so that real wages fall on impact and for some quarters. On the external front, imports decline due to the increase in its prices, both of energy and imports from the rest of the Euro area, and the fall in domestic demand. Exports also decline, due to the fall in demand from the rest of the Euro area, but this decline is smaller than the one of imports and the trade balance improves. If the rest of the world were endogenous, exports to the rest of the world would also fall due to the loss in competitiveness and the impact on the trade balance would be less clear. In terms of sectoral impact of the shock, it is stronger in the sector which is more energy intensive, the tradable sector. In this sector, marginal costs increase more and so do prices, while activity and factors' demand suffer most from the shock. It is worth mentioning that the housing sector is least affected by this shock since we have assumed that this sector does not use energy as a factor of production. 
Figure 6.5: Households' preferences shock
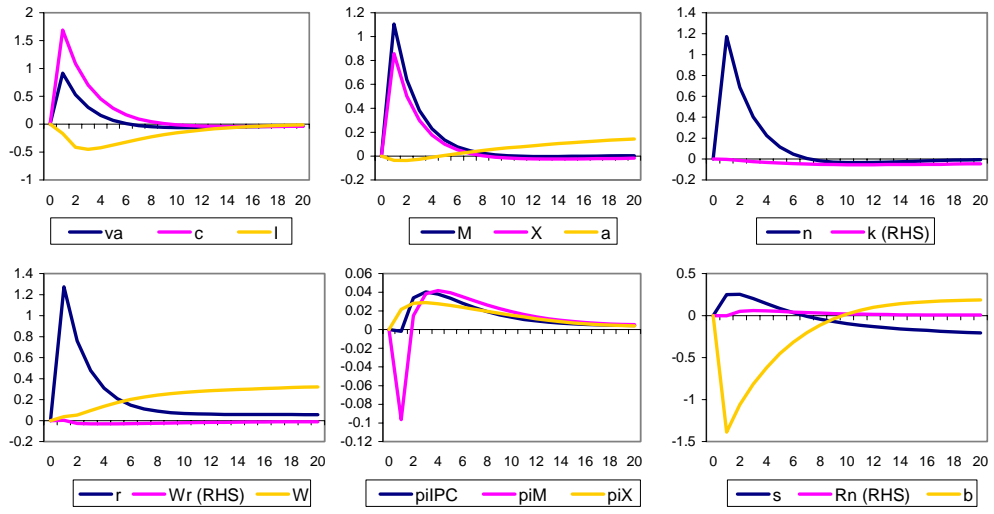

\subsubsection{Household Preference shock}

Figure 6.5 shows the impact of a 1 per cent standard deviation temporary rise in the discount rate of households in the Euro area, with a persistence of 0.7. A rise in the discount rate of households makes them more impatient and therefore try to intertemporally substitute savings for current consumption, this increases domestic demand, activity and prices. Investment declines moderately due to the reaction of interest rates to higher inflation. When the shock impacts on consumers of both regions of the Euro area, the trade balance improves since the rise in imports, due to the increase in domestic demand, is lower than the rise in exports from the rest of the Euro area, consequence of the increase in foreign demand. Furthermore, in this case prices rise in both regions, so that the price of imports falls only due to the appreciation of the exchange rate, and imports do not rise by as much.

When the shock affects only consumers in one of the regions of the Euro area, e.g. Spain, the trade balance worsens, since the rise in imports is stronger, because of the larger decline in import prices, and there is a decline in exports to the rest of the Euro area, because of the loss in competitiveness due to the rise in export prices.

\subsection{Asymmetric calibration}

The simulations using a different calibration for the steady state ratios of Spain and the rest of the Euro area show qualitatively similar results to the ones just 
Figure 6.6: Impact of shocks with asymetric calibration Impact on activity and inflation
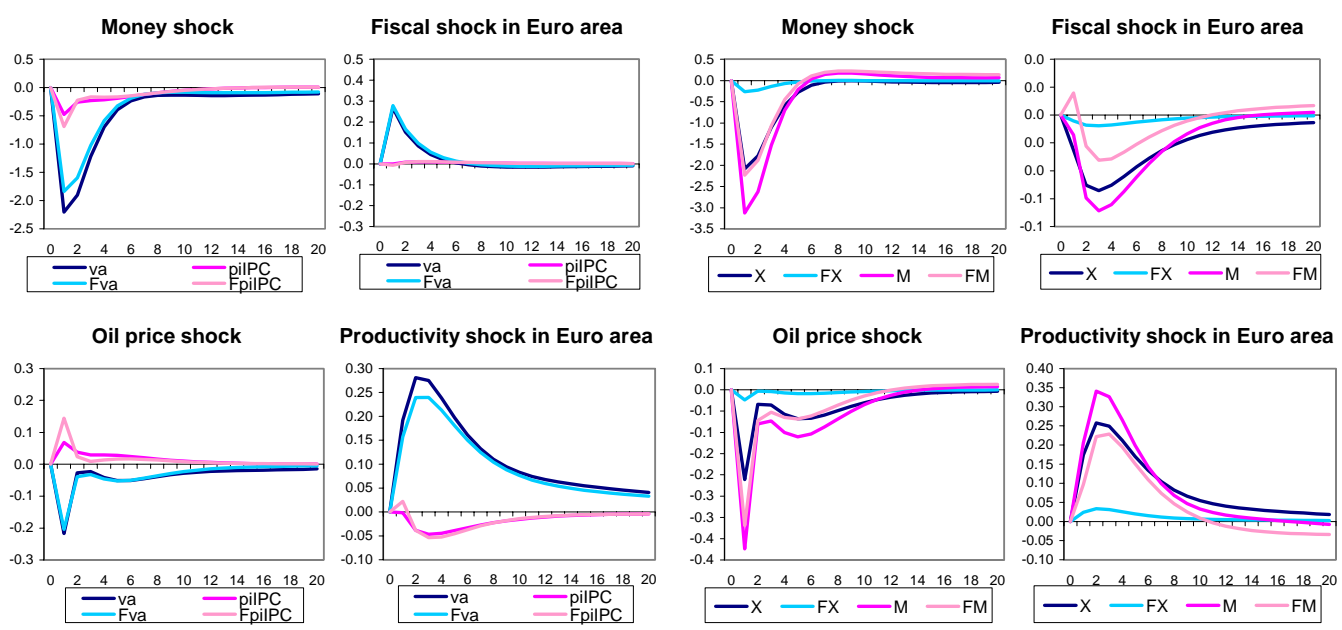

discussed; the main differences can be found in the magnitude of the impact of shocks and in the response of trade variables. Figure 6.6 compares the impact of each shock considered on aggregate value added, CPI inflation, exports and imports. The dynamics of output and inflation are similar across shocks, but the impact on activity is larger in Spain, while on inflation is larger in the Euro area. These differences are mainly due to the much smaller response of trade variables in the rest of the Euro area, since Spain is relatively small compared to it and the rest of the world is exogenous. In particular, the left hand side panel of figure 6.6 shows that Spanish imports and, specially, exports react much more to all shocks, making net exports more volatile in Spain.

Figure 6.7 compares the impact of an idiosyncratic fiscal and productivity shock to Spain on variables across both countries. It is clear from this graph that under an asymmetric calibration the impact on the Euro area from shocks in Spain is very small due to big differences in size between both areas. In addition, the impact on Spanish activity is also higher under this calibration since the weight of Spain in the Taylor rule is much smaller (around 10 per cent), allowing Spanish inflation to deviate more from its steady state value. 
Figure 6.7: Impact of shocks in Spain under asymmetric calibration
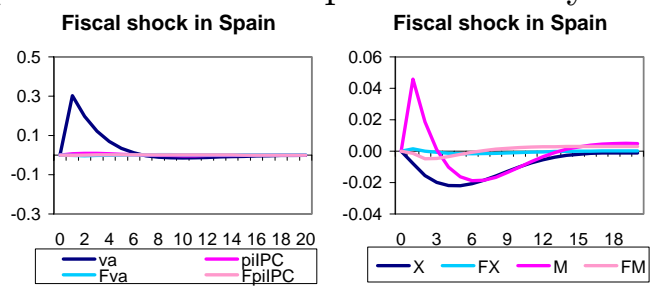

Productivity shock in Spain
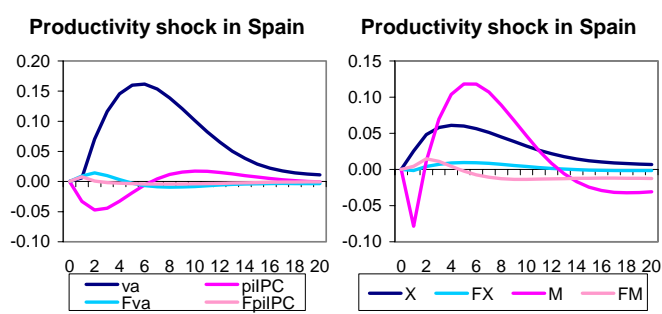

0.10

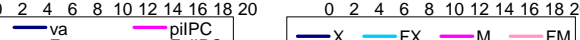

\section{Concluding remarks:}

In this paper we have presented a new dynamic general equilibrium model developed at the Banco de España for two regions of the Euro area: Spain and the rest of the Euro area. This model incorporates most of the standard mechanisms developed in this literature. In particular, it characterizes an economy where the consumption, labour supply, saving and investment decisions are taken by a representative rational household that faces no restrictions in the financial markets. Production is undertaken using labour, capital and imported raw materials as inputs by a continuum of firms which enjoy some degree of monopoly power in product markets. Since firms set prices and negotiate wages in a staggered manner, the model incorporates nominal inertia in wages and prices, which may differ across traded and non-traded goods and investment and consumption goods. Finally, households exhibit habits in consumption and face real capital adjustment costs which also generates inertia in some real variables.

The main theoretical contributions of this work are in terms of the country structure, since we model a monetary union composed of two regions, while the literature has concentrated its attention on modelling either a small open economy or two countries with independent monetary policy, generally the Euro area and the US. In addition, this work also contributes in terms of the degree and detail of the disaggregation considered for each country in the model, which allows us 
to replicate most variables included in the Quarterly National Accounts.

We have shown simulation results for two alternative calibrations, one symmetric across both countries forming the Euro area and based on Spain, while the other is asymmetric and incorporates characteristics specific to each region. The simulations using the symmetric calibration are quite standard and comparable to other models in the literature. On the other hand the results using the asymmetric calibration highlight some of the relevant differences between Spain and the rest of the Euro area. In particular, the main differences are in the magnitude of the impact of shocks, with a larger impact on activity in Spain and on inflation in the rest of the Euro area. These differences are due to the much smaller response of trade variables in the rest of the Euro area both, because Spain is more open than the rest of the area and the trade with the rest of the world is exogenous, which represents the largest share of trade for the rest of the Euro area. In addition, this is amplified by the fact that the weight of Spain in the Taylor rule of the Euro area is small, allowing for larger deviations of inflation from the target in Spain. Finally, idiosyncratic shocks in Spain have little impact on the rest of the Euro area given the differences in size.

The work presented in this paper constitutes the first stage of a larger project taking place at the Banco de España to develop and estimate a DSGE model of the Spanish economy. The following stages will consist on both, developing the theoretical structure and estimating the model presented here. The theoretical developments that we are planning to explore are the inclusion of a financial sector and credit restrictions, and of a non-competitive labour market of the matching type, and the interactions between them.

From an empirical perspective, the strategy for further work would be to estimate using Bayesian techniques smaller versions of the model presented here, concentrating on different sets of coefficients each time. In particular, we have two projects in mind. The first one consists in estimating a model of two regions of a monetary union, with a lower sectoral disaggregation than the one presented here, to try to identify differences in nominal inertia in prices and wages that could explain the inflation differentials between Spain and the rest of the Euro area. The second project consists in estimating a model for the Spanish economy, with a similar degree of detail to the one detailed here, to try to identify differences across sectors in nominal and real inertia that could explain the dual inflation phenomenon typical of the Spanish economy. 


\section{A. Appendix: Housing intermediate-goods producing firms.}

The housing intermediate-goods producing firms face a similar problem to other firms, with the exception that they do not use oil in the production process. Thus, the housing sector the firm $j$ chooses $n_{t}^{D}(j)$ and $k_{t}^{D}(j)$ to minimize total costs:

$$
\min _{\left\{n_{t}^{D}(j) k_{H, t}^{D,}(j), c u_{t}^{D}(j)\right\}}\left\{\frac{W_{t}}{P_{t}^{D}(j)} n_{t}^{D}(j)+\frac{P C_{t} r_{t}}{P_{t}^{D}(j)} k_{t}^{D}(j)+h\left(c u_{t}^{D}(j)\right)\right\}
$$

subject to

$$
y_{t}^{D}(j)=\left(c u_{t}^{D}(j) k_{t}^{D}(j)\right)^{\alpha_{D}}\left(z_{t} z_{t}^{D} n_{t}^{D}(j)\right)^{1-\alpha_{D}}
$$

being $z_{t}^{D}$ the total factor productivity shock. Factor demands are given by:

$$
\begin{gathered}
m c_{t}^{D}(j) \frac{\partial y_{t}^{D}(j)}{\partial n_{H t}^{D}(j)}=\frac{W_{t}}{P_{t}^{D}(j)} \\
m c_{t}^{D}(j) \frac{\partial y_{t}^{D}(j)}{\partial k_{t}^{D}(j)}=\frac{P C_{t} r_{t}}{P_{t}^{D}(j)} \\
m c_{t}^{D}(j) \frac{\partial y_{t}^{D}(j)}{\partial c u_{t}^{D}(j)}=\frac{\partial h\left(c u_{t}^{D}\right)}{\partial c u_{t}^{D}(j)}
\end{gathered}
$$

where $m c_{t}^{D}(j)$ is the real marginal cost in the housing sector. 


\section{B. Appendix: From value added deflators to production prices.}

Starting with the definition of nominal GDP,

$$
P v_{t} \cdot v a_{t}=P C_{t} c_{t}+P I_{t} \cdot I_{t}+P C_{t}^{N} g_{t}+P_{t}^{X} X_{t}-P_{t}^{M} M_{t}
$$

using the definition of each component of demand and its subcomponents,

$$
\begin{gathered}
P C_{t} c_{t}=P C_{t}^{N} c_{t}^{N}+P C_{t}^{T} c_{t}^{T} \\
P C_{t}^{T} c_{t}^{T}=P_{t}^{C} c_{H, t}+F P_{t}^{C} c_{F, t}+s_{t}^{-1} P_{t}^{O i l} c_{t}^{o i l}+s_{t}^{-1} W P_{t}^{C} c_{W, t} \\
P I_{t} I_{t}=P I_{t}^{P} I_{t}^{P}+P^{D} I_{t}^{D} \\
P I_{t}^{P} I_{t}^{P}=P I_{t}^{N} I_{t}^{N}+P I_{t}^{T} I_{t}^{T} \\
P I_{t}^{T} I_{t}^{T}=P_{t}^{I} I_{H, t}+F P_{t}^{I} I_{F, t}+W P_{t}^{I} I_{N, t} \\
P_{t}^{X} X_{t}=P_{t}^{C} F C_{H, t}+P_{t}^{C} W C_{H, t}+P_{t}^{I} F I_{H, t}+P_{t}^{I} W I_{H, t} \\
P_{t}^{M} M_{t}=F P_{t}^{C} C_{F, t}+\frac{W P_{t}^{C}}{s_{t}} C_{W, t}+\frac{P_{t}^{o i l}}{s_{t}} C_{t}^{o i l}+F P_{t}^{I} I_{F, t}+s_{t}^{-1} W P_{t}^{C} I_{W, t}+s_{t}^{-1} P_{t}^{O i l}\left(O_{t}^{T}+O_{t}^{N}\right)
\end{gathered}
$$

substituting them into equation (B.1) we get the following,

$$
\begin{aligned}
P v_{t} v a_{t}= & P C_{t}^{N} C_{t}^{N}+\left[P_{t}^{C} C_{H, t}+F P_{t}^{C} D_{F, t}+s_{t}^{-1} P_{t}^{O i l} a^{o i l}+s_{t}^{-1} W P_{t}^{C} C W_{t}\right] \\
& +P_{t}^{D} I_{t}^{D}+P_{t}^{N} I_{t}^{N}+\left[P_{t}^{I} I_{H, t}+F P_{t}^{I} I_{H, t}+W P_{t}^{I} I_{W, t}\right] \\
& +P C_{t}^{N} g_{t}+\left[P_{t}^{C} F C_{H, t}+P_{t}^{C} N C_{H, t}+P_{t}^{I} F I_{H, t}+P_{t}^{I} W I_{H, t}\right] \\
& -\left[F P_{t}^{C} C_{F, t}+s_{t}^{-1} W P_{t}^{C} C_{W, t}+s_{t}^{-1} P_{t}^{O i l} a^{\text {oil }}+F P_{t}^{I} I_{F, t}+s_{t}^{-1} W P_{t}^{C} I_{W, t}+s_{t}^{-1} P_{t}^{O i l}\left(O_{t}^{T}+O_{t}^{N}\right)\right]
\end{aligned}
$$

now simplifying,

$$
\begin{aligned}
P v_{t} v a_{t}= & P C_{t}^{N} C_{t}^{N}+P_{t}^{C} C_{H, t}+P_{t}^{D} I_{t}^{D} P_{t}^{N} I_{t}^{N}+P_{t}^{I} I_{H, t} \\
& +P C_{t}^{N} g_{t}+P_{t}^{C} F C_{H, t}+P_{t}^{C} N C_{H, t} \\
& +P_{t}^{I} F I_{H, t}+P_{t}^{I} W_{H, t}-s_{t}^{-1} P_{t}^{O i l}\left(O_{t}^{T}+O_{t}^{N}\right)
\end{aligned}
$$

and rearranging:

$$
\begin{aligned}
P v_{t} v a_{t}= & {\left[P C_{t}^{N} C_{t}^{N}+P C_{t}^{N} g_{t}\right]+\left[P_{t}^{C} C_{H, t}+P_{t}^{C} F C_{H, t}+P_{t}^{C} N C_{H, t}\right] } \\
& +P_{t}^{D} I_{t}^{D}+P_{t}^{N} I_{t}^{N} \\
& +\left[P_{t}^{I} I_{H, t}+P_{t}^{I} F I_{H, t}+P_{t}^{I} W I_{H, t}\right]-s_{t}^{-1} P_{t}^{O i l}\left(O_{t}^{T}+O_{t}^{N}\right)
\end{aligned}
$$


Using the following definitions from the supply side,

$$
\begin{gathered}
P_{t} y_{t}=P_{t}^{T} y_{t}^{T}+P_{t}^{N} y_{t}^{N}+P_{t}^{D} y_{t}^{D} \\
P v_{t} v a_{t}=P v_{t}^{T} v a_{t}^{T}+P v_{t}^{N} v a_{t}^{N}+P_{t}^{D} \cdot y_{t}^{D} \\
y_{t}^{D}=I_{t}^{D} \\
P v_{t}^{T} v a_{t}^{T}=P_{t}^{T} y_{t}^{T}-s_{t}^{-1} P_{t}^{O i l} O_{t}^{T} \\
P_{t}^{T} y_{t}^{T}=P_{t}^{C} y_{t}^{T C}+P_{t}^{I} y_{t}^{T I} \\
P_{t}^{C} y_{t}^{T C}=\left(c_{H, t}+F c_{H, t}+W c_{H, t}\right) P_{t}^{C} \\
P_{t}^{I} y_{t}^{T I}=\left(I_{H, t}+F I_{H, t}+W I_{H, t}\right) P_{t}^{I} \\
y^{T}=y^{T C}+y^{T I} \\
P v_{t}^{N} v a_{t}^{N}=P_{t}^{N} y_{t}^{N}-\frac{p_{t}^{o i l}}{S_{t}} O_{t}^{N} \\
P_{t}^{N} \cdot y_{t}^{N}=P C_{t}^{N} y_{t}^{N C}+P I_{t}^{N} I_{t}^{N} \\
P C_{t}^{N} y_{t}^{N C}=P C_{t}^{N}\left(c_{t}^{N}+g_{t}\right) \\
y^{N}=y^{N C}+y^{N I}
\end{gathered}
$$

we get,

$$
\begin{aligned}
P v_{t} v a_{t}= & {\left[P C_{t}^{N} y_{t}^{N C}+P_{t}^{N} I_{t}^{N}\right]+} \\
& {\left[P_{t}^{C} y_{t}^{T C}+P_{t}^{I} y_{t}^{I T}\right]+P_{t}^{D} I_{t}^{D}-s_{t}^{-1} P_{t}^{O i l}\left(O_{t}^{T}+O_{t}^{N}\right) }
\end{aligned}
$$

and substituting further we get,

$$
P v_{t} v a_{t}=P_{t}^{N} y_{t}^{N}+P_{t}^{T} y_{t}^{T}+P_{t}^{D} y_{t}^{D}-s_{t}^{-1} P_{t}^{O i l}\left(O_{t}^{T}+O_{t}^{N}\right)
$$

finally, using the definition of nominal production we get to the definition of nominal GDP in production terms:

$$
P v_{t} v a_{t}=P_{t} y_{t}-s_{t}^{-1} P_{t}^{O i l} O_{t}
$$




\section{Appendix: Log-linearizing prices and wages.}

\section{C.1. Prices}

The aggregate first order condition,

$$
\widetilde{P}_{t}^{C}=\left(\frac{\theta^{c}}{\theta^{c}-1}\right) \frac{E_{t} \sum_{k=0}^{\infty}(\beta \theta)^{k} \zeta_{t+k} P_{t+k}^{T} m c_{t, t+k}^{T} y_{t+k}^{T C}}{E_{t} \sum_{k=0}^{\infty}(\beta \theta)^{k} \zeta_{t+k} \prod_{i=1}^{k}\left(\pi_{t+i-1}^{C}\right)^{\xi^{P}} y_{t+k}^{T C}(j)}
$$

can be expressed as,

$$
\begin{aligned}
& \left(E_{t} \sum_{k=0}^{\infty}(\beta \theta)^{k} \zeta_{t+k} \prod_{i=1}^{k}\left(\pi_{t+i-1}^{C}\right)^{\xi^{P}} y_{t+k}^{T C}\right) \widetilde{p}_{t}^{C} \\
= & \left(\frac{\theta^{c}}{\theta^{c}-1}\right) E_{t} \sum_{k=0}^{\infty}(\beta \theta)^{k} \zeta_{t+k} p_{t+k}^{T} \prod_{i=1}^{k} \pi_{t+i}^{C} m c_{t, t+k}^{T} y_{t+k}^{T C}
\end{aligned}
$$

where: $p_{t+k}^{T}=\frac{P_{t+k}^{T}}{P_{t+k}^{C}}, \widetilde{p}_{t}^{C}=\frac{\widetilde{P}_{t}^{C}}{P_{t}^{C}}, \pi_{t+i}^{C}=\frac{P_{t+i}^{C}}{P_{t+i-1}^{C}}$. Rearranging terms:

$$
\begin{aligned}
& {\left[\begin{array}{c}
\left(\zeta_{t} y_{t}^{T C}\right) \widetilde{p}_{t}^{C}+ \\
\left(\beta \theta \zeta_{t+1}\left(\pi_{t}^{C}\right)^{\xi^{P}}\right. \\
\left.y_{t+1}^{T C}\right) \widetilde{p}_{t}^{C}+ \\
\left((\beta \theta)^{2} \zeta_{t+2}\left(\pi_{t}^{C} \pi_{t+1}^{C}\right)^{\xi^{P}} y_{t+2}^{T C}\right) \widetilde{p}_{t}^{C}+\ldots
\end{array}\right] } \\
= & \left(\frac{\theta^{c}}{\theta^{c}-1}\right)\left[\begin{array}{c}
\left(\zeta_{t} y_{t}^{T C}\right) p_{t}^{T} m c_{t, t}^{T}+ \\
\left(\beta \theta \zeta_{t+1} \pi_{t+1}^{C} y_{t+1}^{T C}\right) p_{t+1}^{T} m c_{t, t+1}^{T}+ \\
\left((\beta \theta)^{2} \zeta_{t+2} \pi_{t+1}^{C} \pi_{t+2}^{C} y_{t+2}^{T C}\right) p_{t+2}^{T} m c_{t, t+2}^{T}+\ldots
\end{array}\right]
\end{aligned}
$$

now, leading one period the previous expression and multiplying it by $\beta \theta \pi_{t+1}^{C}$ we obtain,

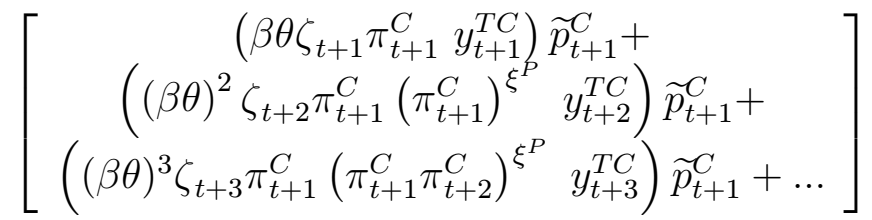

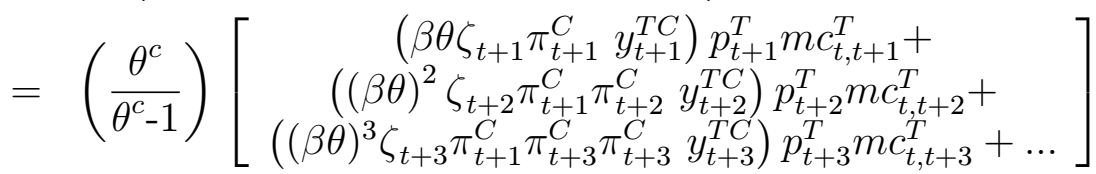


that can be further rearranged by multiplying the left hand side by $\left(\frac{\pi_{t}^{C}}{\pi_{t}^{C}}\right)^{\xi^{P}}$ as,

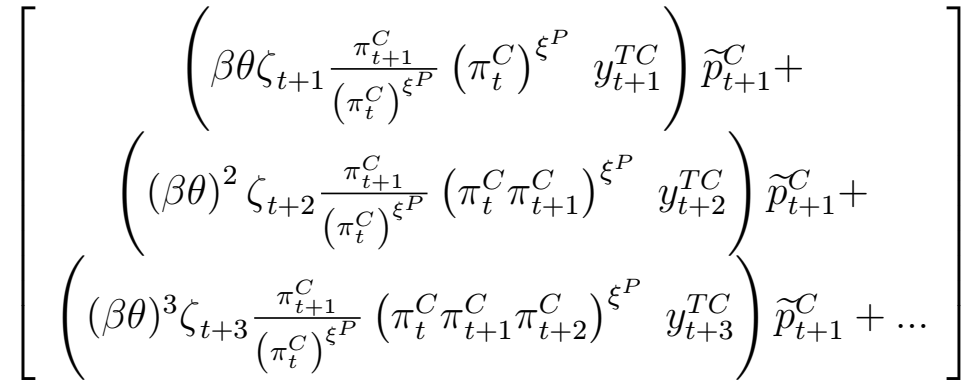

$$
\begin{aligned}
& =\left(\frac{\theta^{c}}{\theta^{c}-1}\right)\left[\begin{array}{c}
\left(\beta \theta \zeta_{t+1} \pi_{t+1}^{C} y_{t+1}^{T C}\right) p_{t+1}^{T} m c_{t, t+1}^{T}+ \\
\left((\beta \theta)^{2} \zeta_{t+2} \pi_{t+1}^{C} \pi_{t+2}^{C} y_{t+2}^{T C}\right) p_{t+2}^{T} m c_{t, t+2}^{T}+ \\
\left((\beta \theta)^{3} \zeta_{t+3} \pi_{t+1}^{C} \pi_{t+3}^{C} \pi_{t+3}^{C} y_{t+3}^{T C}\right) p_{t+3}^{T} m c_{t, t+3}^{T}+\ldots
\end{array}\right]
\end{aligned}
$$

Now subtracting (C.2) from (C.1):

$$
\begin{aligned}
& {\left[\left(\zeta_{t} T c_{H, t}\right) \widetilde{p}_{t}^{C}+\left(\widetilde{p}_{t}^{C}-\widetilde{p}_{t+1}^{C}\left(\frac{\pi_{t+1}^{C}}{\left(\pi_{t}^{C}\right)^{\xi^{P}}}\right)\right)\left(\sum_{k=1}^{\infty}(\beta \theta)^{k} \zeta_{t+k} \prod_{i=1}^{k}\left(\pi_{t+i-1}^{C}\right)^{\xi^{P}} y_{t+k}^{T C}\right)\right] } \\
= & \left(\frac{\theta^{c}}{\theta^{c}-1}\right)\left[\left(\zeta_{t} y_{t}^{T C}\right) p_{t}^{T} m c_{t, t}^{T}\right]
\end{aligned}
$$

The steady state (computed at $\pi^{C}=1$ ) is:

$$
\widetilde{p}^{C}=\left(\frac{\theta^{c}}{\theta^{c}-1}\right)\left[p^{T} m c^{T}\right]
$$

Now linearizing (C.3),

$$
\begin{aligned}
& {\left[\begin{array}{c}
\left(\zeta y^{T C} \widetilde{p}^{C}\right)\left(1+\widehat{\zeta}_{t}+\widehat{y}_{t}^{T C}+\widehat{\widetilde{p}}_{t}^{C}\right)+ \\
\left(\zeta y^{T C} \widetilde{p}^{C} \frac{\beta \theta}{(1-\beta \theta)}\right)\left(\widehat{\widetilde{p}}_{t}^{C}-\widehat{\widetilde{p}}_{t+1}^{C}-\left(\widehat{\pi}_{t+1}^{C}-\xi^{P} \widehat{\pi}_{t}^{C}\right)\right)
\end{array}\right] } \\
= & \left(\frac{\theta^{c}}{\theta^{c}-1}\right)\left(\zeta y^{T C} p^{T} m c^{T}\right)\left(1+\widehat{\zeta}_{t}+\widehat{y}_{t}^{T C}+\widehat{p}_{t}^{T}+\widehat{m c}_{t, t}^{T}\right)
\end{aligned}
$$

and substituting (C.4) we obtain,

$$
\widehat{\widetilde{p}}_{t}^{C}-\beta \theta \widehat{\widetilde{p}}_{t+1}^{C}=\beta \theta\left(\widehat{\pi}_{t+1}^{C}-\xi^{P} \widehat{\pi}_{t}^{C}\right)+(1-\beta \theta)\left(\widehat{p}_{t}^{T}+\widehat{m c}_{t, t}^{T}\right)
$$


Let us now divide (3.15) by $P_{t}^{C}$ and take a log-linear approximation,

$$
\widehat{\widetilde{p}}_{t}^{C}=\frac{\theta}{1-\theta} \widehat{\pi}_{t}^{C}-\frac{\theta \xi^{P}}{1-\theta} \widehat{\pi}_{t-1}^{C}
$$

using this expression we can compute:

$$
\widehat{\widetilde{p}}_{t}^{C}-\beta \theta \widehat{\widetilde{p}}_{t+1}^{C}=\left(\frac{\theta}{1-\theta}+\frac{\theta \xi^{P}}{1-\theta}\right) \widehat{\pi}_{t}^{C}-\frac{\theta}{1-\theta} \xi^{P} \widehat{\pi}_{t-1}^{C}-\frac{\beta \theta^{2}}{1-\theta} \widehat{\pi}_{t+1}^{C}
$$

Now using (C.5) and (C.7) we can derive the expression for inflation in domestically produced consumption goods:

$$
\left(\widehat{\pi}_{t}^{C}-\xi^{P} \widehat{\pi}_{t-1}^{C}\right)=\beta\left(\widehat{\pi}_{t+1}^{C}-\xi^{P} \widehat{\pi}_{t}^{C}\right)+\left(\frac{(1-\beta \theta)(1-\theta)}{\theta}\right)\left(\widehat{m c}_{t}^{T}+\widehat{p}_{t}^{T}\right)
$$

or

$$
\left(\widehat{\pi}_{t}^{C}-\xi^{P} \widehat{\pi}_{t-1}^{C}\right)=\beta\left(\widehat{\pi}_{t+1}^{C}-\xi^{P} \widehat{\pi}_{t}^{C}\right)+\left(\frac{(1-\beta \theta)(1-\theta)}{\theta}\right)\left(\widehat{m c}_{t}^{T}+\widehat{P}_{t}^{T}-\widehat{P}_{t}^{C}\right)
$$

\section{C.2. Wages}

The law of motion for the aggregate wage index is given by:

$$
W_{t}=\left[\left(1-\theta_{w}\right)\left(\widetilde{W}_{t}\right)^{1-\varepsilon_{w}}+\theta_{w}\left(W_{t-1} d_{t}^{\xi^{W}}\right)^{1-\varepsilon_{w}}\right]^{\frac{1}{1-\varepsilon_{w}}}
$$

or

$$
1=\left[\left(1-\theta_{w}\right)\left(\widetilde{w}_{t}\right)^{1-\varepsilon_{w}}+\theta_{w}\left(\frac{d_{t}^{\xi^{W}}}{\pi_{t}^{W}}\right)^{1-\varepsilon_{w}}\right]^{\frac{1}{1-\varepsilon_{w}}}
$$

Log-linearizing expression (C.9) around a steady state with zero wage inflation (that implies $\widetilde{w}=1$ ) yields:

$$
\begin{gathered}
\widehat{\pi}_{t}^{w}=\left(1-\theta_{w}\right)\left(\widehat{\widetilde{W}}_{t}-\widehat{W}_{t-1}\right)+\xi^{W} \theta_{w} \widehat{d}_{t} \\
\widehat{\pi}_{t}^{w}-\xi^{W} \widehat{d}_{t}=\left(\frac{1-\theta_{w}}{\theta_{w}}\right) \widehat{\widetilde{w}}_{t}
\end{gathered}
$$


Let us write (2.16) relative to the aggregate wage,

$$
E_{t} \sum_{k=0}^{\infty}\left(\beta \theta_{w}\right)^{k} n_{t, t+k} U_{c, t+k}\left(\frac{\widetilde{w}_{t} w_{t+k} \prod_{i=1}^{k} d_{t+i}^{\xi^{W}}}{\prod_{i=1}^{k} \pi_{t+i}^{w}}-\frac{\varepsilon_{w}}{\varepsilon_{w}-1} M R S_{t, t+k}\right)=0
$$

where $\pi_{t+i}^{W}=\frac{W_{t+i}}{W_{t+i-i}}, \widetilde{w}_{t}=\frac{\widetilde{W}_{t}}{W_{t}}, w_{t+k}=\frac{W_{t+k}}{P C_{t+k}}$. This can be written as,

$$
\begin{aligned}
& {\left[\begin{array}{c}
\left(n_{t, t} U_{c, t} w_{t}\right) \widetilde{w}_{t}+ \\
\left(\beta \theta n_{t, t+1} U_{c, t+1} w_{t+1} \frac{d_{t+1}^{\xi^{W}}}{\pi_{t+1}^{w}}\right) \widetilde{w}_{t}+ \\
\left((\beta \theta)^{2} n_{t, t+2} U_{c, t+2} w_{t+2} \frac{d_{t+1}^{\xi W}}{\pi_{t+1}^{w}} \frac{d_{t+2}^{\xi}}{\pi_{t+2}^{w}}\right) \widetilde{w}_{t}+\ldots
\end{array}\right] } \\
= & \left(\frac{\varepsilon_{w}}{\varepsilon_{w}-1}\right)\left[\begin{array}{c}
n_{t, t} U_{c, t} M R S_{t, t}+ \\
\beta \theta n_{t, t+1} U_{c, t+1} M R S_{t, t+1}+ \\
(\beta \theta)^{2} n_{t, t+2} U_{c, t+2} M R S_{t, t+2}+\ldots
\end{array}\right]
\end{aligned}
$$

That in the steady state $\left(d=\pi^{w}=1\right)$ implies,

$$
\widetilde{w}=\left(\frac{\varepsilon_{w}}{\varepsilon_{w}-1}\right) \frac{M R S}{w}
$$

Now log-linearizing this expression around $\left(d=\pi^{w}=1\right)$ yields,

$$
\begin{aligned}
& {\left[\begin{array}{c}
n U_{c} w \widetilde{w}\left(1+\widehat{n}_{t, t}+\widehat{U}_{c, t}+\widehat{w}_{t}+\widehat{\widetilde{w}}_{t}\right)+ \\
1+\widehat{n}_{t, t+1}+\widehat{U}_{c, t+1} \\
\beta \theta n U_{c} w \widetilde{w}\left(\begin{array}{c} 
\\
+\widehat{w}_{t+1}+\widehat{\widetilde{w}}_{t}-\left(\widehat{\pi}_{t+1}^{w}-\xi^{W} \widehat{d}_{t+1}\right)
\end{array}\right)+ \\
1 \beta \theta)^{2} n U_{c} w \widetilde{w}\left(\begin{array}{c}
1+\widehat{n}_{t, t+2}+\widehat{U}_{c, t+2}+\widehat{w}_{t+2}+ \\
\widehat{\widetilde{w}}_{t}-\left(\widehat{\pi}_{t+1}^{w}-\xi^{W} \widehat{d}_{t+1}+\widehat{\pi}_{t+2}^{w}-\xi^{W} \widehat{d}_{t+2}\right)
\end{array}\right)+\ldots
\end{array}\right]} \\
& =\left(\frac{\varepsilon_{w}}{\varepsilon_{w}-1}\right)\left[\begin{array}{c}
n U_{c} M R S\left(1+\widehat{n}_{t, t}+\widehat{U}_{c, t}+\widehat{M R S}_{t, t}\right)+ \\
\beta \theta n U_{c} M R S\left(1+\widehat{n}_{t, t+1}+\widehat{U}_{c, t+1}+\widehat{M R S}_{t, t+1}\right)+ \\
(\beta \theta)^{2} n U_{c} M R S\left(1+\widehat{n}_{t, t+2}+\widehat{U}_{c, t+2}+\widehat{M R S}_{t, t+2}\right)+\ldots
\end{array}\right]
\end{aligned}
$$

or,

$$
\widehat{\widetilde{w}}_{t}=\left(1-\beta \theta_{w}\right) \sum_{k=0}^{\infty}\left(\beta \theta_{w}\right)^{k}\left(\widehat{M R S}_{t, t+k}-\widehat{w}_{t+k}+\sum_{i=1}^{k}\left(\widehat{\pi}_{t+1}^{w}-\xi^{W} \widehat{d}_{t+1}\right)\right)
$$


Now, let us solve the model in terms $\widehat{M R S}_{t}$ of rather than $\widehat{M R S}_{t, t}$. The household real wage $t+k$ periods after the last re-optimization is related to the average real wage as follows,

$$
\begin{aligned}
\frac{W_{t, t+k}}{P C_{t+k}} & =\frac{W_{t+k}}{P C_{t+k}} \frac{W_{t, t+k}}{\widetilde{W}_{t}} \frac{\widetilde{W_{t}}}{W_{t}} \frac{W_{t}}{W_{t+k}} \\
& =\left(\frac{W_{t+k}}{P C_{t+k}}\right)\left(\frac{\widetilde{W_{t}}}{W_{t}}\right)\left[\prod_{i=1}^{k}\left(\frac{W_{t+i}}{W_{t+i-1}}\right)\right]^{-1} \prod_{i=1}^{k} d_{t+i}^{\xi^{W}} \\
& =\left(\frac{W_{t+k}}{P C_{t+k}}\right)\left(\frac{\widetilde{W}_{t}}{W_{t}}\right) \prod_{i=1}^{k}\left(\frac{d_{t+i}^{\xi^{W}}}{\pi_{t+i}^{W}}\right)
\end{aligned}
$$

log-linearizing the previous expression yields,

$$
\widehat{W}_{t, t+k}-\widehat{P C}_{t+k}=\left(\widehat{W}_{t+k}-\widehat{P C}_{t+k}\right)+\left(\widehat{\widetilde{W}}_{t}-\widehat{W}_{t}\right)-\sum_{i=1}^{k}\left(\widehat{\pi}_{t+i}^{w}-\xi^{W} \widehat{d}_{t+i}\right)
$$

now, using

$$
M R S_{t, t+k}=M R S_{t+k}\left(\frac{n_{t, t+k}}{n_{t+k}}\right)^{\varphi}=M R S_{t+k}\left[\left(\frac{\widetilde{W_{t}}}{W_{t}}\right) \prod_{i=1}^{k} d_{t+i}^{\xi^{W}}\right]^{-\varphi \varepsilon_{w}}
$$

we obtain:

$$
\widehat{M R S}_{t, t+k}=\widehat{M R S}_{t+k}-\varphi \varepsilon_{w}\left[\widehat{\widetilde{w}}_{t}-\sum_{i=1}^{k}\left(\widehat{\pi}_{t+i}^{w}-\xi^{W} \widehat{d}_{t+i}\right)\right]
$$

Plugging (C.13) in (C.14) we obtain,

$$
\widehat{\widetilde{w}}_{t}=\left[\left(1-\beta \theta_{w}\right) \sum_{k=0}^{\infty}\left(\beta \theta_{w}\right)^{k}\left(\begin{array}{c}
\widehat{M R S}_{t+k}-\widehat{w}_{t+k}-\varphi \varepsilon_{w} \widehat{\widetilde{w}}_{t} \\
\left(1+\varphi \varepsilon_{w}\right) \sum_{i=1}^{k}\left(\widehat{\pi}_{t+i}^{w}-\xi^{W} \widehat{d}_{t+i}\right)
\end{array}\right)\right]
$$

and substituting (C.10),

$$
\widehat{\widetilde{w}}_{t}=\left[\begin{array}{c}
\left(\frac{1-\beta \theta_{w}}{1+\varphi \varepsilon_{w}}\right) \sum_{k=0}^{\infty}\left(\beta \theta_{w}\right)^{k}\left(\widehat{M R S}_{t+k}-\widehat{w}_{t+k}\right)+ \\
\left(1-\beta \theta_{w}\right) \sum_{k=0}^{\infty}\left(\beta \theta_{w}\right)^{k} \sum_{i=1}^{k}\left(\widehat{\pi}_{t+i}^{w}-\xi^{W} \widehat{d}_{t+i}\right)
\end{array}\right]
$$


that can be quasi-differenced to obtain,

$$
\widehat{\widetilde{w}}_{t}-\beta \theta_{w} \widehat{\widetilde{w}}_{t+1}=\left[\left(\frac{1-\beta \theta_{w}}{1+\varphi \varepsilon_{w}}\right)\left(\widehat{M R S}_{t}-\widehat{w}_{t}\right)+\beta \theta_{w}\left(\widehat{\pi}_{t+1}^{w}-\xi^{W} \widehat{d}_{t+1}\right)\right]
$$

And from (C.10),

$$
\widehat{\widetilde{w}}_{t}-\beta \theta_{w} \widehat{\widetilde{w}}_{t+1}=\left(\frac{\theta_{w}}{1-\theta_{w}}\right)\left(\widehat{\pi}_{t}^{w}-\xi^{W} \widehat{d}_{t}-\beta \theta_{w}\left(\widehat{\pi}_{t+1}^{w}-\xi^{W} \widehat{d}_{t+1}\right)\right)
$$

and from (C.15) and (C.10) we obtain:

$$
\widehat{\pi}_{t}^{w}-\xi^{W} \widehat{d}_{t}=\left[\beta E_{t}\left\{\left(\widehat{\pi}_{t+1}^{w}-\xi^{W} \widehat{d}_{t+1}\right)\right\}-\lambda_{w} \mu_{w}\right]
$$

where $\lambda_{w}=\frac{\left(1-\beta \theta_{w}\right)\left(1-\theta_{w}\right)}{\theta_{w}\left(1+\varphi \varepsilon_{w}\right)}$ and $\mu_{w}=\left[\widehat{w}_{t}-\widehat{M R S}_{t}\right]$ 


\section{Appendix: The complete model.}

$$
\begin{aligned}
& \lambda_{t}=\beta E_{t} \frac{R_{t} \lambda_{t+1}}{\pi_{t+1}^{I P C}} \Psi\left(a_{t-1}\right) \\
& \frac{E_{t} s_{t+1} \lambda_{t} \pi_{t+1}^{I P C}}{W R_{t}}=\beta s_{t} \lambda_{t+1} \Psi\left(a_{t-1}\right) \\
& \lambda_{t}=U_{c, t} \\
& U_{c, t}=\left[\begin{array}{c}
\varepsilon_{t}^{a}\left[\frac{c_{t}}{\left(c_{t-1}\right)^{\gamma}}\right]^{-\sigma} \frac{1}{\left(c_{t-1}\right)^{\gamma}} \\
-\beta \gamma E_{t} \varepsilon_{t+1}^{a}\left[\frac{c_{t+1}}{\left(c_{t}\right)^{\gamma}}\right]^{-\sigma} c_{t+1} \frac{\left(c_{t}\right)^{\gamma-1}}{\left(c_{t}\right)^{2 \gamma}}
\end{array}\right] \\
& \widetilde{W}_{t}=\frac{\varepsilon_{w}}{\varepsilon_{w}-1} \frac{E_{t} \sum_{k=0}^{\infty}\left(\beta \theta_{w}\right)^{k} n_{t, t+k} U_{c, t+k} M R S_{t, t+k}}{E_{t} \sum_{k=0}^{\infty}\left(\beta \theta_{w}\right)^{k} n_{t, t+k} U_{c, t+k} \frac{\left(1-\tau_{w}\right)}{\left(1+\tau_{c}\right)} \frac{\prod_{i=1}^{k} d_{t+i}^{\xi W}}{P C_{t+k}}} \\
& W_{t}=\left[\left(1-\theta_{w}\right)\left(\widetilde{W}_{t}\right)^{1-\varepsilon_{w}}+\theta_{w}\left(W_{t-1} d_{t}^{\xi^{W}}\right)^{1-\varepsilon_{w}}\right]^{\frac{1}{1-\varepsilon_{w}}} \\
& M R S_{t, t+k}=M R S_{t+k}\left[\left(\frac{\widetilde{W_{t}}}{W_{t}}\right) \prod_{i=1}^{k} d_{t+i}^{\xi^{W}}\right]^{-\varphi \varepsilon_{w}} \\
& M R S_{t+k}=\frac{\left(1+\tau_{c}\right) \varepsilon_{t+k}^{a}\left(n_{t+k}\right)^{\varphi}}{\left(1-\tau_{w}\right) \lambda_{t+k}} \\
& d_{t}=\pi_{t-1}^{I P C} \\
& n_{t, t+k}=\left(\frac{\widetilde{W_{t}} \prod_{i=1}^{k} d_{t+i}^{\xi^{W}}}{W_{t+k}}\right)^{-\varepsilon_{w}} n_{t+k}
\end{aligned}
$$

Note: In fact there are $k$ such equations but we shall only need one because the price and wage equations can be written as quasi-difference equations and thus can be expressed in terms of a linear difference equation in the log-linear model.

$$
\begin{gathered}
q_{t}=\frac{1}{\Phi^{k^{\prime}}\left(\frac{I_{t}^{P}}{k_{t}}\right)} \\
q_{t}=\frac{\lambda_{t}^{k}\left(1+\tau_{c}\right) P C_{t}}{\lambda_{t} P I_{t}^{P}}
\end{gathered}
$$




$$
\begin{aligned}
& q_{t}=\beta E_{t}\left\{\frac{\pi_{t+1}^{I P} \lambda_{t+1}}{\pi_{t+1}^{I P C} \lambda_{t}}\left[\begin{array}{c}
\frac{P C_{t+1}}{P I_{t+1}^{P}}\left(1-\tau_{k}\right) r_{t+1} \\
+q_{t+1}\left(\Phi_{t+1}-\Phi_{t+1}^{\prime} \frac{I_{t+1}^{P}}{k_{t}}+(1-\delta)\right)
\end{array}\right]\right\} \\
& q_{t}^{D}=\frac{1}{\Phi^{D^{\prime}}\left(\frac{I_{t}^{D}}{D_{t-1}}\right)} \\
& q_{t}^{D}=\frac{\lambda_{t}^{D}\left(1+\tau_{c}\right) P C_{t}}{\lambda_{t} P_{t}^{D}} \\
& q_{t}^{D}=\beta E_{t}\left\{\frac{\pi_{t+1}^{D} \lambda_{t+1}}{\pi_{t+1}^{I P C} \lambda_{t}}\left[\begin{array}{c}
\frac{\varepsilon_{t+1}^{a}}{\lambda_{t+1}} \frac{P C_{t+1}}{P_{t+1}^{D}}\left(1+\tau_{k}\right) D_{t}^{-\sigma_{D}} \\
+q_{t+1}^{D}\left(\Phi_{t+1}^{D}-\Phi_{t+1}^{D^{\prime}} \frac{I_{t+1}^{D}}{D_{t}}+\left(1-\delta_{D}\right)\right)
\end{array}\right]\right\} \\
& k_{t}=\Phi\left(\frac{I_{t}^{P}}{k_{t-1}}\right) k_{t-1}+(1-\delta) k_{t-1} \\
& D_{t}=\Phi^{D}\left(\frac{I_{t}^{D}}{D_{t-1}}\right) D_{t-1}+\left(1-\delta_{D}\right) D_{t-1} \\
& c_{t}=\left[\left(\omega_{C}^{N}\right)^{\frac{1}{\rho^{c}}}\left(c_{t}^{N}\right)^{\frac{\rho^{c}-1}{\rho^{c}}}+\left(\omega_{C}^{T}\right)^{\frac{1}{\rho^{c}}}\left(c_{t}^{T}\right)^{\frac{\rho^{c}-1}{\rho^{c}}}\right]^{\frac{\rho^{c}}{\rho^{c}-1}} \\
& \frac{c_{t}^{N}}{c_{t}^{T}}=\frac{\omega_{C}^{N}}{\omega_{C}^{T}}\left(\frac{P C_{t}^{N}}{P C_{t}^{T}}\right)^{-\rho^{c}} \\
& P C_{t}=\left[\omega_{C}^{N}\left(P C_{t}^{N}\right)^{1-\rho^{c}}+\omega_{C}^{T}\left(P C_{t}^{T}\right)^{1-\rho^{c}}\right]^{\frac{1}{1-\rho^{c}}} \\
& c_{t}^{T}=\left[\begin{array}{c}
\left(\omega_{H C}\right)^{\frac{1}{\rho^{c T}}}\left(c_{H, t}\right)^{\frac{\rho^{c T}-1}{\rho^{c T}}}+\left(\omega_{F C}\right)^{\frac{1}{\rho^{c T}}}\left(c_{F, t}\right)^{\frac{\rho^{c T}-1}{\rho^{c T}}}+ \\
\left(\omega_{C}^{O i l}\right)^{\frac{1}{\rho^{c T}}}\left(c_{t}^{O i l}\right)^{\frac{\rho^{c T}-1}{\rho^{c T}}}+ \\
\left(\omega_{W C}\right)^{\frac{1}{\rho^{c T}}}\left(c_{W, t}\right)^{\frac{\rho^{c T}-1}{\rho^{c T}}}
\end{array}\right]^{\frac{\rho^{c T}}{\rho^{c T}-1}} \\
& \frac{c_{F, t}}{c_{H, t}}=\frac{\omega_{F C}}{\omega_{H C}}\left(\frac{F P_{t}^{C}}{P_{t}^{C}}\right)^{-\rho^{c T}} \\
& \frac{c_{t}^{O i l}}{c_{H, t}}=\frac{\omega_{C}^{O i l}}{\omega_{H C}}\left(\frac{s_{t}^{-1} P_{t}^{O i l}}{P_{t}^{C}}\right)^{-\rho^{c T}}
\end{aligned}
$$




$$
\begin{aligned}
& \frac{c_{W, t}}{c_{H, t}}=\frac{\omega_{W C}}{\omega_{H C}}\left(\frac{s_{t}^{-1} W P_{t}^{C}}{P_{t}^{C}}\right)^{-\rho^{c T}} \\
& P C_{t}^{T}=\left[\begin{array}{c}
\omega_{H C}\left(P_{t}^{C}\right)^{1-\rho^{c T}}+\omega_{F C}\left(F P_{t}^{C}\right)^{1-\rho^{c T}}+ \\
\omega_{C}^{O i l}\left(s_{t}^{-1} P_{t}^{O i l}\right)^{1-\rho^{c T}}+ \\
\left(\omega_{W C}\left(s_{t}^{-1} W P_{t}^{C}\right)^{1-\rho^{c T}}\right.
\end{array}\right]^{\frac{1}{1-\rho^{c T}}} \\
& I_{t}=\left[\left(\omega_{I}^{P}\right)^{\frac{1}{\rho^{I}}}\left(I_{t}^{P}\right)^{\frac{\rho^{I}-1}{\rho^{I}}}+\left(\omega_{I}^{D}\right)^{\frac{1}{\rho^{D}}}\left(I_{t}^{D}\right)^{\frac{\rho^{I}-1}{\rho^{I}}}\right]^{\frac{\rho^{I}}{\rho^{I}-1}} \\
& P I_{t}=\left[\omega_{I}^{P}\left(P I_{t}^{P}\right)^{1-\rho^{I}}+\omega_{I}^{D}\left(P_{t}^{D}\right)^{1-\rho^{I}}\right]^{\frac{1}{1-\rho^{I}}} \\
& \frac{I_{t}^{P}}{I_{t}^{D}}=\frac{\omega_{I}^{P}}{\omega_{I}^{D}}\left(\frac{P I_{t}^{P}}{P_{t}^{D}}\right)^{-\rho^{I}} \\
& I_{t}^{P}=\left[\left(\omega_{I}^{N}\right)^{\frac{1}{\rho^{I P}}}\left(I_{t}^{N}\right)^{\frac{\rho^{I P}-1}{\rho^{I P}}}+\left(\omega_{I}^{T}\right)^{\frac{1}{\rho^{I P}}}\left(I_{t}^{T}\right)^{\frac{\rho^{I P}-1}{\rho^{I P}}}\right]^{\frac{\rho^{I P}}{\rho^{I P}-1}} \\
& P I_{t}^{P}=\left[\omega_{I}^{N}\left(P I_{t}^{N}\right)^{1-\rho^{I P}}+\omega_{I}^{T}\left(P I_{t}^{T}\right)^{1-\rho^{I P}}\right]^{\frac{1}{1-\rho^{I P}}} \\
& \frac{I_{t}^{N}}{I_{t}^{T}}=\frac{\omega_{I}^{N}}{\omega_{I}^{T}}\left(\frac{P I_{t}^{N}}{P I_{t}^{T}}\right)^{-\rho^{I P}} \\
& I_{t}^{T}=\left[\begin{array}{c}
\left(\omega_{H I}\right)^{\frac{1}{\rho^{I T}}}\left(I_{H, t}\right)^{\frac{\rho^{I T}-1}{\rho^{I T}}}+\left(\omega_{F I}\right)^{\frac{1}{\rho^{I T}}}\left(I_{F, t}\right)^{\frac{\rho^{I T}-1}{\rho^{I T}}} \\
+\left(\omega_{W I}\right)^{\frac{1}{\rho^{I T}}}\left(I_{W, t}\right)^{\frac{\rho^{I T}-1}{\rho^{I T}}}
\end{array}\right]^{\frac{\rho^{I T}}{\rho^{I T}-1}} \\
& \frac{I_{F, t}}{I_{H, t}}=\frac{\omega_{F I}}{\omega_{H I}}\left(\frac{F P_{t}^{I}}{P_{t}^{I}}\right)^{-\rho^{I T}} \\
& \frac{I_{W, t}}{I_{H, t}}=\frac{\omega_{W I}}{\omega_{H I}}\left(\frac{s_{t}^{-1} W P_{t}^{I}}{P_{t}^{I}}\right)^{-\rho^{I T}} \\
& P I_{t}^{T}=\left[\begin{array}{c}
\omega_{H I}\left(P_{t}^{I}\right)^{1-\rho^{I T}}+\omega_{F I}\left(F P_{t}^{I}\right)^{1-\rho^{I T}}+ \\
\omega_{W I}-\omega_{F I}\left(s_{t}^{-1} W P_{t}^{I}\right)^{1-\rho^{I T}}
\end{array}\right]^{\frac{1}{1-\rho^{I T}}} \\
& y_{t}^{T}=y_{t}^{T C}+y_{t}^{T I}
\end{aligned}
$$




$$
\begin{aligned}
& y_{t}^{T C}=c_{H, t}+F c_{H, t}+W c_{H, t} \\
& y_{t}^{T I}=I_{H, t}+F I_{H, t}+W I_{H, t} \\
& \widetilde{P}_{t}^{C}=\left(\frac{\theta^{c}}{\theta^{c}-1}\right) \frac{E_{t} \sum_{k=0}^{\infty}(\beta \theta)^{k} \zeta_{t+k} P_{t+k}^{T} m c_{t, t+k}^{T} y_{t+k}^{T C}}{E_{t} \sum_{k=0}^{\infty}(\beta \theta)^{k} \zeta_{t+k} \prod_{i=1}^{k}\left(\pi_{t+i-1}^{C}\right)^{\xi^{P}} y_{t+k}^{T C}} \\
& P_{t}^{C}=\left[\theta\left(P_{t-1}^{C}\left(\pi_{t-1}^{C}\right)^{\xi^{P}}\right)^{1-\theta^{c}}+(1-\theta) \widetilde{P}_{t}^{C\left(1-\theta^{c}\right)}\right]^{\frac{1}{1-\theta^{c}}} \\
& \widetilde{P}_{t}^{I}=\left(\frac{\theta^{I}}{\theta^{I}-1}\right) \frac{E_{t} \sum_{k=0}^{\infty}(\beta \theta)^{k} \zeta_{t+k} P_{t+k}^{T} m c_{t, t+k}^{T} y_{t+k}^{T I}}{E_{t} \sum_{k=0}^{\infty}(\beta \theta)^{k} \zeta_{t+k} \prod_{i=1}^{k}\left(\pi_{t+i-1}^{I}\right)^{\xi^{P}} y_{t+k}^{T I}} \\
& P_{t}^{I}=\left[\theta\left(P_{t-1}^{I}\left(\pi_{t-1}^{I}\right)^{\xi^{P}}\right)^{1-\theta^{I}}+(1-\theta) \widetilde{P}_{t}^{I\left(1-\theta^{I}\right)}\right]^{\frac{1}{1-\theta^{I}}} \\
& P_{t}^{T} y_{t}^{T}=\left[P_{t}^{C} y_{t}^{T C}+P_{t}^{I} y_{t}^{T I}\right] \\
& y_{t}^{T}=\left[\begin{array}{c}
\varkappa_{\varkappa^{\frac{\psi^{T}}{\psi^{T}}}}\left(O_{t}^{T}\right)^{\frac{\psi^{T}-1}{\psi^{T}}}+ \\
\left(1-\varkappa_{T}\right)^{\frac{\psi^{T}}{\psi^{T}-1}}\left[\left(c u_{t}^{T} k_{t}^{T}\right)^{\alpha_{T}}\left(z_{t} z_{t}^{T} n_{t}^{T}\right)^{1-\alpha_{T}}\right]^{\frac{\psi^{T}-1}{\psi^{T}}}
\end{array}\right]^{\frac{\psi^{T}}{\psi^{T}-1}} \\
& m c_{t}^{T}\left(1-\alpha_{T}\right)\left(\frac{y_{t}^{T}}{n_{t}^{T}}\right)\left[1-\varkappa_{T}^{\frac{\psi^{T}}{\psi^{T}-1}}\left(\frac{O_{t}^{T}}{y_{t}^{T}}\right)^{\frac{\psi^{T}-1}{\psi^{T}}}\right]=\frac{W_{t}}{P_{t}^{T}} \\
& m c_{t}^{T} \alpha_{T}\left(\frac{y_{t}^{T}}{k_{t}^{T}}\right)\left[1-\varkappa_{T}^{\frac{\psi^{T}}{\psi^{T}-1}}\left(\frac{O_{t}^{T}}{y_{t}^{T}}\right)^{\frac{\psi^{T}-1}{\psi^{T}}}\right]=\frac{P C_{t} r_{t}}{P_{t}^{T}} \\
& m c_{t}^{T} \varkappa_{T}^{\frac{\psi^{T}}{\psi^{T}-1}}\left(\frac{y_{t}^{T}}{O_{t}^{T}}\right)^{\frac{1}{\psi^{T}}}=\frac{s_{t}^{-1} P_{t}^{o i l}}{P_{t}^{T}} \\
& m c_{t}^{T} \alpha_{T}\left(\frac{y_{t}^{T}}{c u_{t}^{T}}\right)\left[1-\varkappa_{T}^{\frac{\psi^{T}}{\psi^{T}-1}}\left(\frac{O_{t}^{T}}{y_{t}^{T}}\right)^{\frac{\psi^{T}-1}{\psi^{T}}}\right]=f^{\prime}\left(c u_{t}^{T}\right) \\
& P v_{t}^{T} v a_{t}^{T}=P_{t}^{T} y_{t}^{T}-s_{t}^{-1} P_{t}^{O i l} O_{t}^{T} \\
& v a_{t}^{T}=y_{t}^{T}-O_{t}^{T} \\
& y_{t}^{N}=y_{t}^{N C}+y_{t}^{N I}
\end{aligned}
$$




$$
\begin{aligned}
& y_{t}^{N C}=c_{t}^{N}+g_{t} \\
& y_{t}^{N I}=I_{t}^{N} \\
& \widetilde{P C}_{t}^{N}=\left(\frac{\theta^{c N}}{\theta^{c N}-1}\right) \frac{E_{t} \sum_{k=0}^{\infty}(\beta \theta)^{k} \zeta_{t+k} P_{t+k}^{N} m c_{t, t+k}^{N} c_{t+k}^{N}}{E_{t} \sum_{k=0}^{\infty}(\beta \theta)^{k} \zeta_{t+k} \prod_{i=1}^{k}\left(\pi_{t+i-1}^{c N}\right)^{\xi^{P}} c_{t+k}^{N}} \\
& \left.P C_{t}^{N}=\left[\theta\left(P C_{t-1}^{N}\left(\pi_{t-1}^{c N}\right)^{\xi^{P}}\right)^{1-\theta^{c N}}+(1-\theta) \widetilde{P C}_{t}^{N\left(1-\theta^{c N}\right.}\right)\right]^{\frac{1}{1-\theta^{c N}}} \\
& \widetilde{P I}_{t}^{N}=\left(\frac{\theta^{I N}}{\theta^{I N}-1}\right) \frac{E_{t} \sum_{k=0}^{\infty}(\beta \theta)^{k} \zeta_{t+k} P_{t+k}^{T} m c_{t, t+k}^{T} I_{t+k}^{N}}{E_{t} \sum_{k=0}^{\infty}(\beta \theta)^{k} \zeta_{t+k} \prod_{i=1}^{k}\left(\pi_{t+i-1}^{I N}\right)^{\xi^{P}} I_{t+k}^{N}} \\
& \left.P I_{t}^{N}=\left[\theta\left(P I_{t-1}^{N}\left(\pi_{t-1}^{I N}\right)^{\xi^{P}}\right)^{1-\theta^{I N}}+(1-\theta) \widetilde{P I}{ }_{t}^{N\left(1-\theta^{I N}\right.}\right)\right]^{\frac{1}{1-\theta^{I N}}} \\
& P_{t}^{N}=\frac{P C_{t}^{N} c_{t}^{N}+P I_{t}^{N} I_{t}^{N}+P_{t}^{N} g_{t}}{y_{t}^{N}} \\
& y_{t}^{N}=\left[\begin{array}{c}
\varkappa_{N}^{\frac{\psi^{N}}{\psi^{N}-1}}\left(O_{t}^{N}\right)^{\frac{\psi^{N}-1}{\psi^{N}}}+ \\
\left(1-\varkappa_{N}\right)^{\frac{\psi^{N}}{\psi^{N}-1}}\left[\left(c u_{t}^{N} k_{t}^{N}\right)^{\alpha_{N}}\left(z_{t} z_{t}^{N} n_{t}^{N}\right)^{1-\alpha_{N}}\right]^{\frac{\psi^{N}-1}{\psi^{N}}}
\end{array}\right]^{\frac{\psi^{N}}{\psi^{N}-1}} \\
& m c_{t}^{N}\left(1-\alpha_{N}\right)\left(\frac{y_{t}^{N}}{n_{t}^{N}}\right)\left[1-\varkappa_{N}^{\frac{\psi^{N}}{\psi^{N}}}\left(\frac{O_{t}^{N}}{y_{t}^{N}}\right)^{\frac{\psi^{N}-1}{\psi^{N}}}\right]=\frac{W_{t}}{P_{t}^{N}} \\
& m c_{t}^{N} \alpha_{N}\left(\frac{y_{t}^{N}}{k_{t}^{N}}\right)\left[1-\varkappa_{N}^{\frac{\psi^{N}}{\psi^{N}-1}}\left(\frac{O_{t}^{N}}{y_{t}^{N}}\right)^{\frac{\psi^{N}-1}{\psi^{N}}}\right]=\frac{P C_{t} r_{t}}{P_{t}^{N}} \\
& m c_{t}^{N} \varkappa^{\frac{\psi^{N}}{\psi^{N}-1}}\left(\frac{y_{t}^{N}}{O_{t}^{N}}\right)^{\frac{1}{\psi N}}=\frac{s_{t}^{-1} P_{t}^{o i l}}{P_{t}^{N}} \\
& m c_{t}^{N} \alpha_{N}\left(\frac{y_{t}^{N}}{c u_{t}^{N}}\right)\left[1-\varkappa_{N}^{\frac{\psi^{N}}{\psi^{N}-1}}\left(\frac{O_{t}^{N}}{y_{t}^{N}}\right)^{\frac{\psi^{N}-1}{\psi^{N}}}\right]=f^{\prime}\left(c u_{t}^{N}\right) \\
& P v_{t}^{N} v a_{t}^{N}=P_{t}^{N} y_{t}^{N}-s_{t}^{-1} P_{t}^{O i l} O_{t}^{N} \\
& v a_{t}^{N}=y_{t}^{N}-O_{t}^{N}
\end{aligned}
$$




$$
\begin{gathered}
\widetilde{P}_{t}^{D}=\left(\frac{\theta^{D}}{\theta^{D}-1}\right) \frac{E_{t} \sum_{k=0}^{\infty}(\beta \theta)^{k} \zeta_{t+k} P_{t+k}^{D} m c_{t, t+k}^{D} I_{t+k}^{D}}{E_{t} \sum_{k=0}^{\infty}(\beta \theta)^{k} \zeta_{t+k} \prod_{i=1}^{k}\left(\pi_{t+i-1}^{D}\right)^{\xi^{P}} I_{t+k}^{D}} \\
P_{t}^{D}=\left[\theta\left(P_{t-1}^{D}\left(\pi_{t-1}^{D}\right)^{\xi^{P}}\right)^{1-\theta^{D}}+(1-\theta) \widetilde{P}_{t}^{D\left(1-\theta^{D}\right)}\right]^{\frac{1}{1-\theta^{D}}} \\
y_{t}^{D}=\left(c u_{t}^{D} k_{t}^{D}\right)^{\alpha_{D}}\left(z_{t} z_{t}^{D} n_{t}^{D}\right)^{1-\alpha_{D}} \\
m c_{t}^{D}\left(1-\alpha_{D}\right)\left(\frac{y_{t}^{D}}{n_{t}^{D}}\right)=\frac{W_{t}}{P_{t}^{D}} \\
m c_{t}^{D} \alpha_{D}\left(\frac{y_{t}^{D}}{k_{t}^{D}}\right)=\frac{P C_{t} r_{t}}{P_{t}^{D}} \\
m c_{t}^{D} \alpha_{D}\left(\frac{y_{t}^{D}}{c u_{t}^{D}}\right)=f^{\prime}\left(c u_{t}^{D}\right)
\end{gathered}
$$

Equations for $m c_{t, t+k}^{T}, m c_{t, t+k}^{N}, m c_{t, t+k}^{D}$ will be needed if we assume ex-post imperfect capital mobility.

$$
\begin{gathered}
\frac{\zeta_{t+k}}{\zeta_{t}}=\frac{U_{C, t+k}}{U_{C, t}} \\
k_{t-1}=k_{t}^{T}+k_{t}^{N}+k_{t}^{D} \\
n_{t}=n_{t}^{T}+n_{t}^{N}+n_{t}^{D} \\
y_{t}^{D}=I_{t}^{D} \\
y_{t}=y_{t}^{N}+y_{t}^{T}+y_{t}^{D} \\
P_{t} y_{t}=P_{t}^{N} y_{t}^{N}+P_{t}^{T} y_{t}^{T}+P_{t}^{D} y_{t}^{D} \\
v a_{t}=v a_{t}^{T}+v a_{t}^{N}+y_{t}^{D} \\
P v_{t}=\frac{P v_{t}^{T} v a_{t}^{T}+P v_{t}^{N} v a_{t}^{N}+P_{t}^{D} y_{t}^{D}}{v a_{t}}
\end{gathered}
$$

define $a_{t}=\frac{A_{t}}{P v_{t} v a_{t}}$

$$
\begin{gathered}
s_{t}^{-1} W R_{t} \Psi\left(a_{t-1}\right) a_{t-1} \frac{v a_{t-1}}{\pi_{t}^{V A} v a_{t}}+\frac{P_{t}^{X} X_{t}-P_{t}^{M} M_{t}}{P v_{t} v a_{t}}=s_{t}^{-1} a_{t} \\
\pi_{t}=\frac{P_{t}}{P_{t-1}}
\end{gathered}
$$




$$
\begin{aligned}
& \pi_{t}^{V A}=\frac{P v_{t}}{P v_{t-1}} \\
& \pi_{t}^{C}=\frac{P_{t}^{C}}{P_{t-1}^{C}} \\
& \pi_{t}^{I P C}=\frac{P C_{t}}{P C_{t-1}} \\
& \pi_{t}^{C N}=\frac{P C_{t}^{N}}{P C_{t-1}^{N}} \\
& \pi_{t}^{I}=\frac{P_{t}^{I}}{P_{t-1}^{I}} \\
& \pi_{t}^{I P}=\frac{P I_{t}^{P}}{P I_{t-1}^{P}} \\
& \pi_{t}^{I N}=\frac{P I_{t}^{N}}{P I_{t-1}^{N}} \\
& \pi_{t}^{D}=\frac{P_{t}^{D}}{P_{t-1}^{D}} \\
& M_{t}=c_{F, t}+I_{F, t}+c_{W, t}+I_{W, t}+c_{t}^{O i l}+O_{t}^{T}+O_{t}^{N} \\
& X_{t}=F c_{H, t}+W c_{H, t}+F I_{H, t}+W I_{H, t} \\
& P_{t}^{M}=\frac{F P_{t}^{C} c_{F, t}+F P_{t}^{I} I_{F, t}+s_{t}^{-1} W P_{t}^{C} c_{W, t}+s_{t}^{-1} W P_{t}^{I} I_{W, t}+s_{t}^{-1} P_{t}^{O i l}\left(c_{t}^{O i l}+O_{t}^{T}+O_{t}^{N}\right)}{M_{t}} \\
& P_{t}^{X}=\frac{P_{t}^{C} F c_{H, t}+P_{t}^{I} F I_{H, t}+P_{t}^{C} W c_{H, t}+P_{t}^{I} W I_{H, t}}{X_{t}} \\
& \frac{b_{t}}{R_{t}}=\frac{v a_{t-1}}{v a_{t} \pi_{t}^{V A}} b_{t-1}+\frac{P_{t}^{N}}{P v_{t}} \frac{g_{t}}{v a_{t}}-\frac{P C_{t}}{P v_{t}} \frac{T_{t}}{v a_{t}}-\frac{P C_{t}}{P v_{t}} \tau_{k} r_{t} \frac{k_{t}}{v a_{t}} \\
& -\frac{P C_{t}}{P v_{t}} \frac{W_{t}}{P C_{t}} \tau_{w} \frac{n_{t}}{v a_{t}}-\frac{c_{t}}{v a_{t}} \tau_{c} \frac{P C_{t}}{P v_{t}} \\
& \frac{T_{t}}{v a_{t}}=T_{0}+T_{1}\left(b_{t}-\bar{b}\right) \\
& R_{t}=R_{t-1}^{\rho_{R}}\left(\pi_{t}^{V A} F \pi_{t}^{V A}\right)^{\left(\frac{\left(1-\rho_{R}\right) \rho_{\pi}}{2}\right)}\left(v a_{t} F v a_{t}\right)^{\left(\frac{\left(1-\rho_{R}\right) \rho_{V A}}{2}\right)} \varepsilon_{t}^{R}
\end{aligned}
$$




$$
\begin{aligned}
& F \lambda_{t}=\beta E_{t} \frac{R_{t} F \lambda_{t+1}}{F \pi_{t+1}^{I P C}} \Psi\left(F a_{t-1}\right) \\
& F \lambda_{t}=F U_{C, t} \\
& F U_{C, t}=\left[\begin{array}{c}
F \varepsilon_{t}^{a}\left[\frac{F c_{t}}{\left(F c_{t-1}\right)^{\gamma}}\right]^{-\sigma} \frac{1}{\left(F c_{t-1}\right)^{\gamma}} \\
-\beta \gamma E_{t} F \varepsilon_{t+1}^{a}\left[\frac{F c_{t+1}}{\left(F c_{t}\right)^{\gamma}}\right]^{-\sigma} F c_{t+1} \frac{\left(F c_{t}\right)^{\gamma-1}}{\left(F c_{t}\right)^{2 \gamma}}
\end{array}\right] \\
& \widetilde{F W}_{t}=\frac{\varepsilon_{w}}{\varepsilon_{w}-1} \frac{E_{t} \sum_{k=0}^{\infty}\left(\beta \theta_{w}\right)^{k} F n_{t, t+k} F U_{c, t+k} F M R S_{t, t+k}}{E_{t} \sum_{k=0}^{\infty}\left(\beta \theta_{w}\right)^{k} F n_{t, t+k} F U_{c, t+k} \frac{\left(1-\tau_{w}\right)}{\left(1+\tau_{c}\right)} \frac{\prod_{i=1}^{k} F d_{t+i}^{\xi^{W}}}{F P C_{t+k}}} \\
& F W_{t}=\left[\left(1-\theta_{w}\right)\left(\widetilde{F W}_{t}(i)\right)^{1-\varepsilon_{w}}+\theta_{w}\left(F W_{t-1} F d_{t}^{\xi^{W}}\right)^{1-\varepsilon_{w}}\right]^{\frac{1}{1-\varepsilon_{w}}} \\
& F M R S_{t, t+k}=F M R S_{t+k}\left[\left(\frac{\widetilde{F W}}{F W_{t}}\right) \prod_{i=1}^{k} F d_{t+i}^{\xi^{W}}\right]^{-\varphi \varepsilon_{w}} \\
& F M R S_{t+k}=\frac{\left(1+\tau_{c}\right) F \varepsilon_{t}^{a}\left(F n_{t+k}\right)^{\varphi}}{\left(1-\tau_{w}\right) F \lambda_{t+k}} \\
& F d_{t}=F \pi_{t-1}^{I P C} \\
& F n_{t, t+k}=\left(\frac{\widetilde{F W}_{t} \prod_{i=1}^{k} d_{t+i}^{\xi^{W}}}{F W_{t+k}}\right)^{-\varepsilon_{w}} F n_{t+k}
\end{aligned}
$$

Note: In fact there are $k$ such equations but we shall only need one because the price and wage equations can be written as quasi-difference equations and thus can be expressed in terms of a linear difference equation in the log-linear model.

$$
\begin{gathered}
F q_{t}=\frac{1}{F \Phi^{k^{\prime}}\left(\frac{F I_{t}^{P}}{F k_{t-1}}\right)} \\
F q_{t}=\frac{F \lambda_{t}^{k}\left(1+F \tau_{c}\right) F P C_{t}}{F \lambda_{t} F P I_{t}^{P}} \\
F q_{t}=\beta E_{t}\left\{\frac{F \pi_{t+1}^{I P} F \lambda_{t+1}}{F \pi_{t+1}^{I P C} F \lambda_{t}}\left[\begin{array}{c}
\frac{F P C_{t+1}}{F P I_{t+1}^{P}}\left(1-F \tau_{k}\right) F r_{t+1}+ \\
F q_{t+1}\left(F \Phi_{t+1}-F \Phi_{t+1}^{\prime} \frac{F I_{t+1}^{P}}{F k_{t}}+(1-\delta)\right)
\end{array}\right]\right\}
\end{gathered}
$$




$$
\begin{aligned}
& F q_{t}^{D}=\frac{1}{F \Phi^{D^{\prime}}\left(\frac{F I_{t}^{D}}{F D_{t-1}}\right)} \\
& F q_{t}^{D}=\frac{F \lambda_{t}^{D}\left(1+F \tau_{c}\right) F P C_{t}}{F \lambda_{t} F P_{t}^{D}} \\
& F q_{t}^{D}=\beta E_{t}\left\{\frac{F \pi_{t+1}^{D} F \lambda_{t+1}}{F \pi_{t+1}^{I P C} F \lambda_{t}}\left[\begin{array}{c}
\frac{F \varepsilon_{t+1}^{a}}{F \lambda_{t+1}} \frac{F P C_{t+1}}{F P_{t+1}^{D}}\left(1+F \tau_{k}\right) F D_{t+1}^{-\sigma_{D}} \\
+F q_{t+1}^{D}\left(F \Phi_{t+1}^{D}-F \Phi_{t+1}^{D^{\prime}} \frac{F I_{t+1}^{D}}{F D_{t}}+\left(1-\delta_{D}\right)\right)
\end{array}\right]\right\} \\
& F k_{t+1}=F \Phi\left(\frac{F I_{t}^{P}}{F k_{t-1}}\right) F k_{t}+(1-\delta) F k_{t-1} \\
& F D_{t+1}=F \Phi^{D}\left(\frac{F I_{t}^{D}}{F D_{t-1}}\right) F D_{t}+\left(1-\delta_{D}\right) F D_{t-1} \\
& F c_{t}=\left[\left(F \omega_{C}^{N}\right)^{\frac{1}{\rho^{c}}}\left(F c_{t}^{N}\right)^{\frac{\rho^{c}-1}{\rho^{c}}}+\left(F \omega_{C}^{T}\right)^{\frac{1}{\rho^{c}}}\left(F c_{t}^{T}\right)^{\frac{\rho^{c}-1}{\rho^{c}}}\right]^{\frac{\rho^{c}}{\rho^{c}-1}} \\
& \frac{F c_{t}^{N}}{F c_{t}^{T}}=\frac{F \omega_{C}^{N}}{F \omega_{C}^{T}}\left(\frac{F P C_{t}^{N}}{F P C_{t}^{T}}\right)^{-\rho^{c}} \\
& F P C_{t}=\left[F \omega_{C}^{N}\left(F P C_{t}^{N}\right)^{1-\rho^{c}}+F \omega_{C}^{T}\left(F P C_{t}^{T}\right)^{1-\rho^{c}}\right]^{\frac{1}{1-\rho^{c}}} \\
& F c_{t}^{T}=\left[\begin{array}{c}
\left.\left(F \omega_{F C}\right)^{\frac{1}{\rho^{c T}}}\left(F c_{F, t}\right)^{\frac{\rho^{c T}-1}{\rho^{c T}}}+\left(F \omega_{H C}\right)^{\frac{1}{\rho^{c T}}}\left(F c_{H, t}\right)^{\frac{\rho^{c T}-1}{\rho^{c T}}}+\right]^{\frac{\rho^{c T}}{\rho^{c T}-1}} \\
+\left(F \omega_{C}^{O i l}\right)^{\frac{1}{\rho^{c T}}}\left(F c_{t}^{O i l}\right)^{\frac{\rho^{c T}-1}{\rho^{c T}}} \\
+\left(F \omega_{W C}\right)^{\frac{1}{\rho^{c T}}}\left(F c_{W, t}\right)^{\frac{\rho^{c T}-1}{\rho^{c T}}}
\end{array}\right]^{c} \\
& \frac{F c_{H, t}}{F c_{F, t}}=\frac{F \omega_{H C}}{F \omega_{F C}}\left(\frac{P_{t}^{C}}{F P_{t}^{C}}\right)^{-\rho^{c T}} \\
& \frac{F c_{t}^{O i l}}{F c_{F, t}}=\frac{F \omega_{C}^{O i l}}{F \omega_{F C}}\left(\frac{s_{t}^{-1} P_{t}^{O i l}}{F P_{t}^{C}}\right)^{-\rho^{c T}} \\
& \frac{F c_{W, t}}{F c_{F, t}}=\frac{F \omega_{W C}}{F \omega_{F C}}\left(\frac{s_{t}^{-1} W P_{t}^{C}}{F P_{t}^{C}}\right)^{-\rho^{c T}}
\end{aligned}
$$




$$
\begin{aligned}
& F P C_{t}^{T}=\left[\begin{array}{c}
F \omega_{F C}\left(F P_{t}^{C}\right)^{1-\rho^{c T}}+F \omega_{H C}\left(P_{t}^{C}\right)^{1-\rho^{c T}} \\
+F \omega_{C}^{O i l}\left(s_{t}^{-1} P_{t}^{O i l}\right)^{1-\rho^{c T}} \\
+F \omega_{W C}\left(s_{t}^{-1} W P_{t}^{C}\right)^{1-\rho^{c T}}
\end{array}\right]^{\frac{1}{1-\rho^{c T}}} \\
& F I_{t}=\left[\left(F \omega_{I}^{P}\right)^{\frac{1}{\rho^{I}}}\left(F I_{t}^{P}\right)^{\frac{\rho^{I}-1}{\rho^{I}}}+\left(F \omega_{I}^{D}\right)^{\frac{1}{\rho^{D}}}\left(F I_{t}^{D}\right)^{\frac{\rho^{I}-1}{\rho^{I}}}\right]^{\frac{\rho^{I}}{\rho^{I}-1}} \\
& F P I_{t}=\left[F \omega_{I}^{P}\left(F P I_{t}^{P}\right)^{1-\rho^{I}}+F \omega_{I}^{D}\left(F P_{t}^{D}\right)^{1-\rho^{I}}\right]^{\frac{1}{1-\rho^{I}}} \\
& \frac{F I_{t}^{P}}{F I_{t}^{D}}=\frac{F \omega_{I}^{P}}{F \omega_{I}^{D}}\left(\frac{F P I_{t}^{P}}{F P_{t}^{D}}\right)^{-\rho^{I}} \\
& F I_{t}^{P}=\left[\left(F \omega_{I}^{N}\right)^{\frac{1}{\rho^{I P}}}\left(F I_{t}^{N}\right)^{\frac{\rho^{I P}-1}{\rho^{I P}}}+\left(F \omega_{I}^{T}\right)^{\frac{1}{\rho^{I P}}}\left(F I_{t}^{T}\right)^{\frac{\rho^{I P}-1}{\rho^{I P}}}\right]^{\frac{\rho^{I P}}{\rho^{I P}-1}} \\
& F P I_{t}^{P}=\left[F \omega_{I}^{N}\left(F P I_{t}^{N}\right)^{1-\rho^{I P}}+F \omega_{I}^{T}\left(F P I_{t}^{T}\right)^{1-\rho^{I P}}\right]^{\frac{1}{1-\rho^{I P}}} \\
& \frac{F I_{t}^{N}}{F I_{t}^{T}}=\frac{F \omega_{I}^{N}}{F \omega_{I}^{T}}\left(\frac{F P I_{t}^{N}}{F P I_{t}^{T}}\right)^{-\rho^{I P}} \\
& F I_{t}^{T}=\left[\begin{array}{c}
\left(F \omega_{F I}\right)^{\frac{1}{\rho^{I T}}}\left(F I_{F, t}\right)^{\frac{\rho^{I T}-1}{\rho^{I T}}}+\left(F \omega_{H I}\right)^{\frac{1}{\rho^{I T}}}\left(F I_{H, t}\right)^{\frac{\rho^{I T}-1}{\rho^{I T}}} \\
+\left(F \omega_{W I}\right)^{\frac{1}{\rho^{I T}}}\left(F I_{W, t}\right)^{\frac{\rho^{I T}-1}{\rho^{I T}}}
\end{array}\right]^{\frac{\rho^{I T}}{\rho^{I T}-1}} \\
& \frac{F I_{H, t}}{F I_{F, t}}=\frac{F \omega_{H I}}{F \omega_{F I}}\left(\frac{P_{t}^{I}}{F P_{t}^{I}}\right)^{-\rho^{I T}} \\
& \frac{F I_{W, t}}{F I_{F, t}}=\frac{F \omega_{W I}}{F \omega_{F I}}\left(\frac{s_{t}^{-1} W P_{t}^{I}}{F P_{t}^{I}}\right)^{-\rho^{I T}} \\
& F P I_{t}^{T}=\left[\begin{array}{c}
F \omega_{F I}\left(F P_{t}^{I}\right)^{1-\rho^{I T}}+F \omega_{H I}\left(P_{t}^{I}\right)^{1-\rho^{I T}} \\
+F \omega_{W I}\left(W P_{t}^{I}\right)^{1-\rho^{I T}}
\end{array}\right]^{\frac{1}{1-\rho^{I T}}} \\
& F y_{t}^{T}=F y_{t}^{T C}+F y_{t}^{T I} \\
& F y_{t}^{T C}=F c_{F, t}+c_{F, t}+W c_{F, t} \\
& F y_{t}^{T I}=F I_{F, t}+I_{F, t}+W I_{F, t}
\end{aligned}
$$




$$
\begin{aligned}
& \widetilde{F P}_{t}^{C}=\left(\frac{\theta^{c}}{\theta^{c}-1}\right) \frac{E_{t} \sum_{k=0}^{\infty}(\beta \theta)^{k} \zeta_{t+k} F P_{t+k}^{T} F m c_{t, t+k}^{T} F y_{t+k}^{T C}}{E_{t} \sum_{k=0}^{\infty}(\beta \theta)^{k} \zeta_{t+k} \prod_{i=1}^{k}\left(F \pi_{t+i-1}^{C}\right)^{\xi^{P}} F y_{t+k}^{T C}} \\
& F P_{t}^{C}=\left[\theta\left(F P_{t-1}^{C}\left(F \pi_{t-1}^{C}\right)^{\xi^{P}}\right)^{1-\theta^{c}}+(1-\theta) \widetilde{F P_{t}^{C\left(1-\theta^{c}\right)}}\right]^{\frac{1}{1-\theta^{c}}} \\
& \widetilde{F P}_{t}^{I}=\left(\frac{\theta^{I}}{\theta^{I}-1}\right) \frac{E_{t} \sum_{k=0}^{\infty}(\beta \theta)^{k} \zeta_{t+k} F P_{t+k}^{T} F m c_{t, t+k}^{T} F y_{t+k}^{T I}}{E_{t} \sum_{k=0}^{\infty}(\beta \theta)^{k} \zeta_{t+k} \prod_{i=1}^{k}\left(F \pi_{t+i-1}^{I}\right)^{\xi^{P}} F y_{t+k}^{T I}} \\
& F P_{t}^{I}=\left[\theta\left(F P_{t-1}^{I}\left(F \pi_{t-1}^{I}\right)^{\xi^{P}}\right)^{1-\theta^{I}}+(1-\theta) \widetilde{F P}_{t}^{I\left(1-\theta^{I}\right)}\right]^{\frac{1}{1-\theta^{I}}} \\
& F P_{t}^{T} F y_{t}^{T}=\left[F P_{t}^{C} F y_{t}^{T C}+F P_{t}^{I} F y_{t}^{T I}\right] \\
& F y_{t}^{T}=\left[\begin{array}{c}
\varkappa_{T}^{\frac{\psi^{T}}{\psi^{T}-1}}\left(F O_{t}^{T}\right)^{\frac{\psi^{T}-1}{\psi^{T}}}+ \\
\left(1-\varkappa_{T}\right)^{\frac{\psi^{T}}{\psi^{T}-1}}\left[\left(F c u_{t}^{T} k_{t}^{T}\right)^{\alpha_{T}}\left(F z_{t} F z_{t}^{T} F n_{t}^{T}\right)^{1-\alpha_{T}}\right]^{\frac{\psi^{T}-1}{\psi^{T}}}
\end{array}\right]^{\frac{\psi^{T}}{\psi^{T}-1}} \\
& F m c_{t}^{T}\left(1-\alpha_{T}\right)\left(\frac{F y_{t}^{T}}{F n_{t}^{T}}\right)\left[1-\varkappa_{T}^{\frac{\psi^{T}}{\psi^{T}-1}}\left(\frac{F O_{t}^{T}}{F y_{t}^{T}}\right)^{\frac{\psi^{T}-1}{\psi^{T}}}\right]=\frac{F W_{t}}{F P_{t}^{T}} \\
& F m c_{t}^{T} \alpha_{T}\left(\frac{F y_{t}^{T}}{F k_{t}^{T}}\right)\left[1-\varkappa_{T}^{\frac{\psi^{T}}{\psi^{T}-1}}\left(\frac{F O_{t}^{T}}{F y_{t}^{T}}\right)^{\frac{\psi^{T}-1}{\psi^{T}}}\right]=\frac{F P C_{t} F r_{t}}{F P_{t}^{T}} \\
& F m c_{t}^{T} \varkappa_{T}^{\frac{\psi^{T}}{\psi^{T}-1}}\left(\frac{F y_{t}^{T}}{F O_{t}^{T}}\right)^{\frac{1}{\psi^{T}}}=\frac{s_{t}^{-1} P_{t}^{o i l}}{F P_{t}^{T}} \\
& F m c_{t}^{T} \alpha_{T}\left(\frac{F y_{t}^{T}}{F c u_{t}^{T}}\right)\left[1-\varkappa_{T}^{\frac{\psi^{T}}{\psi^{T}-1}}\left(\frac{F O_{t}^{T}}{F y_{t}^{T}}\right)^{\frac{\psi^{T}-1}{\psi^{T}}}\right]=f^{\prime}\left(F c u_{t}^{T}\right) \\
& F P v_{t}^{T} F v a_{t}^{T}=F P_{t}^{T} F y_{t}^{T}-s_{t}^{-1} P_{t}^{O i l} F O_{t}^{T} \\
& F v a_{t}^{T}=F y_{t}^{T}-F O_{t}^{T} \\
& F y_{t}^{N}=F y_{t}^{N C}+F y_{t}^{N I} \\
& F y_{t}^{N C}=F c_{t}^{N}+F g_{t} \\
& F y_{t}^{N I}=F I_{t}^{N}
\end{aligned}
$$




$$
\begin{aligned}
& \widetilde{F P C}_{t}^{N}=\left(\frac{\theta^{c N}}{\theta^{c N}-1}\right) \frac{E_{t} \sum_{k=0}^{\infty}(\beta \theta)^{k} \zeta_{t+k} F P_{t+k}^{N} F m c_{t, t+k}^{N} F c_{t+k}^{N}}{E_{t} \sum_{k=0}^{\infty}(\beta \theta)^{k} \zeta_{t+k} \prod_{i=1}^{k}\left(F \pi_{t+i-1}^{c N}\right)^{\xi^{P}} F c_{t+k}^{N}} \\
& \left.F P C_{t}^{N}=\left[\theta\left(F P C_{t-1}^{N}\left(F \pi_{t-1}^{c N}\right)^{\xi^{P}}\right)^{1-\theta^{c N}}+(1-\theta) \widetilde{F P C}_{t}^{N\left(1-\theta^{c N}\right.}\right)\right]^{\frac{1}{1-\theta^{c N}}} \\
& \widetilde{F P I}_{t}^{N}=\left(\frac{\theta^{I N}}{\theta^{I N}-1}\right) \frac{E_{t} \sum_{k=0}^{\infty}(\beta \theta)^{k} \zeta_{t+k} F P_{t+k}^{T} F m c_{t, t+k}^{T} F I_{t+k}^{N}}{E_{t} \sum_{k=0}^{\infty}(\beta \theta)^{k} \zeta_{t+k} \prod_{i=1}^{k}\left(F \pi_{t+i-1}^{I N}\right)^{\xi^{P}} F I_{t+k}^{N}} \\
& \left.F P I_{t}^{N}=\left[\theta\left(F P I_{t-1}^{N}\left(F \pi_{t-1}^{I N}\right)^{\xi^{P}}\right)^{1-\theta^{I N}}+(1-\theta) \widetilde{F P I}_{t}^{N\left(1-\theta^{I N}\right.}\right)\right]^{\frac{1}{1-\theta^{I N}}} \\
& F P_{t}^{N}=\frac{F P C_{t}^{N} F c_{t}^{N}+F P I_{t}^{N} F I_{t}^{N}+F P_{t}^{N} F g_{t}}{F y_{t}^{N}} \\
& F y_{t}^{N}=\left[\begin{array}{c}
\varkappa_{N}^{\frac{\psi^{N}}{\psi^{N}}}\left(F O_{t}^{N}\right)^{\frac{\psi^{N}-1}{\psi^{N}}}+ \\
\left(1-\varkappa_{N}\right)^{\frac{\psi^{N}}{\psi^{N}-1}}\left[\left(F c u_{t}^{N} k_{t}^{N}\right)^{\alpha_{N}}\left(F z_{t} F z_{t}^{N} F n_{t}^{N}\right)^{1-\alpha_{N}}\right]^{\frac{\psi^{N}-1}{\psi^{N}}}
\end{array}\right]^{\frac{\psi^{N}}{\psi^{N}-1}} \\
& F m c_{t}^{N}\left(1-\alpha_{N}\right)\left(\frac{F y_{t}^{N}}{F n_{t}^{N}}\right)\left[1-\varkappa_{N}^{\frac{\psi^{N}}{\psi^{N}-1}}\left(\frac{F O_{t}^{N}}{F y_{t}^{N}}\right)^{\frac{\psi^{N}-1}{\psi^{N}}}\right]=\frac{F W_{t}}{F P_{t}^{N}} \\
& F m c_{t}^{N} \alpha_{N}\left(\frac{F y_{t}^{N}}{F k_{t}^{N}}\right)\left[1-\varkappa_{N}^{\frac{\psi^{N}}{\psi^{N}-1}}\left(\frac{F O_{t}^{N}}{F y_{t}^{N}}\right)^{\frac{\psi^{N}-1}{\psi^{N}}}\right]=\frac{F P C_{t} F r_{t}}{F P_{t}^{N}} \\
& F m c_{t}^{N} \varkappa_{N}^{\frac{\psi^{N}}{\psi^{N}-1}}\left(\frac{F y_{t}^{N}}{F O_{t}^{N}}\right)^{\frac{1}{\psi N}}=\frac{s_{t}^{-1} P_{t}^{o i l}}{F P_{t}^{N}} \\
& F m c_{t}^{N} \alpha_{N}\left(\frac{F y_{t}^{N}}{F c u_{t}^{N}}\right)\left[1-\varkappa_{N}^{\frac{\psi^{N}}{\psi^{N}-1}}\left(\frac{F O_{t}^{N}}{F y_{t}^{N}}\right)^{\frac{\psi^{N}-1}{\psi^{N}}}\right]=f^{\prime}\left(F c u_{t}^{N}\right) \\
& F P v_{t}^{N} F v a_{t}^{N}=F P_{t}^{N} F y_{t}^{N}-s_{t}^{-1} P_{t}^{O i l} F O_{t}^{N} \\
& F v a_{t}^{N}=F y_{t}^{N}-F O_{t}^{N} \\
& \widetilde{F P}_{t}^{D}=\left(\frac{\theta^{D}}{\theta^{D}-1}\right) \frac{E_{t} \sum_{k=0}^{\infty}(\beta \theta)^{k} \zeta_{t+k} F P_{t+k}^{D} F m c_{t, t+k}^{D} F I_{t+k}^{D}}{E_{t} \sum_{k=0}^{\infty}(\beta \theta)^{k} \zeta_{t+k} \prod_{i=1}^{k}\left(F \pi_{t+i-1}^{D}\right)^{\xi^{P}} F I_{t+k}^{D}}
\end{aligned}
$$




$$
\begin{gathered}
F P_{t}^{D}=\left[\theta\left(F P_{t-1}^{D}\left(F \pi_{t-1}^{D}\right)^{\xi^{P}}\right)^{1-\theta^{D}}+(1-\theta) \widetilde{F P}_{t}^{D\left(1-\theta^{D}\right)}\right]^{\frac{1}{1-\theta^{D}}} \\
F y_{t}^{D}=\left(F c u_{t}^{D} k_{t}^{D}\right)^{\alpha_{D}}\left(F z_{t} F z_{t}^{D} F n_{t}^{D}\right)^{1-\alpha_{D}} \\
F m c_{t}^{D}\left(1-\alpha_{D}\right)\left(\frac{F y_{t}^{D}}{F n_{t}^{D}}\right)=\frac{F W_{t}}{F P_{t}^{D}} \\
F m c_{t}^{D} \alpha_{D}\left(\frac{F y_{t}^{D}}{F k_{t}^{D}}\right)=\frac{F P C_{t} F r_{t}}{F P_{t}^{D}} \\
F m c_{t}^{D} \alpha_{D}\left(\frac{F y_{t}^{T}}{F c u_{t}^{T}}\right)=f^{\prime}\left(F c u_{t}^{D}\right)
\end{gathered}
$$

Equations for $F m c_{t, t+k}^{T}, F m c_{t, t+k}^{N}, F m c_{t, t+k}^{D}$ will be needed if we assume ex-post imperfect capital mobility.

$$
\begin{gathered}
\frac{F \zeta_{t+k}}{F \zeta_{t}}=\frac{F U_{C, t+k}}{F U_{C, t}} \\
F k_{t-1}=F k_{t}^{T}+F k_{t}^{N}+F k_{t}^{D} \\
F n_{t}=F n_{t}^{T}+F n_{t}^{N}+F n_{t}^{D} \\
F y_{t}^{D}=F I_{t}^{D} \\
F y_{t}=F y_{t}^{N}+F y_{t}^{T}+F y_{t}^{D} \\
F P_{t} F y_{t}=F P_{t}^{N} F y_{t}^{N}+F P_{t}^{T} F y_{t}^{T}+F P_{t}^{D} F y_{t}^{D} \\
F v a_{t}=F v a_{t}^{T}+F v a_{t}^{N}+F y_{t}^{D} \\
F P v_{t}^{T} F v a_{t}^{T}+F P v_{t}^{N} F v a_{t}^{N}+F P_{t}^{D} F y_{t}^{D} \\
F v a_{t} \\
s_{t}^{-1} W R_{t} \Psi\left(F a_{t-1}\right) F a_{t-1} \frac{F v a_{t-1}}{F \pi_{t}^{V A} F v a_{t}}+\frac{\left(F P_{t}^{X} F X X_{t}-F P_{t}^{M} F M_{t}\right)}{F P v_{t} F v a_{t}}=s_{t}^{-1} F a_{t} \\
F \pi_{t}=\frac{F P_{t}}{F P_{t-1}} \\
F \pi_{t}^{V A}=\frac{F P v_{t}}{F P v_{t-1}} \\
F \pi_{t}^{C}=\frac{F P_{t}^{C}}{F P_{t-1}^{C}}
\end{gathered}
$$




$$
\begin{aligned}
& F \pi_{t}^{I P C}=\frac{F P C_{t}}{F P C_{t-1}} \\
& F \pi_{t}^{C N}=\frac{F P C_{t}^{N}}{F P C_{t-1}^{N}} \\
& F \pi_{t}^{I}=\frac{F P_{t}^{I}}{F P_{t-1}^{I}} \\
& F \pi_{t}^{I P}=\frac{F P I_{t}^{P}}{F P I_{t-1}^{P}} \\
& F \pi_{t}^{I N}=\frac{F P I_{t}^{N}}{F P I_{t-1}^{N}} \\
& F \pi_{t}^{D}=\frac{F P_{t}^{D}}{F P_{t-1}^{D}} \\
& F M_{t}=F c_{H, t}+F I_{H, t}+F c_{W, t}+F I_{W, t}+F c_{t}^{O i l}+F O_{t}^{T}+F O_{t}^{N} \\
& F X_{t}=c_{F, t}+W c_{F, t}+I_{F, t}+W I_{F, t} \\
& F P_{t}^{M}=\frac{P_{t}^{C} F c_{H, t}+P_{t}^{I} I_{H, t}+s_{t}^{-1} W P_{t}^{C} F c_{W, t}+s_{t}^{-1} W P_{t}^{I} F I_{W, t}+s_{t}^{-1} P_{t}^{O i l}\left(F c_{t}^{O i l}+F O_{t}^{T}+F O_{t}^{N}\right)}{F M_{t}} \\
& F P_{t}^{X}=\frac{F P_{t}^{C} c_{F, t}+F P_{t}^{I} I_{F, t}+F P_{t}^{C} W c_{F, t}+F P_{t}^{C} W I_{F, t}}{F X_{t}} \\
& \begin{aligned}
\frac{F b_{t}}{R_{t}}= & \frac{F v a_{t-1}}{F v a_{t} F \pi_{t}^{V A}} F b_{t-1}+\frac{F P_{t}^{N}}{F P v_{t}} \frac{F g_{t}}{F v a_{t}}-\frac{F P C_{t}}{F P v_{t}} \frac{F T_{t}}{F v a_{t}}-\frac{F P C_{t}}{F P v_{t}} \tau F r_{t} \frac{F k_{t}}{F v a_{t}} \\
& -\frac{F P C_{t}}{F P v_{t}} \frac{F W_{t}}{F P C_{t}} \tau_{w} \frac{F n_{t}}{F v a_{t}}-\frac{F c_{t}}{F v a_{t}} \tau_{c} \frac{F P C_{t}}{F P v_{t}}
\end{aligned} \\
& \frac{F T_{t}}{F v a_{t}}=F T_{0}+F T_{1}\left(F b_{t}-F \bar{b}\right) \\
& W c_{H, t}=W \omega_{H C}\left(\frac{P_{t}^{C}}{s_{t}^{-1} P_{t}^{C}}\right)^{-\rho^{c}} W c_{t} \\
& W c_{F, t}=W \omega_{F C}\left(\frac{F P_{t}^{C}}{s_{t}^{-1} W P_{t}^{C}}\right)^{-\rho^{c}} W c_{t}
\end{aligned}
$$




$$
\begin{aligned}
W I_{H, t}=W \omega_{H I}\left(\frac{P_{t}^{I}}{s_{t}^{-1} W P_{t}^{I}}\right)^{-\rho^{I}} W I_{t} \\
W I_{F, t}=W \omega_{F I}\left(\frac{F P_{t}^{I}}{s_{t}^{-1} W P_{t}^{I}}\right)^{-\rho^{I}} W I_{t} \\
W c_{t}=\bar{W} c_{t} \\
W I_{t}=\overline{W I}_{t} \\
W P_{t}^{C}=\overline{W P_{t}^{C}} \\
W P_{t}^{I}=\overline{W P_{t}^{I}} \\
P_{t}^{O i l}=\bar{P}_{t}^{O i l} \\
W A_{t}+A_{t}+F A_{t}=0 \\
W R_{t}=\overline{W R}_{t}
\end{aligned}
$$




\section{E. Appendix: Log linear Model.}

$$
\begin{gathered}
\widehat{\lambda}_{t}=E_{t} \widehat{\lambda}_{t+1}+\widehat{R}_{t}-E_{t} \widehat{\pi}_{t+1}^{I P C}-\Psi a_{t-1} \\
-\widehat{s}_{t}+\widehat{\lambda}_{t}+E_{t} \widehat{\pi}_{t+1}^{I P C}-\widehat{W R}_{t}=-E_{t} \widehat{s}_{t+1}+E_{t} \widehat{\lambda}_{t+1}-\Psi a_{t-1}
\end{gathered}
$$

(assuming a first order autoregressive process for $\varepsilon^{a}$ with root $\rho_{a}$ )

$$
\begin{aligned}
& \widehat{\lambda}_{t}=\left[\begin{array}{c}
\frac{(\sigma-1) \gamma}{1-\beta \gamma}\left(\widehat{c}_{t-1}+\beta E_{t} \widehat{c}_{t+1}\right) \\
-\frac{\left(\sigma+(\sigma-1) \beta \gamma^{2}-\beta \gamma\right)}{1-\beta \gamma} \widehat{c}_{t}+\frac{1-\beta \gamma \rho_{a}}{1-\beta \gamma} \widehat{\varepsilon}_{t}^{a}
\end{array}\right] \\
& \widehat{\pi}_{t}^{w}-\xi^{W} \widehat{\pi}_{t-1}^{I P C}=\left[\begin{array}{c}
\beta E_{t}\left\{\left(\widehat{\pi}_{t+1}^{w}-\xi^{W} \widehat{\pi}_{t}^{I P C}\right)\right\} \\
-\frac{\left(1-\beta \theta_{w}\right)\left(1-\theta_{w}\right)}{\theta_{w}\left(1+\varphi \varepsilon_{w}\right)}\left(\widehat{w}_{t}-\widehat{M R S}_{t}\right)
\end{array}\right] \\
& \widehat{M R S}_{t}=\widehat{\varepsilon}_{t}^{a}+\varphi \widehat{n}_{t}-\widehat{\lambda}_{t} \\
& \widehat{q}_{t}=-\Phi^{\prime \prime} \delta\left(\widehat{I}_{t}^{P}-\widehat{k}_{t-1}\right) \\
& \widehat{q}_{t}=\widehat{\lambda}_{t}^{k}+\widehat{P C}_{t}-\widehat{\lambda}_{t}-\widehat{P I}_{t}^{P} \\
& \widehat{q}_{t}=\left[\begin{array}{c}
E_{t}\left(\widehat{\lambda}_{t+1}-\widehat{\lambda}_{t}+\widehat{\pi}_{t+1}^{I P}-\widehat{\pi}_{t+1}^{I P C}\right)+ \\
\left(1-(1-\delta) \beta \frac{\bar{\pi}^{I P}}{\bar{\pi}^{I P C}}\right) E_{t}\left(\widehat{P C}_{t+1}-\widehat{P I}_{t+1}^{P}+\widehat{r}_{t+1}\right)+ \\
\beta \frac{\overline{\bar{\pi}}^{I P}}{\bar{\pi}^{I P C}}(1-\delta) E_{t} \widehat{q}_{t+1}-\beta \frac{\bar{\pi}^{I P}}{\bar{\pi}^{I P C}} \delta^{2} \Phi^{\prime \prime} E_{t}\left(\widehat{I}_{t+1}^{P}-\widehat{k}_{t}\right)
\end{array}\right] \\
& \widehat{q}_{t}^{D}=-\Phi_{D}^{\prime \prime} \delta_{D}\left(\widehat{I}_{t}^{D}-\widehat{D}_{t-1}\right) \\
& \widehat{q}_{t}^{D}=\widehat{\lambda}_{t}^{D}+\widehat{P C}_{t}-\widehat{\lambda}_{t}-\widehat{P}_{t}^{D} \\
& \widehat{q}_{t}^{D}=\left[\begin{array}{c}
E_{t}\left(\widehat{\pi}_{t+1}^{D}-\widehat{\pi}_{t+1}^{I P C}-\widehat{\lambda}_{t}\right)+\left(1-\delta_{D}\right) \beta \frac{\bar{\pi}^{D}}{\bar{\pi}^{I P C}} E_{t} \widehat{\lambda}_{t+1} \\
\left(1-\left(1-\delta_{D}\right) \beta \frac{\bar{\pi}^{D}}{\bar{\pi}^{I P C}}\right) E_{t}\left(\widehat{P C}_{t+1}-\widehat{P}_{t+1}^{D}+\rho_{a} \widehat{\varepsilon}_{t}^{a}\right)+ \\
\left(1-\delta_{D}\right) \beta \frac{\bar{\pi}^{D}}{\bar{\pi}^{I P C}} E_{t} \widehat{q}_{t+1}^{D}-\beta \frac{\bar{\pi}^{D}}{\bar{\pi}^{I P C}} \delta_{D}^{2} \Phi_{D}^{\prime \prime} E_{t} \widehat{I}_{t+1}^{D}- \\
{\left[\sigma^{D}\left(1-\beta \frac{\bar{\pi}^{D}}{\bar{\pi}^{I P C}}\left(1-\delta_{D}\right)\right)-\beta \frac{\bar{\pi}^{D}}{\bar{\pi}^{I P C}} \delta_{D}^{2} \Phi_{D}^{\prime \prime}\right] \widehat{D}_{t}}
\end{array}\right] \\
& \widehat{k}_{t}=(1-\delta) \widehat{k}_{t-1}+\delta \widehat{I}_{t}^{P} \\
& \widehat{D}_{t}=\left(1-\delta_{D}\right) \widehat{D}_{t-1}+\delta_{D} \widehat{I}_{t}^{D}
\end{aligned}
$$




$$
\begin{aligned}
& \widehat{c}_{t}=\left[\left(\omega_{C}^{N}\right)^{\frac{1}{\rho^{c}}}\left(\frac{\bar{c}^{N}}{\bar{c}}\right)^{\frac{\rho^{c}-1}{\rho^{c}}} \widehat{c}_{t}^{N}+\left(\omega_{C}^{T}\right)^{\frac{1}{\rho^{c}}}\left(\frac{\bar{c}^{T}}{\bar{c}}\right)^{\frac{\rho^{c}-1}{\rho^{c}}} \widehat{c}_{t}^{T}\right] \\
& \widehat{c}_{t}^{N}-\widehat{c}_{t}^{T}=-\rho^{c}\left(\widehat{P C}_{t}^{N}-\widehat{P C}_{t}^{T}\right) \\
& \widehat{P C}_{t}=\left(\frac{\overline{P C}^{N} \bar{c}^{N}}{\overline{P C} \bar{c}}\right) \widehat{P C}_{t}^{N}+\left(\frac{\overline{P C}^{T} \bar{c}^{T}}{\overline{P C} \bar{c}}\right) \widehat{P C}_{t}^{T} \\
& \widehat{c}_{t}^{T}=\left[\begin{array}{c}
\left(\omega_{H C}\right)^{\frac{1}{\rho^{c T}}}\left(\frac{\bar{c}_{H}}{\bar{c}^{T}}\right)^{\frac{\rho^{c T}-1}{\rho^{c T}}} \widehat{c}_{H, t}+\left(\omega_{F C}\right)^{\frac{1}{\rho^{c T}}}\left(\frac{\bar{c}_{F}}{\bar{c}^{T}}\right)^{\frac{\rho^{c T}-1}{\rho^{c T}}} \widehat{c}_{F, t}+ \\
\left(\omega_{C}^{O i l}\right)^{\frac{1}{\rho^{c T}}}\left(\frac{\bar{c}^{O i l}}{\bar{c}^{T}}\right)^{\frac{\rho^{c T}-1}{\rho^{c T}}} \widehat{c}_{t}^{O i l}+ \\
\left(\omega_{W C}\right)^{\frac{1}{\rho^{c T}}}\left(\frac{\bar{c}_{W}}{\bar{c}^{T}}\right)^{\frac{\rho^{c T}-1}{\rho^{c T}}} \widehat{c}_{W, t}
\end{array}\right] \\
& \widehat{c}_{F, t}-\widehat{c}_{H, t}=-\rho^{c T}\left(\widehat{F P}_{t}^{C}-\widehat{P}_{t}^{C}\right) \\
& \widehat{c}_{t}^{O i l}-\widehat{c}_{H, t}=-\rho^{c T}\left(\widehat{P}_{t}^{O i l}-\widehat{s}_{t}-\widehat{P}_{t}^{C}\right) \\
& \widehat{c}_{W, t}-\widehat{c}_{H, t}=-\rho^{c T}\left(\widehat{W P}_{t}^{C}-\widehat{s}_{t}-\widehat{P}_{t}^{C}\right) \\
& \widehat{P C}_{t}^{T}=\left[\begin{array}{c}
\left(\frac{\bar{P}^{C} \bar{c}_{H}}{\overline{P C}^{T} \bar{c}^{T}}\right) \widehat{P}_{t}^{C}+\left(\frac{\overline{F P}^{C} \bar{c}_{F}}{\overline{P C}^{T} \bar{c}^{T}}\right) \widehat{F P}_{t}^{C}+ \\
\left(\frac{\overline{W P}^{C} \bar{c}_{W}}{\overline{P C}^{T} \bar{c}^{T}}\right)\left(\widehat{W P}_{t}^{C}-\widehat{s}_{t}\right)+\left(\frac{\bar{P}^{O i l} \bar{c}^{O i l}}{\overline{P C}^{T} \bar{c}^{T}}\right)\left(\widehat{P}_{t}^{O i l}-\widehat{s}_{t}\right)
\end{array}\right] \\
& \widehat{I}_{t}=\left(\omega_{I}^{P}\right)^{\frac{1}{\rho^{I}}}\left(\frac{\bar{I}^{P}}{\bar{I}}\right)^{\frac{\rho^{I}-1}{\rho^{I}}} \widehat{I}_{t}^{P}+\left(\omega_{I}^{D}\right)^{\frac{1}{\rho^{I}}}\left(\frac{\bar{I}^{D}}{\bar{I}}\right)^{\frac{\rho^{I}-1}{\rho^{I}}} \widehat{I}_{t}^{D} \\
& \widehat{P I}_{t}=\left(\frac{\overline{P I}^{P} \bar{I}^{P}}{\overline{P I} \bar{I}}\right) \widehat{P I}_{t}^{P}+\left(\frac{\bar{P}^{D} \bar{I}^{D}}{\overline{P I} \bar{I}}\right) \widehat{P}_{t}^{D} \\
& \widehat{I}_{t}^{P}=\left(\omega_{I}^{N}\right)^{\frac{1}{\rho^{I P}}}\left(\frac{\bar{I}^{N}}{\bar{I}^{P}}\right)^{\frac{\rho^{I P}-1}{\rho^{I P}}} \widehat{I}_{t}^{N}+\left(\omega_{I}^{T}\right)^{\frac{1}{\rho^{I P}}}\left(\frac{\bar{I}^{T}}{\bar{I}^{P}}\right)^{\frac{\rho^{I P}-1}{\rho^{I P}}} \widehat{I}_{t}^{T} \\
& \widehat{I}_{t}^{N}-\widehat{I}_{t}^{T}=-\rho^{I P}\left(\widehat{P I}_{t}^{N}-\widehat{P I}_{t}^{T}\right) \\
& \widehat{P I}_{t}^{P}=\left(\frac{\overline{P I}^{N} \bar{I}^{N}}{\overline{P I}^{P} \bar{I}^{P}}\right) \widehat{P I}_{t}^{N}+\left(\frac{\overline{P I}^{T} \bar{I}^{T}}{\overline{P I}^{P} \bar{I}^{P}}\right) \widehat{P I}_{t}^{T}
\end{aligned}
$$




$$
\begin{aligned}
& \widehat{I}_{t}^{T}=\left[\begin{array}{c}
\left(\omega_{H I}\right)^{\frac{1}{\rho^{I T}}}\left(\frac{\bar{I}_{H}}{\bar{I}^{T}}\right)^{\frac{\rho^{I T}-1}{\rho^{I T}}} \widehat{I}_{H, t}+\left(\omega_{F I}\right)^{\frac{1}{\rho^{I T}}}\left(\frac{\bar{I}_{F}}{\bar{I}^{T}}\right)^{\frac{\rho^{I T}-1}{\rho^{I T}}} \widehat{I}_{F, t} \\
+\left(\omega_{W I}\right)^{\frac{1}{\rho^{I T}}}\left(\frac{\bar{I}_{W}}{\bar{I}^{T}}\right)^{\frac{\rho^{I T}-1}{\rho^{I T}}} \widehat{I}_{W, t}
\end{array}\right] \\
& \widehat{I}_{F, t}-\widehat{I}_{H, t}=-\rho^{I T}\left(\widehat{F P}_{t}^{I}-\widehat{P}_{t}^{I}\right) \\
& \widehat{I}_{W, t}-\widehat{I}_{H, t}=-\rho^{I T}\left(\left(\widehat{W P}_{t}^{I}-\widehat{s}_{t}\right)-\widehat{P}_{t}^{I}\right) \\
& \widehat{P I}_{t}^{T}=\left[\begin{array}{c}
\left(\frac{\bar{P}^{I} \bar{I}_{H}}{\overline{P I}^{T} \bar{T}^{T}}\right) \widehat{P}_{t}^{I}+\left(\frac{\overline{F P}^{I} \bar{I}_{F}}{\overline{P I}^{T} \bar{T}^{T}}\right) \widehat{F P}_{t}^{I}+ \\
\left(\frac{W P^{I} \bar{I}_{W}}{\overline{P I}^{T} \bar{I}^{T}}\right)\left(\widehat{W P}_{t}^{I}-\widehat{s}_{t}\right)
\end{array}\right] \\
& \widehat{y}_{t}^{T}=\left(\frac{\bar{y}^{T C}}{\bar{y}^{T}}\right) \widehat{y}_{t}^{T C}+\left(\frac{\bar{y}^{T I}}{\bar{y}^{T}}\right) \widehat{y}_{t}^{T I} \\
& \widehat{y}_{t}^{T C}=\left[\left(\frac{\bar{c}_{H}}{\bar{y}^{T C}}\right) \widehat{c}_{H, t}+\left(\frac{\overline{F c}_{H}}{\bar{y}^{T C}}\right) \widehat{F c}_{H, t}+\left(\frac{\overline{W c}_{H}}{\bar{y}^{T C}}\right) \widehat{W c}_{H, t}\right] \\
& \widehat{y}_{t}^{T I}=\left[\left(\frac{\bar{I}_{H}}{\bar{y}^{T I}}\right) \widehat{I}_{H, t}+\left(\frac{\overline{F I}_{H}}{\bar{y}^{T I}}\right) \widehat{F I}_{H, t}+\left(\frac{\overline{W I}_{H}}{\bar{y}^{T I}}\right) \widehat{W I}_{H, t}\right] \\
& \left(\widehat{\pi}_{t}^{C}-\xi^{P} \widehat{\pi}_{t-1}^{C}\right)=\left[\begin{array}{c}
\beta\left(\widehat{\pi}_{t+1}^{C}-\xi^{P} \widehat{\pi}_{t}^{C}\right) \\
+\left(\frac{(1-\beta \theta)(1-\theta)}{\theta}\right)\left(\widehat{m c}_{t}^{T}+\widehat{P}_{t}^{T}-\widehat{P}_{t}^{C}\right)
\end{array}\right] \\
& \left(\widehat{\pi}_{t}^{I}-\xi^{P} \widehat{\pi}_{t-1}^{I}\right)=\left[\begin{array}{c}
\beta\left(\widehat{\pi}_{t+1}^{I}-\xi^{P} \widehat{\pi}_{t}^{I}\right) \\
+\left(\frac{(1-\beta \theta)(1-\theta)}{\theta}\right)\left(\widehat{m c}_{t}^{T}+\widehat{P}_{t}^{T}-\widehat{P}_{t}^{I}\right)
\end{array}\right]
\end{aligned}
$$

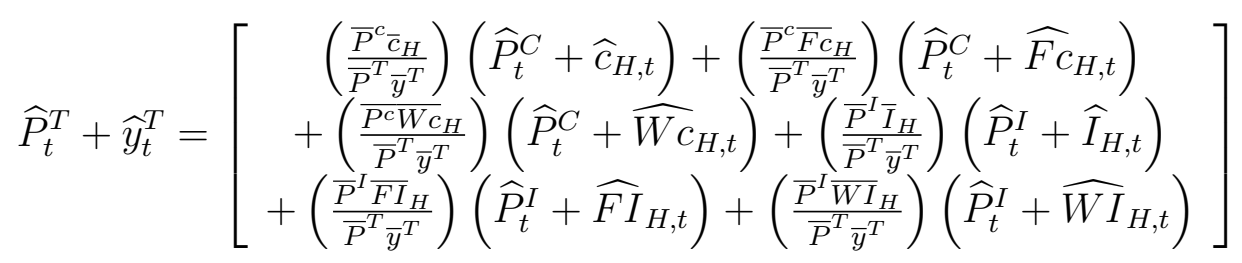

$$
\begin{aligned}
& \widehat{y}_{t}^{T}=\widetilde{\alpha}^{T} \widehat{O}_{t}^{T}+\left(1-\widetilde{\alpha}^{T}\right)\left[\alpha_{T}\left(\widehat{c u}_{t}^{T}+\widehat{k}_{t}^{T}\right)+\left(1-\alpha_{T}\right)\left(\widehat{z}_{t}+\widehat{z}_{t}^{T}+\widehat{n}_{t}^{T}\right)\right]
\end{aligned}
$$

where $\widetilde{\alpha}^{T}=\varkappa_{T}^{\frac{\psi^{T}}{\psi^{T}-1}}\left(\frac{\bar{Q}^{T}}{\bar{y}^{T}}\right)^{\frac{\psi^{T}-1}{\psi^{T}}}$

$$
\widehat{m c}_{t}^{T}+\left(1+\bar{\alpha}^{T}\right) \widehat{y}_{t}^{T}-\widehat{n}_{t}^{T}-\bar{\alpha}^{T} \widehat{O}_{t}^{T}=\widehat{W}_{t}-\widehat{P}_{t}^{T}
$$




$$
\widehat{m c}_{t}^{T}+\left(1+\bar{\alpha}^{T}\right) \widehat{y}_{t}^{T}-\widehat{k}_{t}^{T}-\bar{\alpha}^{T} \widehat{O}_{t}^{T}=\widehat{r}_{t}+\widehat{P C}_{t}-\widehat{P}_{t}^{T}
$$

where $\bar{\alpha}^{T}=\frac{\widetilde{\alpha}^{T}}{\left(1-\widetilde{\alpha}^{T}\right)} \frac{\psi^{T}}{\left(\psi^{T}-1\right)}$

$$
\begin{gathered}
\widehat{m c}_{t}^{T}+\frac{1}{\psi^{T}} \widehat{y}_{t}^{T}-\frac{1}{\psi^{T}} \widehat{O}_{t}^{T}=\left(\widehat{P}_{t}^{o i l}-\widehat{s}_{t}\right)-\widehat{P}_{t}^{T} \\
\widehat{m c}_{t}^{T}+\left(1+\bar{\alpha}^{T}\right) \widehat{y}_{t}^{T}-\bar{\alpha}^{T} \widehat{O}_{t}^{T}=\Upsilon \widehat{c u}_{t}^{T}
\end{gathered}
$$

where $\Upsilon=\left(1+\frac{\overline{c u} f^{\prime}(\overline{c u})}{f^{\prime}(\overline{c u})}\right)>0$

$$
\begin{aligned}
& \widehat{v a}_{t}^{T}=\left(\frac{\bar{y}^{T}}{\overline{v a}^{T}}\right) \widehat{y}_{t}^{T}-\left(\frac{\bar{O}^{T}}{\overline{v a}^{T}}\right) \widehat{O}_{t}^{T} \\
& \widehat{P v}_{t}^{T}+\widehat{v a}_{t}^{T}=\left[\begin{array}{c}
\left(\frac{\bar{P}^{T} \bar{y}^{T}}{\overline{P v}^{T} \overline{v a}^{T}}\right)\left(\widehat{P}_{t}^{T}+\widehat{y}_{t}^{T}\right) \\
-\left(\frac{\bar{P}^{O i l} \bar{O}^{T}}{\overline{P v}^{T} \overline{v a}}\right)^{T}\left(\left(\widehat{P}_{t}^{O i l}-\widehat{s}_{t}\right)+\widehat{O}_{t}^{T}\right)
\end{array}\right] \\
& \widehat{y}_{t}^{N}=\left(\frac{\bar{y}^{N C}}{\bar{y}^{N}}\right) \widehat{y}_{t}^{N C}+\left(\frac{\bar{y}^{N I}}{\bar{y}^{N}}\right) \widehat{y}_{t}^{N I} \\
& \widehat{y}_{t}^{N C}=\left(\frac{\bar{c}^{N}}{\bar{y}^{N C}}\right) \widehat{c}_{t}^{N}+\left(\frac{\bar{g}}{\bar{y}^{N C}}\right) \widehat{g}_{t} \\
& \widehat{y}_{t}^{N I}=\widehat{I}_{t}^{N} \\
& \left(\widehat{\pi}_{t}^{C N}-\xi^{P} \widehat{\pi}_{t-1}^{C N}\right)=\left[\begin{array}{c}
\beta\left(\widehat{\pi}_{t+1}^{C N}-\xi^{P} \widehat{\pi}_{t}^{C N}\right) \\
+\left(\frac{(1-\beta \theta)(1-\theta)}{\theta}\right)^{N}\left(\widehat{m c}_{t}^{N}+\widehat{P}_{t}^{N}-\widehat{P} C_{t}^{N}\right)
\end{array}\right] \\
& \left(\widehat{\pi}_{t}^{I N}-\xi^{P} \widehat{\pi}_{t-1}^{I N}\right)=\left[\begin{array}{c}
\beta\left(\widehat{\pi}_{t+1}^{I N}-\xi^{P} \widehat{\pi}_{t}^{I N}\right) \\
+\left(\frac{(1-\beta \theta)(1-\theta)}{\theta}\right)^{N}\left(\widehat{m c}_{t}^{N}+\widehat{P}_{t}^{N}-\widehat{P} I_{t}^{N}\right)
\end{array}\right] \\
& \widehat{P}_{t}^{N}+\widehat{y}_{t}^{N}=\left[\begin{array}{c}
\left(\frac{\overline{P C}^{N} \bar{c}^{N}}{\bar{P}^{N} \bar{y}^{N}}\right)\left(\widehat{P C}_{t}^{N}+\widehat{c}_{t}^{N}\right)+\left(\frac{\overline{P I}^{N} \bar{I}^{N}}{\bar{P}^{N} \bar{y}^{N}}\right)\left(\widehat{P I}_{t}^{N}+\widehat{I}_{t}^{N}\right) \\
+\left(\frac{\bar{P}^{N} \bar{g}}{\bar{P}^{N} \bar{y}^{N}}\right)\left(\widehat{P}_{t}^{N}+\widehat{g}_{t}\right)
\end{array}\right] \\
& \widehat{y}_{t}^{N}=\widetilde{\alpha}^{N} \widehat{O}_{t}^{N}+\left(1-\widetilde{\alpha}^{N}\right)\left[\alpha_{N}\left(\widehat{c u}_{t}^{N}+\widehat{k}_{t}^{N}\right)+\left(1-\alpha_{N}\right)\left(\widehat{z}_{t}+\widehat{z}_{t}^{N}+\widehat{n}_{t}^{N}\right)\right]
\end{aligned}
$$


where $\widetilde{\alpha}^{N}=\varkappa_{N}^{\frac{\psi^{N}}{\psi^{N}-1}}\left(\frac{\bar{O}^{N}}{\bar{y}^{N}}\right)^{\frac{\psi^{N}-1}{\psi^{N}}}$

$$
\begin{gathered}
\widehat{m c}_{t}^{N}+\left(1+\bar{\alpha}^{N}\right) \widehat{y}_{t}^{N}-\widehat{n}_{t}^{N}-\bar{\alpha}^{N} \widehat{O}_{t}^{N}=\widehat{W}_{t}-\widehat{P}_{t}^{N} \\
\widehat{m c}_{t}^{N}+\left(1+\bar{\alpha}^{N}\right) \widehat{y}_{t}^{N}-\widehat{k}_{t}^{N}-\bar{\alpha}^{T} \widehat{O}_{t}^{N}=\widehat{r}_{t}+\widehat{P C}_{t}-\widehat{P}_{t}^{N}
\end{gathered}
$$

where $\bar{\alpha}^{N}=\frac{\widetilde{\alpha}^{N}}{\left(1-\widetilde{\alpha}^{N}\right)} \frac{\psi^{N}}{\left(\psi^{N}-1\right)}$

$$
\begin{aligned}
& \widehat{m c}_{t}^{N}+\frac{1}{\psi^{N}} \widehat{y}_{t}^{N}-\frac{1}{\psi^{N}} \widehat{O}_{t}^{N}=\left(\widehat{P}_{t}^{o i l}-\widehat{s}_{t}\right)-\widehat{P}_{t}^{N} \\
& \widehat{m c}_{t}^{N}+\left(1+\bar{\alpha}^{N}\right) \widehat{y}_{t}^{N}-\bar{\alpha}^{N} \widehat{O}_{t}^{N}=\Upsilon \widehat{c u}_{t}^{N} \\
& \widehat{v a}_{t}^{N}=\left(\frac{\bar{y}^{N}}{\overline{v a}^{N}}\right) \widehat{y}_{t}^{N}-\left(\frac{\bar{O}^{N}}{\overline{v a}^{N}}\right) \widehat{O}_{t}^{N} \\
& \widehat{P v}_{t}^{N}+\widehat{v a}_{t}^{N}=\left[\begin{array}{c}
\left(\frac{\bar{P}^{N} \bar{y}^{N}}{\overline{P v}^{N} \overline{v a}}\right)\left(\widehat{P}_{t}^{N}+\widehat{y}_{t}^{N}\right) \\
-\left(\frac{\bar{P}^{O i l} \bar{O}^{N}}{\overline{P v}^{N} \overline{v a}}\right)^{N}\left(\left(\widehat{P}_{t}^{O i l}-\widehat{s}_{t}\right)+\widehat{O}_{t}^{N}\right)
\end{array}\right] \\
& \left(\widehat{\pi}_{t}^{D}-\xi^{P} \widehat{\pi}_{t-1}^{D}\right)=\left[\begin{array}{c}
\beta\left(\widehat{\pi}_{t+1}^{D}-\xi^{P} \widehat{\pi}_{t}^{D}\right) \\
+\left(\frac{(1-\beta \theta)(1-\theta)}{\theta}\right) \widehat{m c}_{t}^{D}
\end{array}\right] \\
& \widehat{y}_{t}^{D}=\alpha_{D}\left(\widehat{c u}_{t}^{D}+\widehat{k}_{t}^{D}\right)+\left(1-\alpha_{D}\right)\left(\widehat{z}_{t}+\widehat{z}_{t}^{D}+\widehat{n}_{t}^{D}\right) \\
& \widehat{m c}_{t}^{D}+\widehat{y}_{t}^{D}-\widehat{n}_{t}^{D}=\widehat{W}_{t}-\widehat{P}_{t}^{D} \\
& \widehat{m c}_{t}^{D}+\widehat{y}_{t}^{D}-\widehat{k}_{t}^{D}=\widehat{r}_{t}+\widehat{P C}_{t}-\widehat{P}_{t}^{D} \\
& \widehat{m c}_{t}^{D}+\widehat{y}_{t}^{D}=\Upsilon \widehat{c u}{ }_{t}^{D} \\
& \widehat{k}_{t-1}=\left(\frac{\bar{k}^{T}}{\bar{k}}\right) \widehat{k}_{t}^{T}+\left(\frac{\bar{k}^{N}}{\bar{k}}\right) \widehat{k}_{t}^{N}+\left(\frac{\bar{k}^{D}}{\bar{k}}\right) \widehat{k}_{t}^{D} \\
& \widehat{n}_{t}=\left(\frac{\bar{n}^{T}}{\bar{n}}\right) \widehat{n}_{t}^{T}+\left(\frac{\bar{n}^{N}}{\bar{n}}\right) \widehat{n}_{t}^{N}+\left(\frac{\bar{n}^{D}}{\bar{n}}\right) \widehat{n}_{t}^{D} \\
& \widehat{y}_{t}^{D}=\widehat{I}_{t}^{D} \\
& \widehat{y}_{t}=\left(\frac{\bar{y}^{N}}{\bar{y}}\right) \widehat{y}_{t}^{N}+\left(\frac{\bar{y}^{T}}{\bar{y}}\right) \widehat{y}_{t}^{T}+\left(\frac{\bar{y}^{D}}{\bar{y}}\right) \widehat{y}_{t}^{D}
\end{aligned}
$$




$$
\begin{aligned}
& \widehat{P}_{t}+\widehat{y}_{t}=\left(\frac{\bar{P}^{N} \bar{y}^{N}}{\bar{P} \bar{y}}\right)\left(\widehat{P}_{t}^{N}+\widehat{y}_{t}^{N}\right)+\left(\frac{\bar{P}^{T} \bar{y}^{T}}{\bar{P} \bar{y}}\right)\left(\widehat{P}_{t}^{T}+\widehat{y}_{t}^{T}\right) \\
& +\left(\frac{\bar{P}^{D} \bar{y}^{D}}{\bar{P} \bar{y}}\right)\left(\widehat{P}_{t}^{D}+\widehat{y}_{t}^{D}\right) \\
& \widehat{v a}_{t}=\left(\frac{\overline{v a}^{N}}{\overline{v a}}\right) \widehat{v a}_{t}^{N}+\left(\frac{\overline{v a}^{T}}{\overline{v a}}\right) \widehat{v a}_{t}^{T}+\left(\frac{\bar{y}^{D}}{\overline{v a}}\right) \widehat{y}_{t}^{D} \\
& \widehat{P v}_{t}+\widehat{v a}_{t}=\left(\frac{\overline{P v}^{N} \overline{v a}^{N}}{\overline{P v} \overline{v a}}\right)\left(\widehat{P v}_{t}^{N}+\widehat{v a}_{t}^{N}\right)+\left(\frac{\overline{P v}^{T} \overline{v a}^{T}}{\overline{P v} \overline{v a}}\right)\left(\widehat{P v}_{t}^{T}+\widehat{v a}_{t}^{T}\right) \\
& +\left(\frac{\bar{P}^{D} \bar{y}^{D}}{\overline{P v} \overline{v a}}\right)\left(\widehat{P}_{t}^{D}+\widehat{y}_{t}^{D}\right)
\end{aligned}
$$

assuming $s=1, \bar{a}=0$, defining $a_{t}=\frac{A_{t}}{P v_{t} v a_{t}}$ and $\gamma_{v a}=\left(\frac{\overline{v a_{t+1}}}{v a_{t}}\right)$ define $a_{t}=\frac{A_{t}}{P v_{t} v a_{t}}$

$$
\begin{aligned}
& a_{t}=a_{t-1} \frac{W R}{\gamma_{v a} \pi^{V A}}+\frac{\bar{P}^{X} \bar{X}}{\overline{P v} \overline{v a}}\left(\widehat{P}_{t}^{X}-\widehat{P}_{t}^{M}+\widehat{X}_{t}-\widehat{M}_{t}\right) \\
& \widehat{\pi}_{t}^{V A}=\widehat{P v}_{t}-\widehat{P v}_{t-1} \\
& \widehat{\pi}_{t}^{C}=\widehat{P}_{t}^{C}-\widehat{P}_{t-1}^{C} \\
& \widehat{\pi}_{t}^{I P C}=\widehat{P C}_{t}-\widehat{P C}_{t-1} \\
& \widehat{\pi}_{t}^{C N}=\widehat{P}_{t}^{C N}-\widehat{P}_{t-1}^{C N} \\
& \widehat{\pi}_{t}^{I}=\widehat{P}_{t}^{I}-\widehat{P}_{t-1}^{I} \\
& \widehat{\pi}_{t}^{I P}=\widehat{P I}_{t}^{P}-\widehat{P I}_{t-1}^{P} \\
& \widehat{\pi}_{t}^{I N}=\widehat{P}_{t}^{I N}-\widehat{P}_{t-1}^{I N} \\
& \widehat{\pi}_{t}^{D}=\widehat{P}_{t}^{D}-\widehat{P}_{t-1}^{D} \\
& \widehat{\pi}_{t}^{w}=\widehat{W}_{t}-\widehat{W}_{t-1} \\
& \widehat{w}_{t}=\widehat{W}_{t}-\widehat{P}_{t} \\
& \widehat{M}_{t}=\left[\begin{array}{c}
\left(\frac{\bar{c}_{F}}{\bar{M}}\right) \widehat{c}_{F, t}+\left(\frac{\bar{I}_{F}}{\bar{M}}\right) \widehat{I}_{F, t} \\
+\left(\frac{\bar{c}_{W}}{\bar{M}}\right) \widehat{c}_{W, t}+\left(\frac{\bar{I}_{W}}{\bar{M}}\right)\left(\widehat{I}_{W, t}\right) \\
+\left(\frac{\bar{c}^{o i l}}{\bar{M}}\right) \widehat{c}_{t}^{o i l}+\left(\frac{\bar{O}^{T}}{\bar{M}}\right) \widehat{O}_{t}^{T}+\left(\frac{\bar{O}^{N}}{\bar{M}}\right)\left(\widehat{O}_{t}^{N}\right)
\end{array}\right] \\
& \widehat{X}_{t}=\left[\begin{array}{l}
\left(\frac{\overline{F c}_{H}}{\bar{X}}\right) \widehat{F c}_{H, t}+\left(\frac{\overline{F I}_{H}}{\bar{X}}\right) \widehat{F I}_{H, t}+ \\
\left(\frac{\overline{W c}_{H}}{\bar{X}}\right) \widehat{W C}_{H, t}+\left(\frac{\overline{W I}_{H}}{\bar{X}}\right) \widehat{W I}_{H, t}
\end{array}\right]
\end{aligned}
$$




$$
\begin{aligned}
& \widehat{P}_{t}^{M}+\widehat{M}_{t}=\left[\begin{array}{c}
\left(\frac{\overline{F P}^{c} \bar{c}_{F}}{\bar{P}^{M} \bar{M}}\right)\left(\widehat{F P}_{t}^{C}+\widehat{c}_{F, t}\right)+\left(\frac{\overline{F P}^{I} \bar{I}_{F}}{\bar{P}^{M} \bar{M}}\right)\left(\widehat{F P}_{t}^{I}+\widehat{I}_{F, t}\right) \\
+\left(\frac{\overline{W P}^{c} \bar{c}_{W}}{\bar{P}^{M} \bar{M}}\right)\left(\left(\widehat{W P}_{t}^{C}-\widehat{s}_{t}\right)+\widehat{c}_{W, t}\right) \\
+\left(\frac{\overline{W P}^{I} \bar{I}_{W}}{\bar{P}^{M} \bar{M}}\right)\left(\left(\widehat{W P}_{t}^{I}-\widehat{s}_{t}\right)+\widehat{I}_{W, t}\right) \\
+\left(\frac{\bar{P}^{\text {oil }} \bar{O}^{T}}{\bar{P}^{M} \bar{M}}\right)\left(\left(\widehat{P}_{t}^{o i l}-\widehat{s}_{t}\right)+\widehat{O}_{t}^{T}\right) \\
+\left(\frac{\bar{P}^{\text {oil }} \bar{O}^{N}}{\bar{P}^{M} \bar{M}}\right)\left(\left(\widehat{P}_{t}^{o i l}-\widehat{s}_{t}\right)+\widehat{O}_{t}^{N}\right) \\
+\left(\frac{\bar{P}_{\text {oil }} \bar{c}^{\text {oil }}}{\bar{P}^{M} \bar{M}}\right)\left(\left(\widehat{P}_{t}^{\text {oil }}-\widehat{s}_{t}\right)+\widehat{c}_{t}^{o i l}\right)
\end{array}\right] \\
& \widehat{P}_{t}^{X}+\widehat{X}_{t}=\left[\begin{array}{c}
\left(\frac{\bar{P}^{C} \overline{F c}_{H}}{\bar{P}^{X} \bar{X}}\right)\left(\widehat{P}_{t}^{C}+\widehat{F c}_{H, t}\right) \\
+\left(\frac{\bar{P}^{I} \overline{\overline{F I}_{H}}}{\bar{P}^{X} \bar{X}}\right)\left(\widehat{P}_{t}^{I}+\widehat{F I}_{H, t}\right) \\
+\left(\frac{\bar{P}^{C} \overline{W c}_{H}}{\bar{P}^{X} \bar{X}}\right)\left(\widehat{P}_{t}^{C}+\widehat{W c}_{H, t}\right) \\
+\left(\frac{\bar{P}^{I} \overline{W I}_{H}}{\bar{P}^{X} \bar{X}}\right)\left(\widehat{P}_{t}^{I}+\widehat{W I}_{H, t}\right)
\end{array}\right]
\end{aligned}
$$

$$
\begin{aligned}
& \left(\frac{\bar{b}}{\bar{R}}\right) E_{t}\left[\widehat{b}_{t}-\widehat{R}_{t}\right] \\
& =\left[\begin{array}{c}
\left(\frac{\bar{b}}{\gamma^{v a} \bar{\pi}}\right)\left(\widehat{b}_{t-1}-\widehat{v a}_{t}+\widehat{v a}_{t-1}-\widehat{\pi}_{t}^{V A}\right)+ \\
\left(\frac{\bar{P}}{\overline{P v}} \frac{\bar{g}}{\overline{v a}}\right)\left[\widehat{g}_{t}+\widehat{P}_{t}^{N}-\widehat{P v}_{t}-\widehat{v a}_{t}\right] \\
-\left(\frac{\overline{P C}}{\overline{P v}} \frac{\bar{T}}{\overline{v a}}\right)\left(\widehat{T}_{t}-\widehat{v a}_{t}+\widehat{P C}_{t}-\widehat{P v}_{t}\right) \\
-\tau_{k} \bar{r}\left(\frac{\bar{k}}{\overline{v a}} \frac{\overline{P C}}{\overline{P v}}\right)\left(\widehat{r}_{t}+\widehat{k}_{t}-\widehat{v a}_{t}+\widehat{P C}_{t}-\widehat{P v}_{t}\right) \\
-\left(\tau_{w} \frac{\bar{n}}{\overline{v a}} \frac{\overline{P C}}{\overline{P v}} \frac{\bar{W}}{\overline{P C}}\right)\left[\widehat{W}_{t}-\widehat{P v}_{t}+\widehat{n}_{t}-\widehat{v a}_{t}\right] \\
-\tau_{c}\left(\frac{\overline{P C}}{\overline{P v}} \frac{\bar{c}}{\overline{v a}}\right)\left(\widehat{c}_{t}-\widehat{v a}_{t}+\widehat{P C}_{t}-\widehat{P v}_{t}\right)
\end{array}\right] \\
& \widehat{T}_{t}-\widehat{v a}_{t}=\left(\frac{T_{1}}{(\bar{T} / \overline{v a})}\right) \widehat{b b}_{t} \\
& \widehat{R}_{t}=\left[\begin{array}{c}
\rho_{R} \widehat{R}_{t-1}+\left(\frac{\left(1-\rho_{R}\right) \rho_{\pi}}{2}\right)\left(\widehat{\pi}_{t}^{V A}+\widehat{F \pi}_{t}^{V A}\right) \\
+\left(\frac{\left(1-\rho_{R}\right) \rho_{V A}}{2}\right)\left(\widehat{v a}_{t}+\widehat{F v a}_{t}\right)+\varepsilon_{t}^{R}
\end{array}\right] \\
& \widehat{F \lambda}_{t}=E_{t} \widehat{F \lambda}_{t+1}+\widehat{R}_{t}-E_{t} \widehat{F \pi}_{t+1}^{I P C}-\Psi F a_{t-1}
\end{aligned}
$$


(assuming a first order autoregressive process for $F \varepsilon^{a}$ with root $\rho_{F a}$ )

$$
\begin{aligned}
& \widehat{F \lambda}_{t}=\left[\begin{array}{c}
\frac{(\sigma-1) \gamma}{1-\beta \gamma}\left(\widehat{F c}_{t-1}+\beta E_{t} \widehat{F c}_{t+1}\right) \\
-\frac{\left(\sigma+(\sigma-1) \beta \gamma^{2}-\beta \gamma\right)}{1-\beta \gamma} \widehat{F c}_{t}+\frac{1-\beta \gamma \rho_{F a}}{1-\beta \gamma} \widehat{F \varepsilon}_{t}^{a}
\end{array}\right] \\
& \widehat{F \pi}_{t}^{w}-\xi^{W} \widehat{F d}_{t}=\left[\begin{array}{c}
\beta E_{t}\left\{\left(\widehat{F \pi}_{t+1}^{w}-\xi^{W} \widehat{F \pi}_{t}^{I P C}\right)\right\} \\
-\frac{\left(1-\beta \theta_{w}\right)\left(1-\theta_{w}\right)}{\theta_{w}\left(1+\varphi \varepsilon_{w}\right)}\left(\widehat{F w}_{t}-\widehat{F M R S_{t}}\right)
\end{array}\right] \\
& \widehat{F M R} S_{t}=\widehat{F \varepsilon}_{t}^{a}+\varphi \widehat{F n}_{t}-\widehat{F \lambda}_{t} \\
& \widehat{F q}_{t}=-F \Phi^{\prime \prime} \delta\left(\widehat{F I}_{t}^{P}-\widehat{F k}_{t-1}\right) \\
& \widehat{F q}_{t}=\widehat{F \lambda}_{t}^{k}+\widehat{F P C}_{t}-\widehat{F \lambda}_{t}-\widehat{F P I}_{t}^{P} \\
& \widehat{F q}_{t}=\left[\begin{array}{c}
E_{t}\left(\widehat{F \lambda}_{t+1}-\widehat{F \lambda}_{t}+\widehat{F \pi}_{t+1}^{I P}-\widehat{F \pi}_{t+1}^{I P C}\right)+ \\
\left(1-(1-\delta) \beta \frac{\overline{F \pi}^{I P}}{\overline{F \pi}^{I P C}}\right) E_{t}\left(\widehat{F P C}_{t+1}-\widehat{F P I}_{t+1}^{P}+\widehat{F r}_{t+1}\right)+ \\
\beta \frac{\overline{F \pi}^{I P}}{\overline{F r}^{I P C}}(1-\delta) E_{t} \widehat{F q}_{t+1}-\beta \frac{\overline{F \pi}^{I P}}{\overline{F \pi}^{I P C}} \delta^{2} F \Phi^{\prime \prime} E_{t}\left(\widehat{F I}_{t+1}^{P}-\widehat{F k}_{t}\right)
\end{array}\right] \\
& \widehat{F q}_{t}^{D}=-F \Phi_{D}^{\prime \prime} \delta_{D}\left(\widehat{F I}_{t}^{D}-\widehat{F D}_{t-1}\right) \\
& \widehat{F q}_{t}^{D}=\widehat{F \lambda}_{t}^{D}+\widehat{F P C}_{t}-\widehat{F \lambda}_{t}-\widehat{F P}_{t}^{D} \\
& \widehat{F q}_{t}^{D}=\left[\begin{array}{c}
E_{t}\left(\widehat{F \pi}_{t+1}^{D}-\widehat{F \pi}_{t+1}^{I P C}-\widehat{F \lambda}_{t}\right)+\left(1-\delta_{D}\right) \beta \frac{\overline{F \pi}^{D}}{\overline{F \pi}^{I P C}} E_{t} \widehat{F \lambda}_{t+1} \\
\left.\left(1-\delta_{D}\right) \beta \frac{\overline{F \pi}^{D}}{\overline{F \pi}^{I P C}}\right) E_{t}\left(\widehat{F P C}_{t+1}-\widehat{F P}_{t+1}^{D}+\rho_{F a} \widehat{F \varepsilon}_{t}^{a}\right)+ \\
\left(1-\delta_{D}\right) \beta \frac{\frac{F \pi}{F \pi}^{D}{ }^{I P C}}{E_{t}} \widehat{F}_{t+1}^{D}-\beta \frac{\overline{F \pi}^{D}}{\overline{F \pi}^{I P C}} \delta_{D}^{2} F \Phi_{D}^{\prime \prime} E_{t} \widehat{F I}_{t+1}^{D}- \\
{\left[\sigma^{D}\left(1-\beta \frac{\overline{F \pi}^{D}}{\overline{F \pi}^{I P C}}\left(1-\delta_{D}\right)\right)-\beta \frac{\overline{F \pi}^{D}}{\overline{F \pi}^{I P C}} \delta_{D}^{2} F \Phi_{D}^{\prime \prime}\right] E_{t} \widehat{F D}_{t}}
\end{array}\right] \\
& \widehat{F k}_{t+1}=(1-\delta) \widehat{F k}_{t-1}+\delta \widehat{F I}_{t}^{P} \\
& \widehat{F D}_{t+1}=\left(1-\delta_{D}\right) \widehat{F D}_{t-1}+\delta_{D} \widehat{F I}_{t}^{D} \\
& \widehat{F c_{t}}=\left[\left(F \omega_{C}^{N}\right)^{\frac{1}{\rho^{c}}}\left(\frac{\overline{F c}^{N}}{\overline{F c}}\right)^{\frac{\rho^{c}-1}{\rho^{c}}} \widehat{F c}_{t}^{N}+\left(F \omega_{C}^{T}\right)^{\frac{1}{\rho^{c}}}\left(\frac{\overline{F c}}{\overline{F c}}\right)^{\frac{\rho^{c}-1}{\rho^{c}}} \widehat{F}_{t}^{T}\right]
\end{aligned}
$$




$$
\begin{aligned}
& \widehat{F c}_{t}^{N}-\widehat{F c}_{t}^{T}=-\rho^{c}\left(\widehat{F P C}_{t}^{N}-\widehat{F P C}_{t}^{T}\right) \\
& \widehat{F P C}_{t}=\left(\frac{\overline{F P C}^{N} \overline{F c}^{N}}{\overline{F P C} \overline{F c}}\right) \widehat{F P C}_{t}^{N}+\left(\frac{\overline{F P C}^{T} \overline{F c}^{T}}{\overline{F P C} \overline{F c}}\right) \widehat{F P C}_{t}^{T}
\end{aligned}
$$

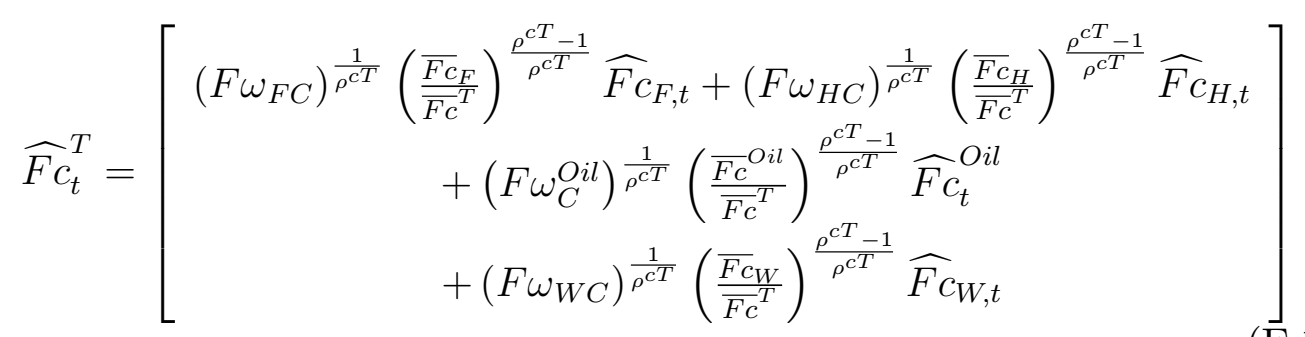

$$
\begin{aligned}
& \widehat{F C}_{H, t}-\widehat{F C}_{F, t}=-\rho^{c T}\left(\widehat{P}_{t}^{C}-\widehat{F P}_{t}^{C}\right) \\
& \widehat{F c}_{t}^{O i l}-\widehat{F C}_{F, t}=-\rho^{c T}\left(\widehat{P}_{t}^{O i l}-\widehat{F P}_{t}^{C}\right) \\
& \widehat{F C}_{W, t}-\widehat{F C}_{F, t}=-\rho^{c T}\left(\widehat{W P}_{t}^{C}-\widehat{F P}_{t}^{C}\right) \\
& \widehat{F P C}_{t}^{T}=\left[\begin{array}{c}
\left(\frac{\overline{F P}^{C} \overline{F c}_{F}}{\overline{F P C}^{T} \overline{F c}^{T}}\right) \widehat{F P}_{t}^{C}+\left(\frac{\bar{P}^{C} \overline{F c}_{H}}{\overline{F P C}^{T} \overline{F c}^{T}}\right) \widehat{P}_{t}^{C}+ \\
\left(\frac{\overline{W P}^{C} \overline{F c}_{W}}{\overline{F P C}^{T} \overline{F c}^{T}}\right)\left(\widehat{W P}_{t}^{C}-\widehat{s}_{t}\right)+\left(\frac{\bar{P}^{O i l i} \overline{F c}^{O i l}}{\overline{F P C}^{T} \overline{F c}^{T}}\right)\left(\widehat{P}_{t}^{O i l}-\widehat{s}_{t}\right)
\end{array}\right] \\
& \widehat{F I}_{t}=\left(F \omega_{I}^{P}\right)^{\frac{1}{\rho^{I}}}\left(\frac{\overline{F I}^{P}}{\overline{F I}}\right)^{\frac{\rho^{I}-1}{\rho^{I}}} \widehat{F I}_{t}^{P}+\left(F \omega_{I}^{D}\right)^{\frac{1}{\rho^{I}}}\left(\frac{\overline{F I}^{D}}{\overline{F I}}\right)^{\frac{\rho^{I}-1}{\rho^{I}}} \widehat{F I}_{t}^{D} \\
& \widehat{F P I}_{t}=\left(\frac{\overline{F P I}^{P} \overline{F I}^{P}}{\overline{F P I} \overline{F I}}\right) \widehat{F P I}_{t}^{P}+\left(\frac{\overline{F P}^{D} \overline{F I}^{D}}{\overline{F P I} \overline{F I}}\right) \widehat{F P}_{t}^{D} \\
& \widehat{F I}_{t}^{P}=\left(F \omega_{I}^{N}\right)^{\frac{1}{\rho^{I P}}}\left(\frac{\overline{F I}^{N}}{\overline{F I}^{P}}\right)^{\frac{\rho^{I P}-1}{\rho^{I P}}} \widehat{F I}_{t}^{N}+\left(F \omega_{I}^{T}\right)^{\frac{1}{\rho^{I P}}}\left(\frac{\overline{F I}^{T}}{\overline{F I}^{P}}\right)^{\frac{\rho^{I P}-1}{\rho^{I P}}} \widehat{F I}_{t}^{T} \\
& \widehat{F I}_{t}^{N}-\widehat{F I}_{t}^{T}=-\rho^{I P}\left(\widehat{F P I}_{t}^{N}-\widehat{F P I}_{t}^{T}\right) \\
& \widehat{F P I}_{t}^{P}=\left(\frac{\overline{F P I}^{N} \overline{F I}^{N}}{\overline{F P I}^{P} \overline{F I}^{P}}\right) \widehat{F P I}_{t}^{N}+\left(\frac{\overline{F P I}^{T} \overline{F I}^{T}}{\overline{F P I}^{P} \overline{F I}^{P}}\right) \widehat{F P I}_{t}^{T}
\end{aligned}
$$




$$
\begin{aligned}
& \widehat{F I}_{t}^{T}=\left[\begin{array}{c}
\left(F \omega_{F I}\right)^{\frac{1}{\rho^{I T}}}\left(\frac{\overline{F I}_{F}}{\overline{F I}^{T}}\right)^{\frac{\rho^{I T}-1}{\rho^{I T}}} \widehat{F I}_{F, t}+\left(F \omega_{H I}\right)^{\frac{1}{\rho^{I T}}}\left(\frac{\overline{F I}_{H}}{\overline{F I}^{T}}\right)^{\frac{\rho^{I T}-1}{\rho^{I T}}} \widehat{F I}_{H, t} \\
+\left(F \omega_{W I}\right)^{\frac{1}{\rho^{I T}}}\left(\frac{\overline{F I}_{W}}{\overline{F I}^{T}}\right)^{\frac{\rho^{I T}-1}{\rho^{I T}}} \widehat{F I}_{W, t}
\end{array}\right] \\
& \widehat{F I}_{H, t}-\widehat{F I}_{F, t}=-\rho^{I T}\left(\widehat{P}_{t}^{I}-\widehat{F P}_{t}^{I}\right) \\
& \widehat{F I}_{W, t}-\widehat{F I}_{F, t}=-\rho^{I T}\left(\left(\widehat{W P}_{t}^{I}-\widehat{s}_{t}\right)-\widehat{F P}_{t}^{I}\right) \\
& \widehat{F P I}_{t}^{T}=\left(\frac{\overline{F P I} \overline{F I}_{F}}{\overline{F P I}^{T} \overline{F I}^{T}}\right) \widehat{F P}_{t}^{I}+\left(\frac{\overline{P I} \overline{F I}_{H}}{\overline{F P I}^{T} \overline{F I}^{T}}\right) \widehat{P}_{t}^{I}+\left(\frac{\overline{W P I} \overline{F I}_{W}}{\overline{F P I}^{T} \overline{F I}^{T}}\right) \widehat{W P}_{t}^{I} \\
& \widehat{F y}_{t}^{T}=\left(\frac{\overline{F y}^{T C}}{\overline{F y}^{T}}\right) \widehat{F y}_{t}^{T C}+\left(\frac{\overline{F y}^{T I}}{\overline{F y}^{T}}\right) \widehat{F y}_{t}^{T I} \\
& \widehat{F y}_{t}^{T C}=\left[\left(\frac{\overline{F c}_{F}}{\overline{F y}^{T C}}\right) \widehat{F c}_{F, t}+\left(\frac{\bar{c}_{F}}{\overline{F y}^{T C}}\right) \widehat{c}_{F, t}+\left(\frac{\overline{W c}_{F}}{\overline{F y}^{T C}}\right) \widehat{W C}_{F, t}\right] \\
& \widehat{F y}_{t}^{T}=\left[\left(\frac{\overline{F I}_{F}}{\overline{F y}^{T I}}\right) \widehat{F I}_{F, t}+\left(\frac{\bar{I}_{F}}{\overline{F y}^{T I}}\right) \widehat{I}_{F, t}+\left(\frac{\overline{W I}_{F}}{\overline{F y}^{T I}}\right) \widehat{W I}_{F, t}\right] \\
& \left(\widehat{F \pi}_{t}^{C}-\xi^{P} \widehat{F \pi}_{t-1}^{C}\right)=\left[\begin{array}{c}
\beta\left(\widehat{F \pi}_{t+1}^{C}-\xi^{P} \widehat{F \pi}_{t}^{C}\right)+ \\
\left(\frac{(1-\beta \theta)(1-\theta)}{\theta}\right)\left(\widehat{F m c}_{t}^{T}+\widehat{F P}_{t}^{T}-\widehat{F P}_{t}^{C}\right)
\end{array}\right] \\
& \left(\widehat{F \pi}_{t}^{I}-\xi^{P} \widehat{F \pi}_{t-1}^{I}\right)=\beta\left(\widehat{F \pi}_{t+1}^{I}-\xi^{P} \widehat{F \pi}_{t}^{I}\right)+\left(\frac{(1-\beta \theta)(1-\theta)}{\theta}\right)\left(\widehat{F m c}_{t}^{T}+\widehat{F P}_{t}^{T}-\widehat{F P}_{t}^{I}\right) \\
& \widehat{F P}_{t}^{T}+\widehat{F y}_{t}^{T}=\left[\begin{array}{l}
\quad\left(\frac{\overline{F P}^{c} \overline{F c}_{F}}{\overline{F P}^{T} \overline{F y}^{T}}\right)\left(\widehat{F P}_{t}^{C}+\widehat{F c}_{F, t}\right)+\left(\frac{\overline{F P}^{c} \bar{c}_{F}}{\overline{F P}^{T} \overline{F y}^{T}}\right)\left(\widehat{F P}_{t}^{C}+\widehat{c}_{F, t}\right) \\
+\left(\frac{\overline{F P}^{c} \overline{W c}_{F}}{\overline{F P}^{T} \overline{F r}^{T}}\right)\left(\widehat{F P}_{t}^{C}+\widehat{W C}_{F, t}\right)+\left(\frac{\overline{F P}^{I} \overline{F I}_{F}}{\overline{F P}^{T} \overline{F y}}\right)\left(\widehat{F P}_{t}^{I}+\widehat{F I}_{F, t}\right) \\
+\left(\frac{\overline{F P}^{I} \bar{I}_{F}}{\overline{F P}^{T} \overline{F y}^{T}}\right)\left(\widehat{F P}_{t}^{I}+\widehat{I}_{F, t}\right)+\left(\frac{\overline{F P}^{I} \overline{W I}}{\overline{F P}^{T} \overline{F y}^{T}}\right)\left(\widehat{F P}_{t}^{I}+\widehat{W I}_{F, t}\right)
\end{array}\right] \\
& \widehat{F y}_{t}^{T}=\widetilde{F \alpha}^{T} \widehat{F O}_{t}^{T}+\left(1-\widetilde{F \alpha}^{T}\right)\left[\alpha_{T}\left(\widehat{F c u}_{t}^{T}+\widehat{F k}_{t}^{T}\right)+\left(1-\alpha_{T}\right)\left(\widehat{F z}_{t}+\widehat{F z}_{t}^{T}+\widehat{F n}_{t}^{T}\right)\right]
\end{aligned}
$$


where $\widetilde{\alpha}^{T}=\varkappa_{T}^{\frac{\psi^{T}}{\psi^{T}-1}}\left(\frac{\overline{F O}^{T}}{\overline{F y}^{T}}\right)^{\frac{\psi^{T}-1}{\psi^{T}}}$

$$
\begin{gathered}
\widehat{F m c}_{t}^{T}+\left(1+\overline{F \alpha}^{T}\right) \widehat{F y}_{t}^{T}-\widehat{F n}_{t}^{T}-\overline{F \alpha}^{T} \widehat{F O}_{t}^{T}=\widehat{F W}_{t}-\widehat{F P}_{t}^{T} \\
\widehat{F m c}_{t}^{T}+\left(1+\overline{F \alpha}^{T}\right) \widehat{F y}_{t}^{T}-\widehat{F k}_{t}^{T}-\overline{F \alpha}^{T} \widehat{F O}_{t}^{T}=\widehat{F r}_{t}+\widehat{F P C}_{t}-\widehat{F P}_{t}^{T}
\end{gathered}
$$

where $\overline{F \alpha}^{T}=\frac{\widetilde{F \alpha}^{T}}{\left(1-\widetilde{F \alpha}^{T}\right)} \frac{\psi^{T}}{\left(\psi^{T}-1\right)}$

$$
\begin{aligned}
& \widehat{F m c}_{t}^{T}+\frac{1}{\psi^{T}} \widehat{F y}_{t}^{T}-\frac{1}{\psi^{T}} \widehat{F O}_{t}^{T}=\left(\widehat{P}_{t}^{\text {oil }}-\widehat{s}_{t}\right)-\widehat{F P}_{t}^{T} \\
& \widehat{F m c}_{t}^{T}+\left(1+\bar{\alpha}^{T}\right) \widehat{F y}_{t}^{T}-\bar{\alpha}^{T} \widehat{F O}_{t}^{T}=\Upsilon \widehat{F c u}_{t}^{T} \\
& \widehat{F v a}_{t}^{T}=\left(\frac{\overline{F y}^{T}}{\overline{F v a}^{T}}\right) \widehat{F y}_{t}^{T}-\left(\frac{\overline{F O}^{T}}{\overline{F v a}^{T}}\right) \widehat{F O}_{t}^{T} \\
& \widehat{F P v}_{t}^{T}+\widehat{F v a}_{t}^{T}=\left[\begin{array}{c}
\left(\frac{\overline{F P}^{T} \overline{F y}^{T}}{\overline{F P v}^{T} \overline{F v a}^{T}}\right)\left(\widehat{F P}_{t}^{T}+\widehat{F y}_{t}^{T}\right) \\
-\left(\frac{\bar{P}^{O i l l} \overline{F O}^{T}}{\overline{F P v}^{T} \overline{F v a}^{T}}\right)\left(\left(\widehat{P}_{t}^{O i l}-\widehat{s}_{t}\right)+\widehat{F O}_{t}^{T}\right)
\end{array}\right] \\
& \widehat{F y}_{t}^{N}=\left(\frac{\overline{F y}^{N C}}{\overline{F y}^{N}}\right) \widehat{F y}_{t}^{N C}+\left(\frac{\overline{F y}^{N I}}{\overline{F y}^{N}}\right) \widehat{F y}_{t}^{N I} \\
& \widehat{F y}_{t}^{N C}=\left(\frac{\overline{F c}^{N}}{\overline{F y}^{N C}}\right) \widehat{F c}_{t}^{N}+\left(\frac{\overline{F g}}{\overline{F y}^{N C}}\right) \widehat{F g}_{t} \\
& \widehat{F y}_{t}^{N I}=\widehat{F I}_{t}^{N} \\
& \left(\widehat{F \pi}_{t}^{C N}-\xi^{P} \widehat{F \pi}_{t-1}^{C N}\right)=\left[\begin{array}{c}
\beta\left(\widehat{F \pi}_{t+1}^{C N}-\xi^{P} \widehat{F \pi}_{t}^{C N}\right) \\
+\left(\frac{(1-\beta \theta)(1-\theta)}{\theta}\right)\left(\widehat{F m c}_{t}^{N}+\widehat{F P}_{t}^{N}-\widehat{F P C}_{t}^{N}\right)
\end{array}\right] \\
& \left(\widehat{F \pi}_{t}^{I N}-\xi^{P} \widehat{F \pi}_{t-1}^{I N}\right)=\left[\begin{array}{c}
\beta\left(\widehat{F \pi}_{t+1}^{I N}-\xi^{P} \widehat{F \pi}_{t}^{I N}\right) \\
+\left(\frac{(1-\beta \theta)(1-\theta)}{\theta}\right)\left(\widehat{F m c}_{t}^{N}+\widehat{F P}_{t}^{N}-\widehat{F P I}_{t}^{N}\right)
\end{array}\right]
\end{aligned}
$$




$$
\begin{aligned}
& \widehat{F P}_{t}^{N}+\widehat{F y}_{t}^{N}=\left[\begin{array}{c}
\left(\frac{\overline{F P C}^{N} \overline{F c}^{N}}{\overline{F P}^{N} \overline{F y}^{N}}\right)\left(\widehat{F P C}_{t}^{N}+\widehat{F c}_{t}^{N}\right) \\
+\left(\frac{\overline{F P I}^{N} \overline{F I}^{N}}{\overline{F P}^{N} \overline{F y}^{N}}\right)\left(\widehat{F P I}_{t}^{N}+\widehat{F I}_{t}^{N}\right) \\
+\left(\frac{\overline{F P}^{N} \overline{F g}}{\overline{F P}^{N} \overline{F y}}\right)\left(\widehat{F P}_{t}^{N}+\widehat{F g}_{t}\right)
\end{array}\right] \\
& \widehat{F y}_{t}^{N}=\widetilde{F \alpha}^{N} \widehat{F O}_{t}^{N}+\left(1-\widetilde{F \alpha}^{N}\right)\left[\alpha_{N}\left(\widehat{F c u}_{t}^{N}+\widehat{F k}_{t}^{N}\right)+\left(1-\alpha_{N}\right)\left(\widehat{F z}_{t}+\widehat{F z}_{t}^{N}+\widehat{F n}_{t}^{N}\right)\right]
\end{aligned}
$$$$
\text { where } \widetilde{F \alpha}^{N}=\varkappa_{N}^{\frac{\psi^{N}}{\psi^{N}-1}}\left(\frac{\overline{F O}^{N}}{\overline{F y}^{N}}\right)^{\frac{\psi^{N}-1}{\psi^{N}}}
$$

$$
\begin{gathered}
\widehat{F m c}_{t}^{N}+\left(1+\overline{F \alpha}^{N}\right) \widehat{F y}_{t}^{N}-\widehat{F n}_{t}^{N}-\overline{F \alpha}^{N} \widehat{F O}_{t}^{N}=\widehat{F W}_{t}-\widehat{F P}_{t}^{N} \\
\widehat{F m c}_{t}^{N}+\left(1+\overline{F \alpha}^{N}\right) \widehat{F y}_{t}^{N}-\widehat{F k}_{t}^{N}-\overline{F \alpha}^{T} \widehat{O}_{t}^{N}=\widehat{F r}_{t}+\widehat{F P C}_{t}-\widehat{F P}_{t}^{N}
\end{gathered}
$$

where $\overline{F \alpha}^{N}=\frac{\widetilde{F \alpha}^{N}}{\left(1-\widetilde{F \alpha}^{N}\right)} \frac{\psi^{N}}{\left(\psi^{N}-1\right)}$

$$
\begin{aligned}
& \widehat{F m c}_{t}^{N}+\frac{1}{\psi^{N}} \widehat{F y}_{t}^{N}-\frac{1}{\psi^{N}} \widehat{F O}_{t}^{N}=\left(\widehat{P}_{t}^{o i l}-\widehat{s}_{t}\right)-\widehat{F P}_{t}^{N} \\
& \widehat{F m c}_{t}^{N}+\left(1+\bar{\alpha}^{N}\right) \widehat{F y}_{t}^{N}-\bar{\alpha}^{N} \widehat{F O}_{t}^{N}=\Upsilon \widehat{F c u}_{t}^{N} \\
& \widehat{F v a}_{t}^{N}=\left(\frac{\overline{F y}^{N}}{\overline{F v a}^{N}}\right) \widehat{F y}_{t}^{N}-\left(\frac{\overline{F O}^{N}}{\overline{F v a}^{N}}\right) \widehat{F O}_{t}^{N} \\
& \widehat{F P v}_{t}^{N}+\widehat{F v a}_{t}^{N}=\left[\begin{array}{c}
\left(\frac{\overline{F P}^{N} \overline{F y}^{N}}{\overline{F P v}^{N} \overline{F v a}^{N}}\right)\left(\widehat{F P}_{t}^{N}+\widehat{F y}_{t}^{N}\right) \\
-\left(\frac{\bar{P}^{O i l} \overline{F O}}{\overline{F P v}^{N} \overline{F v a}^{N}}\right)\left(\left(\widehat{P}_{t}^{O i l}-\widehat{s}_{t}\right)+\widehat{O}_{t}^{N}\right)
\end{array}\right] \\
& \left(\widehat{F \pi}_{t}^{D}-\xi^{P} \widehat{F \pi}_{t-1}^{D}\right)=\left[\begin{array}{l}
\beta\left(\widehat{F \pi}_{t+1}^{D}-\xi^{P} \widehat{F \pi}_{t}^{D}\right) \\
+\left(\frac{(1-\beta \theta)(1-\theta)}{\theta}\right) \widehat{F m c}_{t}^{D}
\end{array}\right] \\
& \widehat{F y}_{t}^{D}=\alpha_{D}\left(\widehat{F c u}_{t}^{D}+\widehat{F k}_{t}^{D}\right)+\left(1-\alpha_{D}\right)\left(\widehat{F z}_{t}+\widehat{F z}_{t}^{D}+\widehat{F n}_{t}^{D}\right) \\
& \widehat{F m c}_{t}^{D}+\widehat{F y}_{t}^{D}-\widehat{F n}_{t}^{D}=\widehat{F W}_{t}-\widehat{F P}_{t}^{D} \\
& \widehat{F m c}_{t}^{D}+\widehat{F y}_{t}^{D}-\widehat{F k}_{t}^{D}=\widehat{F r}_{t}+\widehat{F P C}_{t}-\widehat{F P}_{t}^{D}
\end{aligned}
$$




$$
\begin{aligned}
& \widehat{F m c}_{t}^{D}+\widehat{F y}_{t}^{D}=\Upsilon \widehat{F c u}_{t}^{D} \\
& \widehat{F k}_{t-1}=\left(\frac{\overline{F k}^{T}}{\overline{F k}}\right) \widehat{F k}_{t}^{T}+\left(\frac{\overline{F k}^{N}}{\overline{F k}}\right) \widehat{F k}_{t}^{N}+\left(\frac{\overline{F k}^{D}}{\overline{F k}}\right) \widehat{k}_{t}^{D} \\
& \widehat{F n}_{t}=\left(\frac{\overline{F n}^{T}}{\overline{F n}}\right) \widehat{F n}_{t}^{T}+\left(\frac{\overline{F n}^{N}}{\overline{F n}}\right) \widehat{F n}_{t}^{N}+\left(\frac{\overline{F n}^{D}}{\overline{F n}}\right) \widehat{F n}_{t}^{D} \\
& \widehat{F y}_{t}^{D}=\widehat{F I}_{t}^{D} \\
& \widehat{F y}_{t}=\left[\left(\frac{\overline{F y}^{N}}{\overline{F y}}\right) \widehat{F y}_{t}^{N}+\left(\frac{\overline{F y}^{T}}{\overline{F y}}\right) \widehat{F y}_{t}^{T}+\left(\frac{\overline{F y}^{D}}{\overline{F y}}\right) \widehat{F y}_{t}^{D}\right]
\end{aligned}
$$

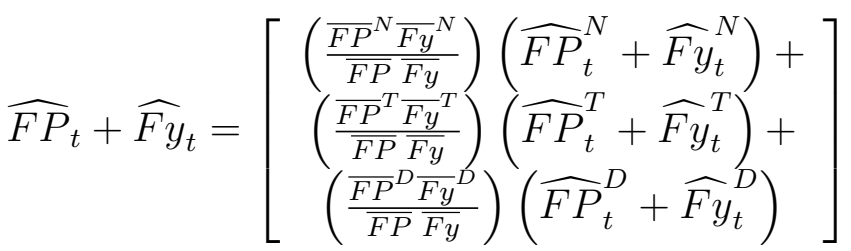

$$
\begin{aligned}
& \widehat{F v a}_{t}=\left(\frac{\overline{F v a}^{N}}{\overline{F v a}}\right) \widehat{F v a}_{t}^{N}+\left(\frac{\overline{F v a}^{T}}{\overline{F v a}}\right) \widehat{F v a}_{t}^{T}+\left(\frac{\overline{F y}^{D}}{\overline{F v a}}\right) \widehat{F y}_{t}^{D} \\
& \widehat{F P v}_{t}+\widehat{F v a}_{t}=\left[\begin{array}{c}
\left(\frac{\overline{F P v}^{N} \overline{F v a}^{N}}{\overline{F P v}}\right)\left(\widehat{F P v}_{t}^{N}+\widehat{F v a}_{t}^{N}\right)+ \\
\left(\frac{F \overline{F v}}{\overline{F v v a}}\right)\left(\widehat{F P v}_{t}^{T}+\widehat{F v a}_{t}^{T}\right)+ \\
\left(\frac{\overline{F v a}}{\overline{F P} D}\right)+\left(\widehat{F P}^{D}+\widehat{F y}^{D}\right)
\end{array}\right]
\end{aligned}
$$

assuming $\overline{F a}=0$,

$$
\begin{aligned}
F a_{t}=\left[\begin{array}{c}
F a_{t-1} \frac{W R}{F \gamma_{v a} F F^{V A}} W R+ \\
\frac{F^{X P}}{\overline{F P V} \bar{F}}\left(\widehat{F P}_{t}^{X}-\widehat{F P}_{t}^{M}+\widehat{F X}_{t}-\widehat{F M}_{t}\right)
\end{array}\right] \\
\widehat{F \pi}_{t}^{V A}=\widehat{F P v}_{t}-\widehat{F P v}_{t-1} \\
\widehat{F \pi}_{t}^{C}=\widehat{F P}_{t}^{C}-\widehat{F P}_{t-1}^{C} \\
\widehat{F \pi}_{t}^{I P C}=\widehat{F P C}_{t}-\widehat{F P C}_{t-1} \\
\widehat{F \pi}_{t}^{C N}=\widehat{F P}_{t}^{C N}-\widehat{F P}_{t-1}^{C N}
\end{aligned}
$$




$$
\begin{aligned}
& \widehat{F \pi}_{t}^{I}=\widehat{F P}_{t}^{I}-\widehat{F P}_{t-1}^{I} \\
& \widehat{F \pi}_{t}^{I P}=\widehat{F P I}_{t}^{P}-\widehat{F P I}_{t-1}^{P} \\
& \widehat{F \pi}_{t}^{I N}=\widehat{F P}_{t}^{I N}-\widehat{F P}_{t-1}^{I N} \\
& \widehat{F \pi}_{t}^{D}=\widehat{F P}_{t}^{D}-\widehat{F P}_{t-1}^{D} \\
& \widehat{F \pi}_{t}^{w}=\widehat{F W}_{t}-\widehat{F W}_{t-1} \\
& \widehat{F w}_{t}=\widehat{F W}_{t}-\widehat{F P}_{t} \\
& \widehat{F M}_{t}=\left[\begin{array}{c}
\left(\frac{\overline{F c}_{H}}{\overline{F M}}\right) \widehat{F c}_{H, t}+\left(\frac{\overline{F I}_{H}}{\overline{F M}}\right) \widehat{F I}_{H, t}+\left(\frac{\overline{F c}_{W}}{\overline{F M}}\right) \widehat{F c}_{W, t}+ \\
\left(\frac{\overline{F I}_{W}}{\overline{F M}}\right)\left(\widehat{F I}_{W, t}\right)+\left(\frac{\overline{F c}^{\text {oil }}}{\overline{F M}}\right) \widehat{F c}_{t}^{\text {oil }}+ \\
\left(\frac{\overline{F O}}{\overline{F M}}\right) \widehat{F O}_{t}^{T}+\left(\frac{\overline{F O}^{N}}{\overline{F M}}\right)\left(\widehat{F O}_{t}^{N}\right)
\end{array}\right] \\
& \widehat{F X}_{t}=\left[\begin{array}{c}
\left(\frac{\bar{c}_{F}}{\overline{F X}}\right) \widehat{c}_{F, t}+\left(\frac{\bar{I}_{F}}{\overline{F X}^{\prime}}\right) \widehat{I}_{F, t}+ \\
\left(\frac{\overline{W c}_{F}}{\overline{F X}}\right) \widehat{W c}_{F, t}+\left(\frac{\overline{W I}_{F}}{\overline{F X}}\right) \widehat{W I}_{F, t}
\end{array}\right]
\end{aligned}
$$

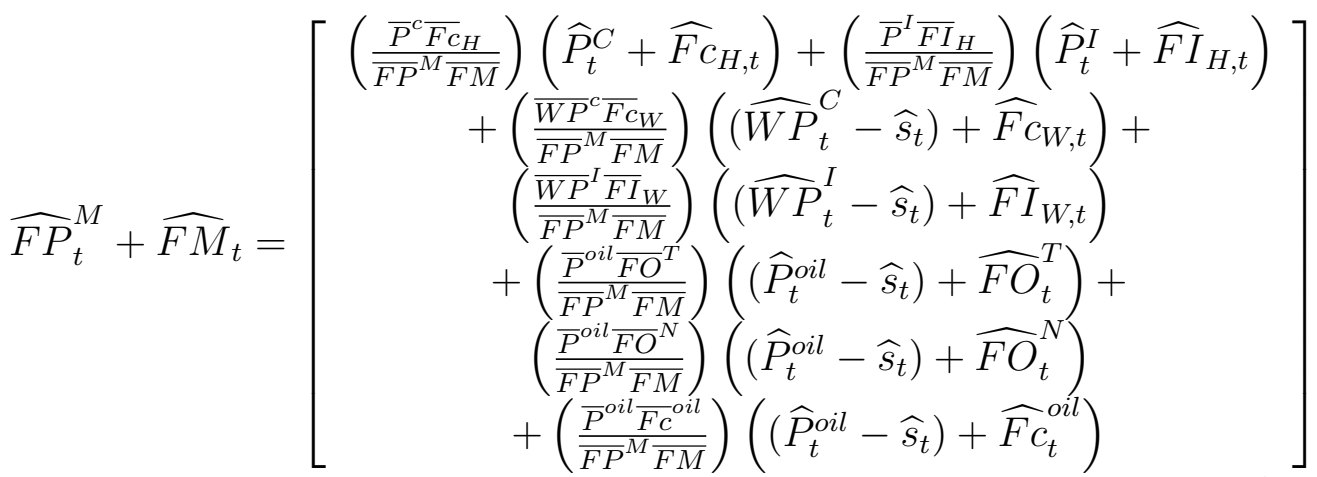

$$
\begin{aligned}
& \widehat{F P}_{t}^{X}+\widehat{F X}_{t}=\left[\begin{array}{c}
\left(\frac{\overline{F P}^{C} \bar{c}_{F}}{\overline{F P}^{X} \overline{F X}}\right)\left(\widehat{F P}_{t}^{C}+\widehat{c}_{F, t}\right)+\left(\frac{\overline{F P}^{I} \bar{I}_{F}}{\overline{F P}^{X} \overline{F X}^{\prime}}\right)\left(\widehat{F P}_{t}^{I}+\widehat{I}_{F, t}\right) \\
+\left(\frac{\overline{F P}^{C} \overline{W c}_{F}}{\overline{F P}^{X} \overline{F X}}\right)\left(\widehat{F P}_{t}^{C}+\widehat{W C}_{F, t}\right)+\left(\frac{\overline{F P}^{I} \overline{F I}_{F}}{\overline{F P}^{X} \overline{F X}}\right)\left(\widehat{F P}_{t}^{I}+\widehat{W I}_{F, t}\right)
\end{array}\right]
\end{aligned}
$$




$$
\begin{aligned}
& \left(\frac{\overline{F b}}{\bar{R}}\right) E_{t}\left[\widehat{F b}_{t}-\widehat{R}_{t}\right]
\end{aligned}
$$

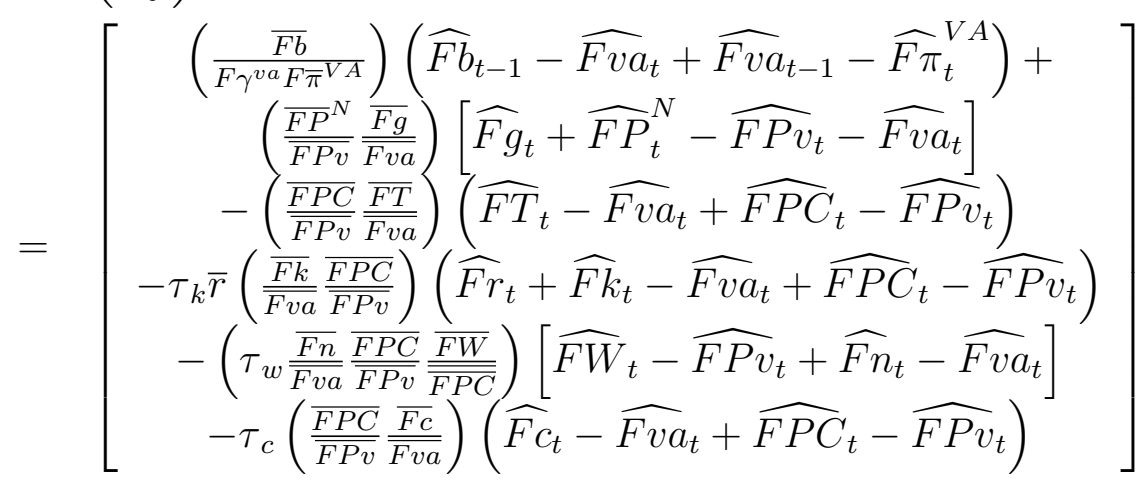

$$
\begin{aligned}
& \widehat{F T}_{t}-\widehat{F v a}_{t}=\left(\frac{F T_{1}}{(\overline{F T} / \overline{F v a})}\right) \overline{F b} \widehat{F b}_{t} \\
& \widehat{W c}_{H, t}-\widehat{W c}_{t}=-\rho^{W c}\left(\widehat{P}_{t}^{C}-\left(\widehat{W P}_{t}^{C}-\widehat{s}_{t}\right)\right) \\
& \widehat{W c}_{F, t}-\widehat{W c}_{t}=-\rho^{W c}\left(\widehat{F P}_{t}^{C}-\left(\widehat{W P}_{t}^{C}-\widehat{s}_{t}\right)\right) \\
& \widehat{W I}_{H, t}-\widehat{W I}_{t}=-\rho^{W I}\left(\widehat{P}_{t}^{I}-\left(\widehat{W P}_{t}^{I}-\widehat{s}_{t}\right)\right) \\
& \widehat{W I}_{F, t}-\widehat{W I}_{t}=-\rho^{W I}\left(\widehat{F P}_{t}^{I}-\left(\widehat{W P}_{t}^{I}-\widehat{s}_{t}\right)\right) \\
& \widehat{W c}_{t}=\widehat{\overline{W c}}_{t} \\
& \widehat{W I}_{t}=\widehat{\overline{W I}}_{t} \\
& \widehat{W P}_{t}^{C}=\widehat{\widehat{W P}}_{t}^{C} \\
& \widehat{W P}_{t}^{I}=\widehat{W P}_{t}^{I} \\
& \widehat{P}_{t}^{\text {Oil }}=\widehat{\widehat{P_{t}^{O i l}}} \\
& \frac{\overline{W P} \overline{W y}}{\overline{P y}} w a_{t+1}+a_{t+1}+\frac{\overline{F P} \overline{F y}}{\overline{P y}} F a_{t+1}=0 \\
& \widehat{W R}_{t}=\widehat{W R}_{t}
\end{aligned}
$$




\section{F. Appendix: Calibration values of parameters.}

Table 1. Calibration of the structural parameters

Parameter
$\beta$ (discount rate)
$\gamma$ (habits)
$\sigma$ (elast. of sub., cons.)
$\sigma_{D}$ (elast. of sub., housing)
$\varphi$ (elast. of sub., labor)
$\theta_{w}$ (prop. of hous. non-adjusting)
$\xi_{w}$ (degree of wage index.)
$\varepsilon_{w}$ (elast. of sub., varieties of labor)
$\delta$ (deprec. rate, prod . investment)
$\delta_{D}$ (deprec. rate, housing)
$\Phi^{\prime \prime}$ (adjust. costs, prod. invest.)
$\Phi_{D}^{\prime \prime}$ (adjust. costs, housing)
$\omega_{C}^{N}$ (share non-traded consumption goods)
$\omega_{H C}$ (share of home prod. traded cons. goods)
$\omega_{F C}$ (share of Euro-area prod.traded cons. goods)
$\omega_{C}^{O i l}$ (share of oil in traded consumption goods)
$\omega_{I}^{P}$ (share of productive invest. in total invest.)
$\omega_{I}^{N}$ (prod. invest. share, non-traded)
$\omega_{I}^{H}$ (traded prod. invest. share, home)
$\omega_{I}^{F}$ (traded prod. invest. share, Euro-area)

$\begin{array}{ccc}\text { Method } & \text { Home } & \text { Euro-area } \\ \text { Consensus } & 0.9927 & 0.9927 \\ \text { Consensus } & 0.7500 & 0.7500 \\ \text { Consensus } & 1.0000 & 1.0000 \\ \text { Consensus } & 1.0000 & 1.0000 \\ \text { Consensus } & 5.0000 & 5.0000 \\ \text { Consensus } & 0.7500 & 0.7500 \\ \text { Consensus } & 1.0000 & 1.0000 \\ \text { Consensus } & 6.0000 & 6.0000 \\ \text { Consensus } & 0.0250 & 0.0250 \\ \text { Consensus } & 0.0050 & 0.0050 \\ \text { Data moments } & -10.0000 & -10.0000 \\ \text { Data moments } & -100.0000 & -100.0000 \\ \text { Steady-state } & 0.5395 & 0.5395 \\ \text { Steady-state } & 0.5604 & 0.5604 \\ \text { Steady-state } & 0.2668 & 0.2668 \\ \text { Steady-state } & 0.0924 & 0.0924 \\ \text { Steady-state } & 0.8863 & 0.8863 \\ \text { Steady-state } & 0.4402 & 0.4402 \\ \text { Steady-state } & 0.4086 & 0.4086 \\ \text { Steady-state } & 0.4393 & 0.4393\end{array}$


Table 1. Calibration of the structural parameters (cont.) Parameter

$\rho^{c}$ (elast. of sub., cons.)

Method

Home Euro-area

$\rho^{c T}$ (elast. of sub., traded cons.)

Guess

$0.3333 \quad 0.3333$

$\rho^{I}$ (elast. of sub., invest.)

Guess

$0.3333 \quad 0.3333$

Guess

$0.3333 \quad 0.3333$

$\rho^{I P}$ (elast. of sub., prod. invest.)

Guess

$0.3333 \quad 0.3333$

$\rho^{I T}$ (elast. of sub., traded prod. invest.)

Guess

$0.3333 \quad 0.3333$

$\varkappa_{T}$ (param. of oil, traded prod.)

Guess

$1.4459 \quad 1.4459$

$\psi_{T}$ (elast. of sub., oil in traded prod.)

Guess

$0.9000 \quad 0.9000$

$\alpha_{T}$ (elast. of sub., cap. in traded va.)

Calibrated IOT

$0.6915 \quad 0.6801$

$\theta$ (prop. of backward-looking firms)

Consensus

$0.7500 \quad 0.7500$

$\varkappa_{N}$ (param. of oil, non-traded prod.)

Guess

$1.7735 \quad 1.7735$

$\psi_{N}$ (elast. of sub., oil in non-traded prod.)

$\alpha_{N}$ (elast. of sub., cap. in non-traded va.)

Guess

$0.9000 \quad 0.9000$

Calibrated IOT

$0.5259 \quad 0.5264$

$\xi^{P}$ (degree of inflation index.)

Consensus

$1.0000 \quad 1.0000$

$\alpha_{D}$ (elast. of sub., cap.l in housing prod.)

$\Upsilon^{T}$ (capital utilization, traded)

Calibrated IOT

Guess

$0.6445 \quad 0.6215$

$\Upsilon^{N}$ (capital utilization, non-traded)

Guess

$1.0000 \quad 1.0000$

$\Upsilon^{D}$ (capital utilization, housing)

Guess

$1.0000 \quad 1.0000$

$\tau_{k}$ (capital income tax rate)

$\tau_{c}$ (cons. tax rate)

$\tau_{w}$ (labor income tax rate)

$\Psi$ (portfolio adjustment costs)

Calibrated IOT

$1.0000 \quad 1.0000$

Calibrated IOT

$0.2658 \quad 0.1952$

Calibrated IOT

$0.1424 \quad 0.2168$

Guess

$\begin{array}{ll}0.3411 & 0.4007\end{array}$

$0.0010 \quad 0.0010$

$\rho_{R}$ (monetary rule, lag of interest rate)

Consensus

0.0000

$\rho_{\pi}$ (monetary rule, inflation)

Consensus

1.5000

$\rho_{v a}$ (monetary rule, output gap)

Consensus

0.0000 
Table 2. Calibration of the autoregresive parameters

Parameter

Home Euro-area

$\rho_{W c H}^{u}$ (world demand of home cons.) $\quad 0.7000$

0.7000

$\rho_{W I H}^{u}$ (world demand of home invest.)

$0.7000 \quad 0.7000$

$\rho_{a}^{u}$ (preferences)

$0.7000 \quad 0.7000$

$\rho_{z T}^{u}$ (productivity in traded)

$0.7000 \quad 0.7000$

$\rho_{z N}^{u}$ (productivity in non-traded)

$0.7000 \quad 0.7000$

$\rho_{z D}^{u}$ (productivity in housing)

$0.7000 \quad 0.7000$

$\rho_{g}^{u}$ (public expenditure)

$0.7000 \quad 0.7000$

$\rho_{W P c}^{u}$ (world cons. deflator)

0.7000

$\rho_{W P I}^{u}$ (world invest. deflator)

0.7000

$\rho_{P O i l}^{u}$ (Oil price)

0.7000

$\rho_{W R n}^{u}$ (World interest rate)

0.7000

$\rho_{R n}^{u}$ (Taylor rule)

0.0000 
Table 3. Calibration of the steady-state parameters Parameter Home Euro-area

SSR1 (prod. invest. inf./cons. inf.)

$1.0000 \quad 1.0000$

SSR2 (housing inf./cons. inf.)

$1.0000 \quad 1.0000$

SSR3 (real non-trad. cons./total cons.)

$\begin{array}{ll}0.4707 & 0.5871\end{array}$

SSR5 (nominal non-trad. cons./total cons.)

$\begin{array}{ll}0.4707 & 0.5871\end{array}$

SSR7 (real home cons./trad. cons.)

$0.4592 \quad 0.4299$

SSR8 (real Euro-area cons./trad. cons.)

$\begin{array}{ll}0.3302 & 0.0794\end{array}$

SSR9 (real oil cons./trad. cons.)

$\begin{array}{ll}0.0820 & 0.0978\end{array}$

SSR11 (nominal home cons./trad. cons.)

$\begin{array}{ll}0.4592 & 0.4299\end{array}$

SSR12 (nominal Euro-area cons./trad. cons.)

$0.3302 \quad 0.0794$

SSR13 (nominal rest of the world.cons./trad. cons.)

$0.1286 \quad 0.3929$

SSR15 (real prod. invest/total invest.)

$\begin{array}{ll}0.9277 & 0.9729\end{array}$

SSR17 (nominal prod. invest/total invest.)

$0.9277 \quad 0.9729$

SSR19 (real non-trad. invest/prod. invest.)

$0.3774 \quad 0.3972$

SSR21 (nominal non-trad. invest/prod. invest.)

$0.3774 \quad 0.3972$

SSR23 (real home invest/trad. invest.)

$0.3209 \quad 0.3616$

SSR24 (real Euro area invest/trad. invest.)

$0.4963 \quad 0.0982$

SSR26 (nominal home invest/trad. invest.)

$0.3209 \quad 0.3616$

SSR27 (nominal Euro area invest/trad. invest.)

$0.4963 \quad 0.0982$

SSR29 (real oil cons./trad. prod.)

$0.1368 \quad 0.1126$

SSR42 (real trad. prod./trad. v.a.)

$1.1368 \quad 1.1126$

SSR44 (nominal trad. prod./trad. v.a.)

$1.1368 \quad 1.1126$

SSR46 (real oil cons./non-trad. prod.)

$0.0046 \quad 0.0028$
0.5062

SSR50 (nominal non-trad. cons./non-trad. prod.)

$0.5062 \quad 0.5217$

SSR52 (nominal public cons./non-trad. prod.)

$0.4122 \quad 0.4110$

SSR53 (real non-trad. prod./non-trad. v.a.)

$1.0047 \quad 1.0028$

SSR55 (nominal non-trad. prod./non-trad. v.a.)

$1.0947 \quad 1.0028$

SSR57 (trad. capital stock/total capital stock)

$\begin{array}{ll}0.3938 & 0.3152\end{array}$

SSR58 (non-trad. capital stock/total capital stock)

0.5966

0.6818

SSR60 (trad. employment/total employment)

0.2544

0.2327 
Table 3. Calibration of the steady-state parameters (cont.) Parameter Home Euro-area

SSR61 (non-trad. employment/total employment) $\quad 0.6940 \quad 0.7421$

SSR63 (real trad. prod./total. prod.) $\quad 0.2689 \quad 0.2696$

SSR64 (real non-trad. prod./total prod.) $\quad 0.6939 \quad 0.7121$

SSR66 (nominal trad. prod./total. prod.) $\quad 0.2689 \quad 0.2696$

SSR67 (nominal non-trad. prod./total. prod.) $\quad 0.6939 \quad 0.7121$

$\begin{array}{lll}\text { SSR69 (real trad. v.a./total v.a.) } & 0.2418 & 0.2473\end{array}$

SSR70 (real non-trad. v.a./total v.a.) $\quad 0.7195 \quad 0.7339$

$\begin{array}{llll}\text { SSR72 (nominal trad. v.a./total v.a.) } & 0.2418 & 0.2473\end{array}$

SSR73 (nominal non-trad. v.a./total v.a.) $\quad 0.7195 \quad 0.7339$

SSR75 (nominal trade balance/total v.a.) $\quad 0.2648 \quad 0.0719$

SSR76 (real cons. imp. Euro area/total imp.) $\quad 0.3440 \quad 0.0775$

SSR77 (real invest. imp. Euro area/total imp.) $\quad 0.2236 \quad 0.0479$

SSR78 (real cons. imp. rest world/total imp.) $\quad 0.1736 \quad 0.4493$

SSR79 (real invest. imp. rest world/total imp.) $\quad 0.0981 \quad 0.2739$

SSR80 (real cons. imp. oil/total imp.) $\quad 0.06420 .0685$

SSR81 (real trad. imp. oil/total imp.) $\quad 0.0874 \quad 0.0758$

SSR83 (real cons. exp. Euro area/total exp.) $\quad 0.5271 \quad 0.0675$

SSR84 (real invest. exp. Euro area/total exp.) $\quad 0.1696 \quad 0.0185$

SSR85 (real cons. exp. rest world/total exp.) $\quad 0.2295 \quad 0.7173$

SSR87 (nominal cons. imp. Euro area/total imp.) $0.3440 \quad 0.0775$

SSR88 (nominal invest. imp. Euro area/total imp.) $0.2236 \quad 0.0479$

SSR89 (nominal cons. imp. rest world/total imp.) $\quad 0.1736 \quad 0.4493$

SSR90 (nominal invest. imp. rest world/total imp.) $0.0981 \quad 0.2739$

SSR91 (nominal cons. imp. oil/total imp.) $\quad 0.0642 \quad 0.0685$

SSR92 (nominal trad. imp. oil/total imp.) $\quad 0.0874 \quad 0.0758$

SSR94 (nominal cons. exp. Euro area/total exp.) $0.5271 \quad 0.0675$

SSR95 (nominal invest. exp. Euro area/total exp.) $0.1696 \quad 0.0185$

SSR96 (nominal cons. exp. rest world/total exp.) $\quad 0.2295 \quad 0.7173$

SSR98 (nominal public/total v.a.) $\quad 0.6481 \quad 0.7811$ 
Table 3. Calibration of the steady-state parameters (cont.)

$\begin{array}{lrc}\text { Parameter } & \text { Home } & \text { Euro-area } \\ \text { SSR99 (nominal public/total v.a. growth cor.) } & 0.6448 & 0.7911 \\ \text { SSR100 (nominal public cons./total v.a.) } & 0.1877 & 0.2188 \\ \text { SSR101 (nominal taxes/total v.a.) } & 0.2148 & 0.4752 \\ \text { SSR102 (nominal capital stock/total v.a.) } & 0.0443 & 0.1429 \\ \text { SSR103 (nominal consumption/total v.a.) } & 0.6029 & 0.5602 \\ \text { SSR104 (nominal compensation/total v.a.) } & 0.6322 & 0.6313 \\ \text { SSR105 (nomnal debt/total v.a. tax cor.) } & 0.4000 & 0.3970 \\ \text { SSR106 (real trad. cons. prod./trad prod.) } & 0.7566 & 0.6870 \\ \text { SSR107 (real trad. home cons./trad. cons. prod) } & 0.4224 & 0.6682 \\ \text { SSR108 (real trad. Euro area cons./trad. cons. prod) } & 0.4024 & 0.0285 \\ \text { SSR109 (real trad. home invest./trad. invest. prod) } & 0.5445 & 0.6682 \\ \text { SSR110 (real trad. Euro area invest./trad. invest. prod) } & 0.4224 & 0.0285 \\ \text { SSR111 (nominal trad. cons. prod./trad prod.) } & 0.7566 & 0.6870 \\ \text { SSR112 (real non-trad. cons. prod./non-trad prod.) } & 0.9185 & 0.9327 \\ \text { SSR113 (real non-trad. cons. prod./non-trad cons.) } & 0.5512 & 0.5594 \\ \text { WR } & 1.0123 \\ \gamma_{v a}^{S S} \text { (v.a. growth rate) } & 1.0050 \\ \pi_{v a}^{S S} \text { (v.a. inf.) } & 1.0050 \\ \text { inf }^{S S} \text { (prod. inf.) } & 1.0050\end{array}$




\section{G. Appendix: Definition of variables.}

\section{COUNTRY H}

$c_{t}$ : consumption goods consumed in home country

$c_{t}^{N}$ : consumption non-traded goods consumed in home country

$c_{t}^{T}$ : consumption traded goods consumed in home country

$c_{H, t}$ : consumption goods produced for consumption in home country

$c_{F, t}$ : consumption goods produced in Euro area for consumption in home country

$c_{W, t}$ : consumption goods produced in rest of world for consumption in home country

$c_{t}^{\text {Oil }}$ : consumption of oil in home country

$U c_{t}$ : marginal utility of consumption in home country

$U_{n_{t}}$ : marginal utility of labour in home country

$I_{t}$ : investment goods invested in home country

$I_{t}^{P}$ : investment productive goods invested in home country

$I_{t}^{N}$ : investment productive non-traded goods invested in home country

$I_{t}^{T}$ : investment productive traded goods invested in home country

$I_{t}^{D}$ : investment housing goods invested in home country

$I_{H, t}$ : investment goods produced for investment in home country

$I_{F, t}$ : investment goods produced in Euro area for investment in home country

$I_{W, t}$ : investment goods produced in rest of world for investment in home country

$P C_{t}$ : (consumption) price deflator of goods consumed in home country

$P C_{t}^{N}$ : (consumption) price deflator of non-traded goods consumed in home country

$\widetilde{P C}_{t}^{N}$ : optimal (consumption) price of non-traded goods consumed in home country

$P C_{t}^{T}$ : (consumption) price deflator of traded goods consumed in home country

$P I_{t}$ : (consumption) price deflator of investment goods invested in home country

$P I_{t}^{P}$ : (consumption) price deflator of investment productive goods invested in home country

$P I_{t}^{N}$ : (consumption) price deflator of investment non-traded goods invested in home country

$\widetilde{P I}_{t}^{N}$ : optimal (consumption) price of investment non-traded goods invested in home country 
$P I_{t}^{T}$ : (consumption) price deflator of investment traded goods invested in home country

$P_{t}^{D}:$ (consumption) price deflator of investment housing goods consumed in home country

$\widetilde{P}_{t}^{D}$ : optimal (consumption) price of investment housing goods consumed in home country

$P_{t}$ : price of goods produced in home country

$P_{t}^{T}$ : price of traded goods produced in home country

$P_{t}^{N}$ : price of non-traded goods produced in home country

$P_{t}^{C}$ : (consumption) price of consumer goods produced and consumed in home country

$\widetilde{P}_{t}^{C}$ : optimal (consumption) price of consumer goods produced and consumed in home country

$P_{t}^{I}$ : (consumption) price of investment goods produced and invested in home country

$\widetilde{P}_{t}^{I}$ : optimal (consumption) price of investment goods produced and invested in home country

$y_{t}$ : production of goods in home country

$y_{t}^{T}$ : production of traded goods in home country

$y_{t}^{T C}$ : production of traded consumption goods in home country

$y_{t}^{T I}$ : production of traded investment goods in home country

$y_{t}^{N}$ : production of non-traded goods in home country

$y_{t}^{D}$ : production of housing goods in home country

$k_{t}$ : stock of capital goods used in production in home country

$k_{t}^{T}$ : stock of capital goods used in production in traded sector in home country

$k_{t}^{N}$ : stock of capital goods used in production in non-traded sector in home country

$k_{t}^{D}$ : stock of capital goods used in production in housing sector in home country

$n_{t}$ : employment in home country

$n_{t}^{T}$ : employment used in production in traded sector in home country

$n_{t}^{N}$ : employment used in production in non-traded sector in home country

$n_{t}^{D}$ : employment used in production in housing sector in home country

$c u_{t}^{T}$ : capacity utilization in production in traded sector in home country

$c u_{t}^{N}$ : capacity utilization in production in non-traded sector in home country

$c u_{t}^{D}$ : capacity utilization in production in housing sector in home country

$O_{t}^{T}$ : oil goods used in production in traded sector in home country 
$O_{t}^{N}$ : oil goods used in production in non-traded sector in home country $m c_{t}^{T}$ : real marginal cost of producing traded goods in home country $m c_{t}^{N}$ : real marginal cost of producing non-traded goods in home country $m c_{t}^{D}$ : real marginal cost of producing housing goods in home country

$W_{t}$ : wage per worker in home country

$\widetilde{W}_{t}$ : optimal wage per worker in home country

$q_{t}$ : Tobin's q of investment in capital goods in home country

$q_{t}^{D}$ : Tobin's q of investment in housing in home country

$r_{t}$ : real interest rate in home country

$D_{t}:$ stock of housing goods

$\pi_{t}$ : inflation of goods produced in home country

$\pi_{t}^{V A}$ : inflation of value added production in home country

$\pi_{t}^{C}$ : inflation of goods produced for consumption in home country

$\pi_{t}^{I P C}$ : inflation of goods consumed in home country

$\pi_{t}^{C N}$ : inflation of non-traded consumption goods consumed in home country

$\pi_{t}^{I}$ : inflation of goods invested in home country

$\pi_{t}^{I P}$ : inflation of productive investment goods invested in in home country

$\pi_{t}^{D}$ : inflation of housing goods invested in home country

$\pi_{t}^{I N}$ : inflation of non-traded investment goods consumed in home country

$\lambda_{t}$ : Lagrange multiplier of budget constraint

$\lambda_{t}^{k}$ : Lagrange multiplier of accumulation of capital for production

$\lambda_{t}^{D}$ : Lagrange multiplier of accumulation of housing capital

$A_{t}$ : Current account of home country

$a_{t}$ : net foreign asset holdings of home country as a percentage of nominal value added $\left(\frac{A_{t}}{P v_{t} v a_{t}}\right)$

$X_{t}$ : nominal exports of home country

$M_{t}$ : nominal imports of home country

$P_{t}^{X}$ : export deflator of home country

$P_{t}^{M}$ : import deflator of home country

$B_{t}$ : debt of home country

$b_{t}$ : debt to GDP ratio of home country $\left(\frac{B_{t}}{P v_{t} v a_{t}}\right)$

$T_{t}$ : taxes of home country

$R_{t}$ : nominal interest rate in home country

$s_{t}$ : exchange rate $(\$ / e)$

$v a_{t}:$ value added in home country

$v a_{t}^{T}$ : value added of traded goods sector in home country

$v a_{t}^{N}$ : value added of non-traded goods sector in home country 
$g_{t}:$ value added of public sector in home country / consumption of non-traded goods by public sector

$P v_{t}$ : value added deflator in home country

$P v_{t}^{T}$ : value added deflator of traded goods in home country

$P v_{t}^{N}$ : value added of non-traded goods in home country

$d_{t}:$ (gross) wage adjustment rate

$\zeta_{t}:$ stochastic discount rate

$M R S_{t}$ : marginal rate of substitution between consumption and working hours

$\varepsilon_{t}^{a}:$ preference shock in home country

$z_{t}$ : productivity shock common to all sectors of production in home country

$z_{t}^{i}=z_{t}^{T}, z_{t}^{N}, z_{t}^{D}:$ productivity shock specific to sector of production $i$ in home country

$\varepsilon_{t}^{R}$ : interest rate shock in Euro area

\section{COUNTRY F}

$F c_{t}$ : consumption goods consumed in rest of Euro area

$F c_{t}^{N}$ : consumption non-traded goods consumed in rest of Euro area

$F c_{t}^{T}$ : consumption traded goods consumed in rest of Euro area

$F c_{F, t}$ : consumption goods produced and consumed in rest of Euro area

$F c_{H, t}$ : consumption goods produced in home country and consumed in rest of Euro area

$F c_{W, t}$ : consumption goods produced in rest of world and consumed in rest of Euro area

$F c_{t}^{\text {Oil }}$ : consumption of oil in rest of Euro area

$F U c_{t}$ : marginal utility of consumption in rest of Euro area

$F U_{n_{t}}$ : marginal utility of labour in rest of Euro area

$F I_{t}$ : investment goods invested in rest of Euro area

$F I_{t}^{P}$ : investment productive goods invested in rest of Euro area

$F I_{t}^{N}$ : investment non-traded goods invested in rest of Euro area

$F I_{t}^{T}$ : investment traded goods invested in rest of Euro area

$F I_{t}^{D}$ : investment housing goods invested in rest of Euro area

$F I_{F, t}$ : investment goods produced and invested in rest of Euro area

$F I_{H, t}$ : investment goods produced in home country and invested in rest of Euro area

$F I_{W, t}$ : investment goods produced in rest of world and invested in rest of Euro area

$F P C_{t}$ : (consumption) price deflator of goods consumed in rest of Euro area 
$F P C_{t}^{N}$ : (consumption) price deflator of non-traded goods consumed in rest of Euro area

$\widehat{P C}_{t}^{N}$ : optimal (consumption) price of non-traded goods consumed in rest of Euro area

$F P C_{t}^{T}$ : (consumption) price deflator of traded goods consumed in rest of Euro area

$F P I_{t}$ : (consumption) price deflator of investment goods invested in rest of Euro area

$F P I_{t}^{P}$ : (consumption) price deflator of investment productive goods invested in rest of Euro area

$F P I_{t}^{N}$ : (consumption) price deflator of investment non-traded goods invested in rest of Euro area

$\widehat{F P I}_{t}^{N}$ : optimal (consumption) price of investment non-traded goods invested in rest of Euro area

$F P I_{t}^{T}$ : (consumption) price deflator of investment traded goods invested in rest of Euro area

$F P_{t}^{D}$ : (consumption) price deflator of investment housing goods consumed in rest of Euro area

$\widehat{F P}_{t}{ }^{2}$ : optimal (consumption) price of investment housing goods consumed in rest of Euro area

$F P_{t}$ : price of goods produced in rest of Euro area

$F P_{t}^{T}$ : price of traded goods produced in rest of Euro area

$F P_{t}^{N}$ : price of non-traded goods produced in rest of Euro area

$F P_{t}^{C}$ : (consumption) price of consumer goods produced in rest of Euro area

$\widetilde{F P}_{t}^{C}$ : optimal (consumption) price of consumer goods produced and consumed in rest of Euro area

$F P_{t}^{I}$ : (consumption) price of investment goods produced in rest of Euro area

$\widetilde{F P}_{t}^{I}$ : optimal (consumption) price of investment goods produced and invested in rest of Euro area

$F y_{t}$ : production of goods in rest of Euro area

$F y_{t}^{T}$ : production of traded goods in rest of Euro area

$F y_{t}^{T C}$ : production of traded consumption goods in rest of Euro area

$F y_{t}^{T I}$ : production of traded investment goods in rest of Euro area

$F y_{t}^{N}$ : production of non-traded goods in rest of Euro area

$F y_{t}^{D}$ : production of housing goods in rest of Euro area

$F k_{t}$ : stock of capital goods used in production in rest of Euro area 
$F k_{t}^{T}$ : stock of capital goods used in production in traded sector in rest of Euro area

$F k_{t}^{N}$ : stock of capital goods used in production in non-traded sector in rest of Euro area

$F k_{t}^{D}$ : stock of capital goods used in production in housing sector in rest of Euro area

$F n_{t}$ : employment in rest of Euro area

$F n_{t}^{T}$ : employment used in production in traded sector in rest of Euro area

$F n_{t}^{N}$ : employment used in production in non-traded sector in rest of Euro area

$F n_{t}^{D}$ : employment used in production in housing sector in rest of Euro area

$F c u_{t}^{T}$ : capacity utilization in production in traded sector in rest of Euro area

$F c u_{t}^{N}$ : capacity utilization in production in non-traded sector in rest of Euro area

$F c u_{t}^{D}$ : capacity utilization in production in housing sector in rest of Euro area

$F O_{t}^{T}$ : oil goods used in production in traded sector in rest of Euro area

$F O_{t}^{N}$ : oil goods used in production in non-traded sector in rest of Euro area

$F m c_{t}^{T}$ : real marginal cost of producing traded goods in rest of Euro area

$F m c_{t}^{N}$ : real marginal cost of producing non-traded goods in rest of Euro area

$F m c_{t}^{D}$ : real marginal cost of producing housing goods in rest of Euro area

$F W_{t}$ : wage per worker in rest of Euro area

$\widetilde{F W_{t}}$ : optimal wage per worker in rest of Euro area

$F q_{t}$ : Tobin's q of investment in capital goods in rest of Euro area

$F q_{t}^{D}$ : Tobin's q of investment in housing in rest of Euro area

$F r_{t}$ : real interest rate in rest of Euro area

$F D_{t}$ : stock of housing goods

$F \pi_{t}$ : inflation of goods produced in rest of Euro area

$F \pi_{t}^{C}$ : inflation of goods produced for consumption in rest of Euro area

$F \pi_{t}^{I P C}$ : inflation of goods consumed in rest of Euro area

$F \pi_{t}^{C N}$ : inflation of non-traded consumption goods consumed in rest of Euro area

$F \pi_{t}^{I}:$ inflation of goods invested in rest of Euro area

$F \pi_{t}^{I P}$ : inflation of productive investment goods invested in rest of Euro area

$F \pi_{t}^{D}$ : inflation of housing goods invested in rest of Euro area

$F \pi_{t}^{I N}$ : inflation of non-traded investment goods consumed in rest of Euro area

$F \lambda_{t}$ : Lagrange multiplier of budget constraint

$F \lambda_{t}^{k}$ : Lagrange multiplier of accumulation of capital for production 
$F \lambda_{t}^{D}$ : Lagrange multiplier of accumulation of housing capital

$F X_{t}$ : nominal exports of rest of Euro area

$F M_{t}$ : nominal imports of rest of Euro area

$F P_{t}^{X}$ : export deflator of rest of Euro area

$F P_{t}^{M}$ : import deflator of rest of Euro area

$F A_{t}$ : Current account of rest of Euro area

$F a_{t}$ : net foreign asset holdings of rest of Euro area as a percentage of nominal value added $\left(\frac{F A_{t}}{F P v_{t} F v a_{t}}\right)$

$F B_{t}$ : debt of rest of Euro area

$F b_{t}$ : debt to GDP ratio of rest of Euro area $\left(\frac{F B_{t}}{F P v v_{t}}\right)$

$F T_{t}$ : taxes of rest of Euro area

$F v a_{t}$ : value added in rest of Euro area

$F v a_{t}^{T}$ : value added of traded goods sector in rest of Euro area

$F v a_{t}^{N}$ : value added of non-traded goods sector in rest of Euro area

$F P v_{t}$ : value added deflator in rest of Euro area

$F P v_{t}^{T}$ : value added deflator of traded goods in rest of Euro area

$F P v_{t}^{N}$ : value added of non-traded goods in rest of Euro area

$F g_{t}$ : value added of public sector in home country / consumption of nontraded goods by public sector of home country

$F d_{t}$ : (gross) wage adjustment rate in rest of Euro area

$F \zeta_{t}$ : stochastic discount rate in rest of Euro area

$F M R S_{t}$ : marginal rate of substitution between consumption and working hours in rest of Euro area

$F \varepsilon_{t}^{a}$ : preference shock in rest of Euro area

$F z_{t}$ : productivity shock common to all sectors of production in rest of Euro area

$F z_{t}^{i}=F z_{t}^{T}, F z_{t}^{N}, F z_{t}^{D}:$ productivity shock specific to sector of production $i$ in rest of Euro area

\section{COUNTRY W}

$W c_{t}$ : consumption goods consumed in rest of the world

$W I_{t}$ : investment goods invested in rest of the world

$W c_{H, t}$ : consumption goods produced in home country and consumed in rest of the world

$W c_{F, t}$ : consumption goods produced in rest of Euro area and consumed in rest of the world 
$W I_{H, t}$ : investment goods produced in home country and consumed in rest of the world

$W I_{F, t}$ : investment goods produced in rest of Euro area and consumed in rest of the world

$W P_{t}^{C}$ : (consumption) price of consumer goods produced in rest of the world in $\$$

$W P_{t}^{I}$ : (consumption) price of investment goods produced in rest of the world in $\$$

$P_{t}^{\text {Oil }}$ : price of oil in $\$$

$W R_{t}$ : nominal rate of interest in rest of the world

$W a_{t}$ : Current account of rest of the world as a percentage of nominal value added 


\section{References}

[1] Adolfson, M., S. Laseén, J. Lindé and M. Villani (2005). Bayesian Estimation of an Open Economy DSGE Model with Incomplete Pass-Through, Sveriges Risbank Working Paper Series No. 179.

[2] Álvarez, L. J., E. Dhyne, M. Hoeberichts, C. Kwapil, H. Le Bihan, P. Lünnemann, F. Martins, R. Sabbatini, H. Stahl, P. Vermeulen and J. Vilmunen (2006). "Sticky prices in the Euro area: a summary of new micro evidence", forthcoming Journal of the European Economic Association, 4 (2-3).

[3] Andrés, J., and R. Doménech (2006). "Fiscal Rules and Macoeconomic Stability" (invited Session of the XXIX Simposio de Análisis Económico), Hacienda Pública Española (forthcoming).

[4] Banco de España (2006). The Analysis of the Spanish Economy, edited by Servicio de Estudios of Banco de España, printed by Artes Gráficas Coyve, SA.

[5] Benigno, P. (2001). Price Stability with Incomplete Risk Sharing, CEPR 2854.

[6] Bils, M., and P. Klenow (2004). "Some Evidence on the Importance of Sticky Prices", Journal of Political Economy, 112, pp. 947-985.

[7] Binette, A., S, Murchison, P. Perrier and A. Rennison (2004). An introduction to TOTEM, mimeo.

[8] Calvo, G. (1983). "Staggered Prices in a Utility Maximizing Framework", Journal of Monetary Economics, 12, pp. 383-398.

[9] Chari, V., P. Kehoe and E. R. McGrattan (2000). "Sticky Price Models of the Business Cycle: Can the Contract Multiplier Solve the Persistence Problem?", Econometrica, 68 (5), pp. 1151-1180.

[10] Christiano, L. J., M. Eichenbaum and C. L. Evans (2005). "Nominal Rigidities and the Dynamic Effects of a Shock to Monetary Policy", Journal of Political Economy, 113 (1), pp. 1-45.

[11] Coenen, G., P. McAdam and R. Straub (2006). Tax Reform and LabourMarket Performance in the Euro Area: a simulation based analysis using the New Area-Wide model, mimeo. 
[12] Erceg, C., L. Guerrieri and C. Gust (2005). "SIGMA: A new open economy model for policy analysis", International Journal of Central Banking, 2 (1), pp. 1-50.

[13] Erceg, C., D. Henderson and A. Levin (2000). "Optimal Monetary Policy with Staggered Wage and Price Contracts", Journal of Monetary Economics, 46, pp. 281-313.

[14] Erceg, C., and A. T. Levin (2002). "Optimal Monetary Policy with Durable and Non-Durable Goods," Computing in Economics and Finance 2002 343, Society for Computational Economics.

[15] Galí, J. (1999). "Technology, employment and the business cycle: Do technology shocks explain aggregate fluctuations?", American Economic Review, March, pp. 249-271..

[16] Galí, J., and M. Gertler (1999). "Inflation Dynamics: A Structural Econometric Analysis", Journal of Monetary Economics, 44 (2), pp. 195-222.

[17] Galí, J., M. Gertler and D. López-Salido (2001). "European inflation dynamics", European Economic Review, 45, pp. 1237-1270.

[18] Harrison, R., K. Nikolov, M. Quinn, G. Ramsey, A. Scott and R. Thomas (2005), The Bank of England Quarterly Model, Bank of England.

[19] Kilponen, J., and A. Ripatti (2006). Introduction to AINO, mimeo.

[20] King, R., C. Plosser and S. Rebelo (1988). "Production, Growth and Business Cycles I: The basic neo-classical model", Journal of Monetary Economics, 2, pp. 195-232.

[21] Kortelainen, M. (2002). EDGE: a model of the Euro area with applications to monetary policy, Bank of Finland Studies, E:23.

[22] Neiss, K., and E. Pappa (2005). "Persistence without too much price stickiness: the role of variable factor utilization", Review of Economic Dynamics, 8 (1), pp. 231-255.

[23] Sbordone, A. (2002). "Prices and unit labor costs: a new test of price stickiness", Journal of Monetary Economics, 49, pp. 265-292. 
[24] Schmitt-Grohé, S., and M. Uribe (1997). "Balanced-Budget Rules, Distortionary Taxes, and Aggregate Instability", Journal of Political Economy, 105(5), pp. 976-1000.

[25] - (2003). "Closing small open economy models", Journal of International Economics, 61, pp. 163-185.

[26] Smets, F., and R. Wouters (2003). "An Estimated Dynamic Stochastic General Equilibrium Model of the Euro Area", Journal of the European Economic Association, 1 (5), pp. 1124-1175.

[27] Woodford, M. (2003). Interest and Prices: Foundations of a Theory of Monetary Policy, Princeton University Press. 
BANCO DE ESPAÑA PUBLICATIONS

\section{WORKING PAPERS ${ }^{1}$}

0527 LUIS J. ÁLVAREZ, PABLO BURRIEL AND IGNACIO HERNANDO: Price setting behaviour in Spain: evidence from micro PPI data.

0528 EMMANUEL DHYNE, LUIS J. ÁLVAREZ, HERVÉ LE BIHAN, GIOVANNI VERONESE, DANIEL DIAS, JOHANNES HOFFMANN, NICOLE JONKER, PATRICK LÜNNEMANN, FABIO RUMLER AND JOUKO VILMUNEN: Price setting in the euro area: some stylized facts from individual consumer price data.

0529 TERESA SASTRE AND JOSÉ LUIS FERNÁNDEZ-SÁNCHEZ: Un modelo empírico de las decisiones de gasto de las familias españolas.

0530 ALFREDO MARTÍN-OLIVER, VICENTE SALAS-FUMÁS AND JESÚS SAURINA: A test of the law of one price in retail banking.

0531 GABRIEL JIMÉNEZ AND JESÚS SAURINA: Credit cycles, credit risk, and prudential regulation.

0532 BEATRIZ DE-BLAS-PÉREZ: Exchange rate dynamics in economies with portfolio rigidities.

0533 ÓSCAR J. ARCE: Reflections on fiscalist divergent price-paths.

0534 M. ${ }^{a}$ DE LOS LLANOS MATEA AND MIGUEL PÉREZ: Differences in changes in fresh food prices by type of establishment. (The Spanish original of this publication has the same number.)

0535 JOSÉ MANUEL MARQUÉS, FERNANDO NIETO AND ANA DEL RíO: Una aproximación a los determinantes de la financiación de las sociedades no financieras en España.

0536 S. FABIANI, M. DRUANT, I. HERNANDO, C. KWAPIL, B. LANDAU, C. LOUPIAS, F. MARTINS, T. MATHÄ, R. SABBATINI, H. STAHL AND A. STOKMAN: The pricing behaviour of firms in the euro area: new survey evidence.

0537 LUIS J. ÁLVAREZ AND I. HERNANDO: The price setting behaviour of Spanish firms: evidence from survey data.

0538 JOSÉ MANUEL CAMPA, LINDA S. GOLDBERG AND JOSÉ M. GONZÁLEZ-MíNGUEZ: Exchange-rate pass-through to import prices in the euro area.

0539 RAQUEL LAGO-GONZÁLEZ AND VICENTE SALAS-FUMÁS: Market power and bank interest rate adjustments.

0540 FERNANDO RESTOY AND ROSA RODRÍGUEZ: Can fundamentals explain cross-country correlations of asset returns?

0541 FRANCISCO ALONSO AND ROBERTO BLANCO: Is the volatility of the EONIA transmitted to longer-term euro money market interest rates?

0542 LUIS J. ÁLVAREZ, EMMANUEL DHYNE, MARCO M. HOEBERICHTS, CLAUDIA KWAPIL, HERVÉ LE BIHAN, PATRICK LÜNNEMANN, FERNANDO MARTINS, ROBERTO SABBATINI, HARALD STAHL, PHILIP VERMEULEN AND JOUKO VILMUNEN: Sticky prices in the euro area: a summary of new micro evidence.

0601 ARTURO GALINDO, ALEJANDRO IZQUIERDO AND JOSÉ MANUEL MONTERO: Real exchange rates, dollarization and industrial employment in Latin America.

0602 JUAN A. ROJAS AND CARLOS URRUTIA: Social security reform with uninsurable income risk and endogenous borrowing constraints.

0603 CRISTINA BARCELÓ: Housing tenure and labour mobility: a comparison across European countries.

0604 FRANCISCO DE CASTRO AND PABLO HERNÁNDEZ DE COS: The economic effects of exogenous fiscal shocks in Spain: a SVAR approach.

0605 RICARDO GIMENO AND CARMEN MARTÍNEZ-CARRASCAL: The interaction between house prices and loans for house purchase. The Spanish case.

0606 JAVIER DELGADO, VICENTE SALAS AND JESÚS SAURINA: The joint size and ownership specialization in banks' lending.

0607 ÓSCAR J. ARCE: Speculative hyperinflations: When can we rule them out?

0608 PALOMA LÓPEZ-GARCÍA AND SERGIO PUENTE: Business demography in Spain: determinants of firm survival.

0609 JUAN AYUSO AND FERNANDO RESTOY: House prices and rents in Spain: Does the discount factor matter?

0610 ÓSCAR J. ARCE AND J. DAVID LÓPEZ-SALIDO: House prices, rents, and interest rates under collateral constraints.

0611 ENRIQUE ALBEROLA AND JOSÉ MANUEL MONTERO: Debt sustainability and procyclical fiscal policies in Latin America.

1. Previously published Working Papers are listed in the Banco de España publications calalogue. 
0612 GABRIEL JIMÉNEZ, VICENTE SALAS AND JESÚS SAURINA: Credit market competition, collateral and firms' finance.

0613 ÁNGEL GAVILÁN: Wage inequality, segregation by skill and the price of capital in an assignment model.

0614 DANIEL PÉREZ, VICENTE SALAS AND JESÚS SAURINA: Earnings and capital management in alternative loan loss provision regulatory regimes.

0615 MARIO IZQUIERDO AND AITOR LACUESTA: Wage inequality in Spain: Recent developments.

0616 K. C. FUNG, ALICIA GARCÍA-HERRERO, HITOMI IIZAKA AND ALAN SUI: Hard or soft? Institutional reforms and infraestructure spending as determinants of foreign direct investment in China.

0617 JAVIER DÍAZ-CASSOU, ALICIA GARCÍA-HERRERO AND LUIS MOLINA: What kind of capital flows does the IMF catalyze and when?

0618 SERGIO PUENTE: Dynamic stability in repeated games.

0619 FEDERICO RAVENNA: Vector autoregressions and reduced form representations of DSGE models.

0620 AITOR LACUESTA: Emigration and human capital: Who leaves, who comes back and what difference does it make?

0621 ENRIQUE ALBEROLA AND RODRIGO CÉSAR SALVADO: Banks, remittances and financial deepening in receiving countries. A model.

0622 SONIA RUANO-PARDO AND VICENTE SALAS-FUMÁS: Morosidad de la deuda empresarial bancaria en España, 1992-2003. Modelos de la probabilidad de entrar en mora, del volumen de deuda en mora y del total de deuda bancaria, a partir de datos individuales de empresa.

0623 JUAN AYUSO AND JORGE MARTÍNEZ: Assessing banking competition: an application to the Spanish market for (quality-changing) deposits.

0624 IGNACIO HERNANDO AND MARÍA J. NIETO: Is the Internet delivery channel changing banks' performance? The case of Spanish banks.

0625 JUAN F. JIMENO, ESTHER MORAL AND LORENA SAIZ: Structural breaks in labor productivity growth: The United States vs. the European Union.

0626 CRISTINA BARCELÓ: A Q-model of labour demand.

0627 JOSEP M. VILARRUBIA: Neighborhood effects in economic growth.

0628 NUNO MARTINS AND ERNESTO VILLANUEVA: Does limited access to mortgage debt explain why young adults live with their parents?

0629 LUIS J. ÁLVAREZ AND IGNACIO HERNANDO: Competition and price adjustment in the euro area.

0630 FRANCISCO ALONSO, ROBERTO BLANCO AND GONZALO RUBIO: Option-implied preferences adjustments, density forecasts, and the equity risk premium.

0631 JAVIER ANDRÉS, PABLO BURRIEL AND ÁNGEL ESTRADA: BEMOD: A DSGE model for the Spanish economy and the rest of the Euro Area.

\begin{tabular}{|r|c|}
\hline & Unidad de Publicaciones \\
BANCODEESPAÑ & Alcalá, 522; 28027 Madrid \\
Eurosistema & Teléfono +34913386363. Fax +34913386488 \\
& correo electrónico: publicaciones@bde.es \\
www.bde.es
\end{tabular}

